\author{
UNIVERSIDADE DE SÃO PAULO \\ ESCOLA DE EDUCAÇÃO FÍSICA E ESPORTE
}

\title{
EFEITOS DE DIFERENTES PADRÕES RESPIRATÓRIOS NO DESEMPENHO E NA BRAÇADA DO NADO CRAWL
}

Marcos Roberto Apolinário 


\title{
EFEITOS DE DIFERENTES PADRÕES RESPIRATÓRIOS NO DESEMPENHO E NA BRAÇADA DO NADO CRAWL
}

MARCOS ROBERTO APOLINÁRIO

\begin{abstract}
Dissertação apresentada à Escola de Educação Física e Esporte da Universidade de São Paulo, como requisito parcial para obtenção do grau de Mestre em Educação Física.
\end{abstract}




\section{AGRADECIMENTOS}

À Profa. Dra. Andrea Michele Freudenheim, pela atenção, dedicação, paciência e principalmente por toda orientação.

Ao Prof. Dr. Umberto Cesar Corrêa, pelas críticas, sugestões e incentivo na construção deste trabalho.

Ao Prof. Dr. Ernani Xavier Filho, pela disponibilidade, atenção e contribuição dada ao projeto.

À Profa. Dra. Paula H. Lobo da Costa, pelas sugestões dadas na elaboração deste trabalho na Qualificação.

Ao Prof. Dr. Luciano Basso, pela atenção, paciência e toda assistência dada na análise estatística;

A todos os Professores pelas sugestões e esclarecimentos feitos ao projeto, que foram fundamentais na elaboração deste trabalho.

A todos os Professores e alunos do Laboratório de Comportamento Motor, pelas críticas, sugestões, questionamentos e esclarecimentos que enriqueceram esse trabalho.

Ao amigo Lúcio, pelo grandioso auxílio no momento decisivo de ingresso no mestrado.

Aos amigos Cleverton e Flávio, pela hospitalidade e grande ajuda prestada durante a minha permanência em São Paulo.

Aos amigos Meico, Thiago Oliveira, Diego, Ronaldo, Paula e Thiago Caldas, pela grande colaboração na coleta de dados.

Aos dirigentes, técnicos, atletas, pais e funcionários do Sport Clube Corinthians Paulista por permitirem a realização desta pesquisa. 
Aos meus pais Pedro e Maria Amélia, por todo amor, carinho, conselhos e orações.

À minha esposa Lilian e meu filho Felipe, os meus mais sinceros agradecimentos pela paciência, compreensão, apoio, companheirismo e principalmente por toda força que me deram durante os momentos mais difíceis.

Em especial, ao Prof. Ms. Sebastião Álvaro Galdino, pela grande amizade, incentivo e principalmente pela grande contribuição na minha formação pessoal e profissional. 
SUMÁRIO

Página

LISTA DE FIGURAS................................................................... vi

LISTA DE SIGLAS E ABREVIAÇÕES............................................. ix

LISTA DE ANEXOS ................................................................. $\mathrm{x}$

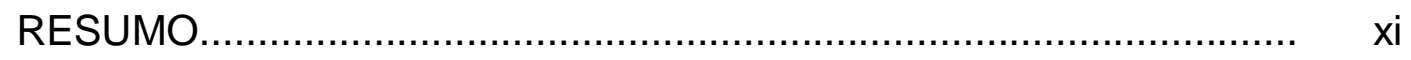

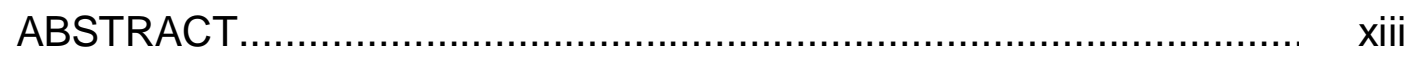

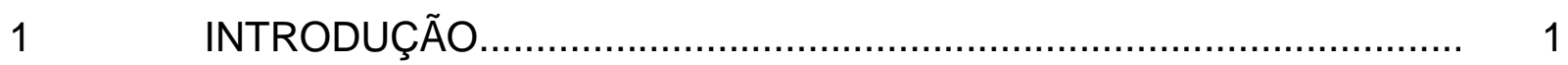

2 REVISÃO DE LITERATURA....................................................... 4

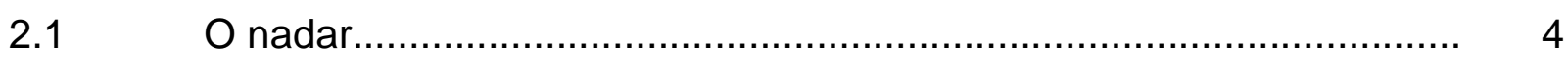

2.1.2 O nado crawl......................................................................... 4

2.1.2.1 Componentes do nado crawl........................................................ 5

2.1.2.1.1 Ação dos braços............................................................................ 5

2.1.2.1.2 Ação das pernas......................................................................... 6

2.1.2.1.3 Ação do tronco....................................................................... 7

2.1.2.1.4 Respiração.......................................................................... 7

2.1.2.2 Interação entre os componentes do nado crawl................................... 9

3 O COMPORTAMENTO MOTOR HABILIDOSO .................................. 11

$4 \quad$ ESTUDOS DO NADO CRAWL............................................... 13

4.1 Estudos sobre os efeitos da respiração na braçada do nado crawl...... 17

5 OBJETIVO...................................................................... 23

$6 \quad$ MÉTODO

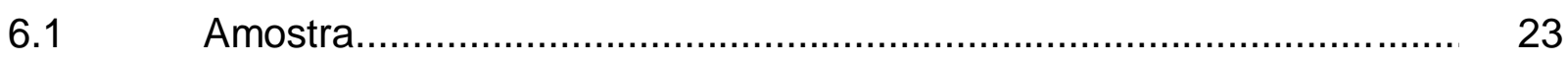

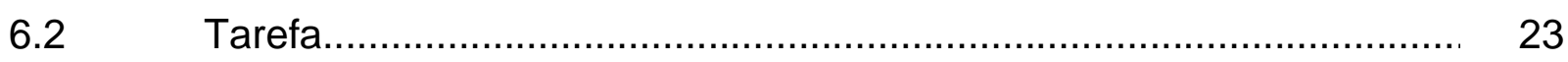

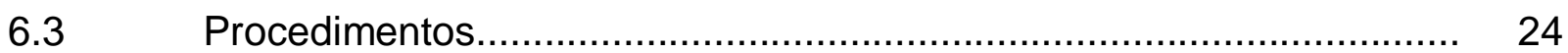

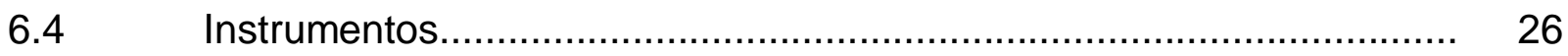

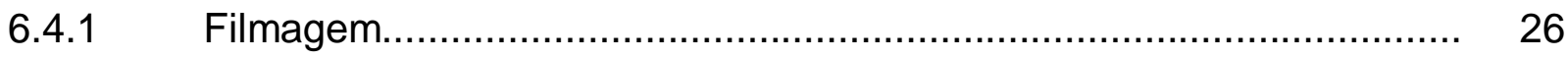


6.4.2 Edição de vídeo e análise............................................................ 27

6.4.3 Identificação da preferência do lado inspiratório................................... 27

$6.5 \quad$ Medidas........................................................................... 27

6.6 Análise estatística....................................................................... 31

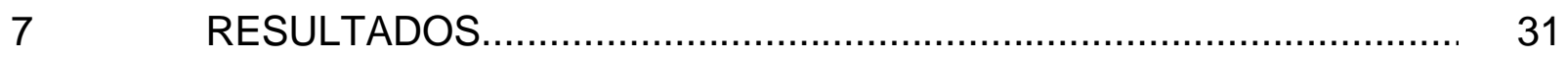

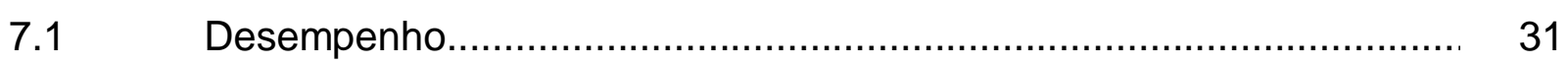

7.2 Aspectos invariantes da braçada.................................................. 35

7.3 Aspectos variantes da braçada...................................................... 39

7.4 Coordenação entre os braços.............................................................. 45

$8 \quad$ DISCUSSÃO E CONCLUSÃO..................................................... 46

REFERÊNCIAS................................................................... 52

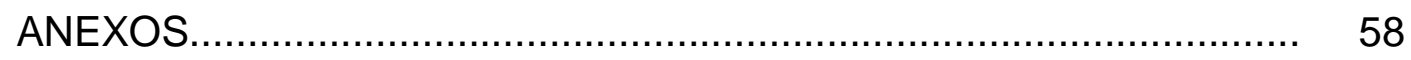




\section{LISTA DE FIGURAS}

Página

FIGURA 1 - Organização hierárquica da habilidade nadar (adaptado de FREUDENHEIM, GAMA \& MOISÉS, 1996)................................ 9

FIGURA 2 - Ambiente de coleta de dados................................................... 26

FIGURA 3 - Representação do índice de coordenação por oposição (adaptado de CHOLLET, CHALIES \& CHATARD, 2000)

FIGURA 4 - Tempo para percorrer 10 metros nadando crawl em velocidade máxima nas condições de inspiração para o lado preferido (LP), lado não preferido (LNP), bilateral $\quad$ (B) e sem inspiração (S)

FIGURA 5 - Velocidade média para percorrer 10 metros nadando crawl em velocidade máxima nas condições de inspiração para o lado preferido (LP), lado não preferido (LNP), bilateral (B) e sem inspiração (S).

FIGURA 6 - Frequência de braçadas para percorrer 10 metros nadando crawl em velocidade máxima nas condições de inspiração para o lado preferido (LP), lado não preferido (LNP), bilateral (B) e sem inspiração (S)

FIGURA 7 - Comprimento de braçada para percorrer 10 metros nadando crawl em velocidade máxima nas condições de inspiração para o lado preferido (LP), lado não preferido (LNP), bilateral (B) e sem inspiração (S) 
FIGURA 8 - Timing relativo aéreo dos braços direito e esquerdo nadando crawl em velocidade máxima nas condições de inspiração para o lado preferido (LP), lado não preferido (LNP), bilateral (B) e sem inspiração (S)

FIGURA 9 - Variabilidade do timing relativo aéreo dos braços direito e esquerdo nadando crawl em velocidade máxima nas condições de inspiração para o lado preferido (LP), lado não preferido (LNP), bilateral (B) e sem inspiração (S).

FIGURA 10 - Timing relativo aquático dos braços direito e esquerdo nadando crawl em velocidade máxima nas condições de inspiração para o lado preferido (LP), lado não preferido (LNP), bilateral (B) e sem inspiração (S).

FIGURA 11 - Variabilidade do timing relativo aquático dos braços direito e esquerdo nadando crawl em velocidade máxima nas condições de inspiração para o lado preferido (LP), lado não preferido (LNP), bilateral (B) e sem inspiração (S).

FIGURA 12 - Tempo total aéreo dos braços direito e esquerdo nadando crawl em velocidade máxima nas condições de inspiração para o lado preferido (LP), lado não preferido (LNP), bilateral (B) e sem inspiração (S).

FIGURA 13 - Variabilidade do tempo total aéreo dos braços direito e esquerdo nadando crawl em velocidade máxima nas condições de inspiração para o lado preferido (LP), lado não preferido (LNP), bilateral (B) e sem inspiração (S)

FIGURA 14 - Tempo total aquático dos braços direito e esquerdo nadando crawl em velocidade máxima nas condições de inspiração para o lado preferido (LP), lado não preferido (LNP), bilateral (B) e sem inspiração (S). 
FIGURA 15 - Variabilidade do tempo total aquático dos braços direito e esquerdo nadando crawl em velocidade máxima nas condições de inspiração para o lado preferido (LP), lado não preferido (LNP), bilateral (B) e sem inspiração (S)

FIGURA 16 - Tempo total dos braços direito e esquerdo nadando crawl em velocidade máxima nas condições de inspiração para o lado preferido (LP), lado não preferido (LNP), bilateral (B) e sem inspiração (S)

FIGURA 17 - Variabilidade do tempo total dos braços direito e esquerdo nadando crawl em velocidade máxima nas condições de inspiração para o lado preferido (LP), lado não preferido (LNP), bilateral (B) e sem inspiração (S).

FIGURA 18 - Índice de coordenação nadando crawl em velocidade máxima nas condições de inspiração para o lado preferido (LP), lado não preferido (LNP), bilateral (B) e sem inspiração (S) 


\section{LISTA DE SIGLAS E ABREVIAÇÕES}

$\begin{array}{ll}\text { Ae } & \text { Aérea } \\ \mathrm{Aq} & \text { Aquática } \\ \mathrm{B} & \text { Bilateral } \\ \mathrm{Bd} & \text { Braço direito } \\ \mathrm{Be} & \text { Braço esquerdo } \\ \mathrm{Cb} & \text { Comprimento de braçada } \\ \mathrm{Fb} & \text { Frequência de braçada } \\ \text { IdC } & \text { Índice de coordenação } \\ \text { IdCd } & \text { Índice de coordenação direito } \\ \text { IdCe } & \text { Índice de coordenação esquerdo } \\ \mathrm{LNP} & \text { Lado não preferido } \\ \mathrm{LP} & \text { Lado preferido } \\ \mathrm{m} & \text { Metros } \\ \mathrm{ms} & \text { Milissegundos } \\ \mathrm{S} & \text { Sem respiração } \\ \mathrm{Tr} & \text { Timing relativo } \\ \mathrm{Tt} & \text { Tempo total } \\ \text { Vm } & \text { Velocidade média } \\ \text { VTr } & \text { Variabilidade do timing relativo } \\ \text { VTt } & \text { Variabilidade do tempo total }\end{array}$




\section{LISTA DE ANEXOS}

Página

ANEXOI - Ilustração da ficha cadastral e questionário utilizado para determinar o lado inspiratório dos nadadores......................... 58

ANEXO II - $\quad$ Termo de consentimento livre e esclarecido.............................. 59

ANEXO III - Ilustração do instrumento utilizado para captar as imagens das fases aérea e aquática da braçada do nado crawl................... 62

ANEXO IV - Ofício de aprovação do Comitê de Ética em Pesquisa

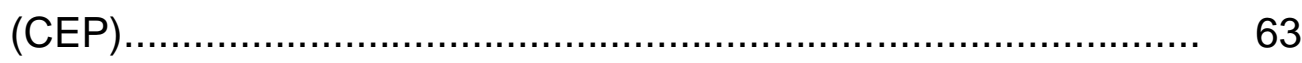

ANEXO V - Quadro das características dos atletas................................. 64

ANEXO VI - Dados utilizados para análise............................................. 65

ANEXO VII - Índice de coordenação (IdC) adotado pelos atletas nas quatro condições experimentais. 
RESUMO

\title{
EFEITOS DE DIFERENTES PADRÕES RESPIRATÓRIOS NO DESEMPENHO E NA BRAÇADA DO NADO CRAWL
}

\author{
Autor: MARCOS ROBERTO APOLINÁRIO \\ Orientadora: PROFA. DRA. ANDREA MICHELE FREUDENHEIM
}

O objetivo deste estudo foi investigar os efeitos de diferentes padrões respiratórios no desempenho e na braçada do nado crawl. Participaram do estudo 21 jovens atletas do gênero masculino. Eles foram filmados nadando 25 metros do nado crawl, em velocidade máxima, em quatro condições de respiração: inspiração para o lado preferido (LP); para o lado não preferido (LNP); bilateral (B); e, sem respiração (S). Duas filmadoras digitais (60fps) captaram as imagens que foram analisadas através do software Kinovea 0.8.7 nos 10 metros centrais do percurso. Os resultados permitiram concluir que o padrão respiratório afeta o desempenho de atletas jovens. Mostraram que em termos de velocidade e tempo, é mais vantajosa a condição de nadar crawl em apneia que em qualquer das condições com inspiração (B, LNP, LP); e, no que diz respeito à frequência e comprimento da braçada a condição $B$ é a mais eficiente e a LNP, a menos eficiente dentre as três condições com inspiração utilizadas no presente estudo. Portanto, o padrão preferido de respiração, não necessariamente, corresponde ao mais eficiente em termos do desempenho. Em relação à braçada, os resultados mostraram que, diante da modificação do padrão respiratório, nadadores peritos jovens mantêm a estrutura temporal das braçadas 
direita e esquerda (aspectos invariantes da braçada) bem como a coordenação entre os braços inalterada enquanto efetuam ajustes na fase aérea da braçada (aspectos variantes).

Palavras-chave: Comportamento motor; natação; nado crawl 


\title{
ABSTRACT
}

\section{EFFECTS OF DIFFERENT BREATHING PATTERNS ON THE PERFORMANCE AND THE ARM STROKE OF THE FRONT CRAWL}

\author{
Author: MARCOS ROBERTO APOLINÁRIO \\ Adviser: PROF. DR. ANDREA MICHELE FREUDENHEIM
}

The aim of this study was to investigate the effects of different breathing patterns on the performance and the arm stroke of the front crawl. Twenty-one young male athletes participated in the study. They were filmed swimming 25 meters at maximum speed using the front crawl stroke, under four breathing conditions: preferential inhalation side (PS); nonpreferential inhalation side (NPS); bilateral inhalation (B) and without inhalation (N). Two digital video cameras (60fps) captured the images that were analyzed using the software Kinovea 0.8.7 in the central 10 meters of the lenght. The results showed that the breathing pattern affects the performance of young athletes. That in terms of speed and time, comparing to any of the inhalation conditions (B, PS, NPS), the more advantageous one to swim front crawl stroke is in apnea $(\mathrm{N})$; and, with respect to frequency and length of stroke the condition B is the most efficient and NPS, the least efficient among the three inhalation conditions of this study. Therefore, the preferred breathing pattern does not necessarily correspond to the most efficient in terms of performance. Regarding arm stroke, the results showed that, given the change in breathing pattern, young expert swimmers maintain the temporal structure of the right and left arm strokes (invariant features of 
the stroke) as well as the coordination between the arms unchanged while adjusting in the aerial phase of the stroke (variant features).

Key words: Motor behavior; swimming; front crawl stroke 
O nadar tem sido praticado por pessoas de diferentes idades, gêneros, classes sociais e características, portadoras ou não de necessidades especiais. Sua importância advém do fato de poder ser praticado em ambientes diversificados (no mar, represas, rios, lagos, e em piscinas), e embora tenha se originado da necessidade de sobrevivência do homem, atualmente atende a necessidades diversificadas, relacionadas, por exemplo, à manutenção da saúde e ao lazer.

O nadar pode ser definido como qualquer ação motora que o indivíduo realiza intencionalmente para sustentar-se ou propulsionar-se através da água por impulso próprio (ANJOS \& FERREIRA, 2004; FREUDENHEIM, 1995). Abordado dentro do escopo do desenvolvimento motor humano (FREUDENHEIM, GAMA \& MOISÉS, 1996), o nado crawl é uma forma específica de deslocamento no meio líquido, culturalmente determinada, que compreende a execução de ações dos braços, pernas, tronco e respiração, em interação (FREUDENHEIM et al., 1996; FREUDENHEIM \& MADUREIRA, 2006). Interação significa que as ações são executadas de maneira relativamente interdependente, na tarefa como um todo (SCHMIDT \& WRISBERG, 2001). Sendo assim, pode ser que uma ação interfira favorecendo ou não a execução de outra ação e/ou no desempenho da tarefa. Por exemplo, pode ser que a ação da respiração interfira na braçada do nado crawl e/ou no desempenho dos nadadores habilidosos.

O comportamento de executantes habilidosos é consistente em relação a algumas características do movimento (aspectos invariantes) e, ao mesmo tempo variável em relação a outras (aspectos variantes). Aspectos como o timing relativo, sequenciamento e força relativa que são mantidos relativamente invariantes ao longo das tentativas (SCHMIDT 1980, 1985) garantem a consistência do comportamento motor habilidoso. Por outro lado, aspectos como timing de movimento, força total e seleção dos músculos, variam para atender as demandas específicas da tarefa (SCHMIDT, 1980, 1985). O nadar crawl não é exceção.

Freudenheim e colaboradores desenvolveram estudos cujo objetivo foi investigar os aspectos relacionados à consistência e à variabilidade da braçada do nado crawl (FREUDENHEIM, BASSO, XAVIER FILHO, SILVA, MADUREIRA \& 
MANOEL, 2005; FREUDENHEIM, 2008; MADUREIRA, 2006; SILVA, 2008). Estes estudos representaram um avanço, pois permitiram inferir que a braçada do nado crawl é caracterizada por consistência aliada à variabilidade e ainda, que os ajustes frente às modificações da tarefa (velocidade) são feitos mediante modificações nos aspectos variantes.

Portanto, estudos que envolvem o nadar crawl habilidoso deveriam possibilitar através das medidas utilizadas a distinção entre os aspectos invariantes, que expressam o padrão de movimento; e, os variantes, que correspondem à parametrização da ação.

Os estudos do nado crawl têm sido desenvolvidos predominantemente com o objetivo de conhecer as características determinantes do nadar habilidoso. Destes estudos merece destaque o desenvolvido por CHOLLET, CHALIES \& CHATARD (2000) no qual os autores propuseram o índice de coordenação da braçada (IdC) do nado crawl e verificaram que o IdC varia, entre outros, em função da velocidade do nado. Após este estudo, foi desenvolvida uma série de estudos utilizando-se o IdC para investigar a organização temporal da braçada, frente ao gênero e a diferentes variáveis como a utilização de roupas (fast skin), a especialidade do atleta (por exemplo, de nadadores e triatletas) e tipo de prova de natação (por exemplo, de $50 \mathrm{e}$ 800 metros).

Recentemente, partindo do pressuposto de que a respiração é um componente importante do nado crawl, tem-se investigado o efeito da respiração na braçada do nado crawl (LERDA, CARDELLI \& CHOLLET, 2001; PAYTON, BARTLETT, BALTZOPOULOS \& COOMBS, 1999; SEIFERT, CHOLLET \& ALLARD, 2005b; SEIFERT, CHEHENSSE, CHOLLET, LEMAITRE \& CHOLLET, 2008; VEZOS, GOURGOULIS, AGGELOUSSIS, KASIMATIS, CHRISTOFORIDIS \& MAVROMATIS, 2007).

De forma geral estes estudos significaram grandes avanços nos conhecimentos sobre o nado crawl, mais especificamente sobre as características determinantes do nadar habilidoso no que se refere à sua braçada. Ainda, os resultados dos estudos sobre os efeitos da respiração na braçada do nado crawl não convergem. No entanto, na maioria destes estudos a tarefa envolveu nadar em velocidade máxima simulada. Por exemplo, no estudo de LERDA et al., (2001) a 
solicitação foi para nadar a distância de 25 metros simulando velocidade de provas de 100 e de 800 metros. Assim, o desempenho, variável crítica do nadar não foi considerada na análise e, em consequência, na interpretação dos resultados. Além disso, como não tiveram como intuito investigar a consistência e a variabilidade da braçada, na seleção das variáveis dependentes e independentes, a consistência da braçada, seus aspectos invariantes, não foram distinguidos da variabilidade da mesma, ou seja, de seus aspectos variantes.

Em suma, embora tenham representado avanços nos conhecimentos sobre as características determinantes do nadar crawl habilidoso, esses estudos esclareceram pouco sobre 0 efeito da respiração sobre o desempenho, a consistência e a variabilidade da braçada do nado crawl.

Somente APOLINÁRIO, SILVA, TERTULIANO, OLIVEIRA, MARQUES e FREUDENHEIM (2007), investigaram o efeito da respiração na braçada do nado crawl, diferenciando os aspectos invariantes dos variantes. Os resultados deste estudo indicaram que os nadadores se adaptaram à mudança para o lado não preferido de inspiração, principalmente a partir de ajustes nos aspectos variantes. Entretanto, este estudo exploratório envolveu poucos participantes e, segundo os autores, a tarefa de nadar em velocidade lenta, além de não ter representado um desafio para os mesmos, inviabilizou a consideração do desempenho como variável independente. Ainda, este estudo apresenta uma limitação ao não considerar a coordenação entre os braços, medida pelo IdC, como variável independente. Assim, neste estudo, além do desempenho, o IdC, variável crítica do nadar habilidoso (CHOLLET et al., 2000), não foi considerado na análise e, em consequência, na interpretação dos resultados.

Com base no exposto, percebeu-se a necessidade de revisitar esta questão, ou seja, de investigar os efeitos do padrão de respiração na braçada do nado crawl, distinguindo entre os aspectos que conferem consistência (aspectos invariantes) e variabilidade (aspectos variantes), levando em consideração também o padrão de coordenação da braçada do nado crawl. Além disso, como o desempenho é uma variável relevante do nadar habilidoso, optou-se neste estudo por utilizar como tarefa nadar em velocidade máxima real e não simulada o que permitiu investigar o efeito do padrão de respiração também no desempenho dos atletas. 


\section{$2.1 \quad$ O nadar}

Segundo o sistema unidimensional (MAGILL, 2000), o nadar pode ser classificado como sendo uma habilidade motora contínua, constituída por movimentos repetitivos sem início e fim identificáveis; habilidade motora grossa, pois requer a utilização de grandes grupos musculares para sua execução. Mas pode ser considerado como habilidade predominantemente aberta, quando executado em ambiente não estável e imprevisível (por exemplo, no mar revolto), ou como predominantemente fechada, caso seja executado em ambiente mais estável e previsível (por exemplo, ao nadar sozinho em uma raia de piscina).

O nadar é praticado para atender a fins diversos como, por exemplo, competitivo, manutenção da saúde e lazer. Nesse sentido, é uma habilidade que possui uma relação meio (ação) e fim (finalidade) indeterminada e abrangente. Por isso quando se fala de nadar, faz-se necessário caracterizar bem o fenômeno ao qual se está referindo.

Procurando caracterizar a habilidade considerando a sucessão de estágios no desenvolvimento das habilidades motoras (FREUDENHEIM et al., 1996), apresentaram o nadar como uma habilidade organizada hierarquicamente, com componentes dispostos horizontal e verticalmente no sentido da interação e não da soma. Ainda, que as habilidades específicas como os nados (crawl, costas, peito e borboleta), saltos ornamentais, nado sincronizado, mergulho, pólo aquático, biribol, dentre outras, se referem a movimentos determinados culturalmente.

\subsubsection{O nado crawl}

O nado crawl é executado mediante a realização, na superfície da água, de ações circulares e alternadas com os braços, de modo que o nadador possa virar o corpo para facilitar a ação respiratória, enquanto as pernas se movimentam em rápidas batidas golpeando a água (ANJOS \& FERREIRA, 2004; YANAI, 2004). O nado crawl é a forma de deslocamento aquático mais eficiente e, por conseguinte, a 
mais praticada. Eficiência deve ser entendida como percorrer uma determinada distância na menor unidade de tempo e menor gasto energético.

Devido às propriedades físicas da água (pressão interna, densidade e viscosidade), o nadador experimenta a resistência hidrodinâmica denominada de arrasto (VORONTSOV \& RUMYANTSEV, 2004). Em relação às demais formas de nadar, o nado crawl compreende um padrão que, proporcionalmente envolve uma magnitude de arrasto diminuído associado à produção de elevada quantidade de propulsão (MADUREIRA, 2006). Propulsão - na natação - é entendida como a força gerada pelos nadadores para impulsioná-los para frente (STAGER \& TANNER, 2008).

O nadar crawl pode ser entendido como um sistema complexo, pois compreende a realização dos componentes: ação dos braços, pernas, tronco e respiração, em interação (FREUDENHEIM \& MADUREIRA, 2006; OLIVEIRA, APOLINÁRIO, FREUDENHEIM \& CORRÊA, 2009). A seguir são apresentados os componentes separadamente e posteriormente, em interação.

\subsubsection{Componentes do nado crawl}

\subsection{Ação dos braços}

A braçada é o principal componente propulsor do nado crawl, pois produz em média 90\% da força propulsora total (DESCHODT, ARSAC, ROUARD, 1999). Ela é composta pelas fases aquática e aérea.

A fase aquática se caracteriza pelo deslocamento do braço dentro da água e tem início - entrada da mão na água (ataque) e fim - saída da mão da água (liberação) bem definidos. Esta fase pode ser subdividida em movimentos não propulsivos, ou seja, entrada e pegada, e propulsivos, puxada e empurrada (CHOLLET et al., 2000). A fase de entrada e pegada consiste no tempo entre a entrada da mão na água e o início do movimento da mão para trás; e, a fase de puxada consiste no tempo entre o início do movimento da mão para trás e a chegada da mão abaixo do plano vertical ao ombro. Esta fase (puxada) corresponde à primeira ação propulsiva da braçada. Por sua vez, a fase de empurrada consiste no 
tempo entre a posição da mão abaixo do plano vertical ao ombro e a liberação da mão e é a segunda ação propulsiva da braçada.

A fase aérea da braçada (não propulsiva), denominada de recuperação, é caracterizada pelo deslocamento do braço fora d'água, e consiste no tempo entre a liberação da mão da água e a próxima entrada da mão na água, ou seja, o ataque. Ela é subdividida em duas fases: a primeira tem início com a ruptura da superfície da água pelo cotovelo e fim quando este passa por cima do ombro; e, a segunda tem início na passagem do cotovelo sobre o ombro e finaliza com o ataque.

Como mencionado, o nado crawl é executado, entre outros, mediante a realização de ações circulares e alternadas de ambos os braços. Nesse sentido, CHOLLET et al., (2000) propuseram que a interação entre os braços pode ser expressa a partir do IdC (índice de coordenação da braçada), calculado através do tempo de atraso (diferença) do início da ação propulsiva de um dos braços e o fim da ação propulsiva do outro braço.

O IdC expressa as três formas de coordenação: por oposição (FIGURA 3), quando o IdC é igual a zero, ou seja, o final da ação propulsiva de um braço é concomitante ao início da ação propulsiva do outro braço; por deslizamento, quando há atraso entre a ação propulsiva dos dois braços resultando em um percentual negativo, ou seja, durante um período o nadador não produz propulsão com nenhum dos braços; e, por sobreposição, quando o IdC é positivo, ou seja, quando há ação propulsiva simultânea dos dois braços.

\subsection{Ação das pernas}

A ação das pernas, como a dos braços, compreende fases propulsiva e de recuperação. $\mathrm{Na}$ fase propulsiva, o deslocamento da perna deve ser para trás, para dentro e para baixo. Portanto os movimentos não devem ocorrer apenas no sentido vertical, mas sim, no sentido vertical e diagonal, como consequência do rolamento do tronco (MAGLISHO, 1999, 2003). Esta fase começa com uma flexão do quadril, seguida pela extensão do joelho. A fase de recuperação compreende a movimentação da perna estendida para cima através da extensão do quadril. A pernada é responsável por $10 \%$ da força propulsiva produzida pelo nadador ao 
realizar o nado crawl (DESCHODT et al., 1999). Sua maior contribuição é na manutenção da estabilidade do corpo do nadador.

\subsection{Ação do tronco}

Consiste em rolar o tronco em torno do seu próprio eixo continuamente de um lado para o outro. O rolamento é uma ajuda indispensável para a manutenção de um bom alinhamento lateral do corpo e para a redução do arrasto. Em geral, os nadadores oscilam entre 30 e 45 graus sem ação respiratória (MAGLISCHO, 1999, 2003) e entre 57 e 66 graus em função da ação respiratória (PAYTON et al., 1999). Se tais inclinações forem ótimas, tornam mais eficazes os movimentos dos braços (MAKARENKO, 2001).

\subsection{Respiração}

A respiração tem como finalidade fornecer oxigênio para o corpo do nadador e melhora a capacidade de difusão pulmonar (MAGLISCHO, 1999, 2003). Por isso é uma variável imprescindível ao rendimento do atleta. Se o mesmo gerenciá-la de forma ineficiente, todo o nado será comprometido.

A respiração ocorre mediante o ciclo de inspiração - fora da água, apneia (bloqueio do ar) e expiração - dentro da água. Quando a face do nadador rompe a superfície da água (emersão), ele inicia a inspiração, a qual deve ser realizada pela boca de forma rápida e profunda. Após a imersão da face, ocorre a expiração. Alguns atletas utilizam a expiração nasal, outros a oral e ainda existem nadadores que exalam o ar pelas duas vias simultaneamente. A maioria dos nadadores realiza a apneia antes da expiração.

As ações respiratórias podem envolver grandes períodos em apneia, ser unilaterais ou bilaterais. Quando nadador opta por periodos prolongados em apneia se desloca mantendo sua face imersa bloqueando o ar, portanto, no periodo correspondente, não efetua a inspiração. Por sua vez, a ação unilateral compreende no indivíduo efetuar a inspiração para um só lado, geralmente, para o seu lado preferido. Já na respiração bilateral o nadador alterna os lados para os quais realiza 
a inspiração, inspirando, normalmente, uma vez para seu lado preferido e na próxima para seu lado não preferido, e assim sucessivamente.

A respiração bilateral pode favorecer o nadador na observação de seus adversários, contribuindo assim, de forma significativa em disputas táticas de uma prova (COLWIN, 2000; FREUDENHEIM \& MADUREIRA, 2006; MAGLISCHO, 1999, 2003). Mesmo assim, o padrão respiratório unilateral, talvez por compreender inspirar somente para o lado preferido, é o mais utilizado por atletas de alto nível.

Em síntese, como apresentado acima, cada um dos componentes do nado crawl possui uma função específica predominante: a braçada é o principal componente propulsor; a pernada contribui especialmente com a manutenção da estabilidade do corpo do nadador; a ação do tronco é importante para a manutenção do alinhamento lateral do corpo; e, a respiração, é fundamental para fornecer oxigênio para o corpo. Portanto, para caracterizar-se como nado crawl, todas estas ações, sem exceção, devem estar sendo executadas. Além disso, vale ressaltar que como apresentado e ilustrado na FIGURA 1, com exceção da ação do tronco, os demais componentes do nado crawl podem ser decompostos em subcomponentes. Especificamente, verifica-se que a ação dos braços, central ao presente estudo, pode ser decomposta nas fases aérea e aquática. Por sua vez, a fase aquática pode mais uma vez ser decomposta nas fases de entrada e pegada, puxada e empurrada (FIGURA 1). 


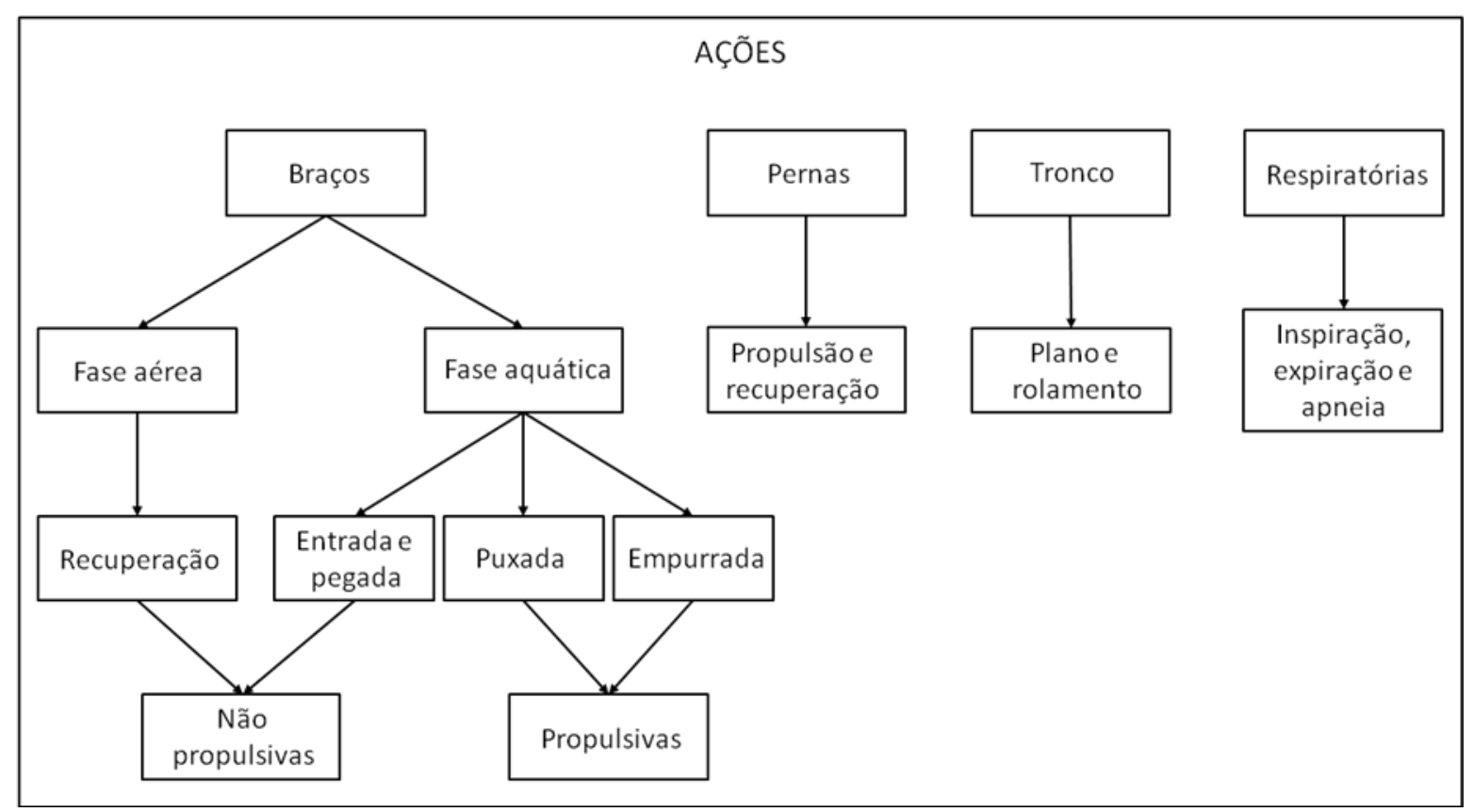

FIGURA 1 - Organização hierárquica do nado crawl (adaptado de FREUDENHEIM \& MADUREIRA, 2006).

A clareza dos momentos iniciais e finais de cada um dos componentes, e de seus respectivos subcomponentes, permite o cálculo do IdC, bem como o cálculo de medidas que expressam a consistência (aspectos invariantes) e a variabilidade (aspectos variantes) da braçada. Estas possibilidades foram exploradas no presente estudo.

2.1.2.2 Interação entre os componentes do nado crawl

O nado crawl é caracterizado pela interação de seus componentes (FREUDENHEIM et al., 1996), ou seja, entre as ações dos braços e respiração; dos braços e tronco; e, entre as ações dos braços e pernas.

O padrão respiratório unilateral, que compreende no indivíduo inspirar somente para o seu lado preferido, resulta numa razão de duas braçadas para uma respiração. Já o padrão bilateral, que compreende no nadador alternar os lados, resulta, normalmente, numa razão de três braçadas para uma respiração completa (inspiração, apneia e expiração). Portanto, comparado ao padrão unilateral, efetua-se 
menos ações de respiração ao adotar o padrão de braçada bilateral. Mas, indiferente se o padrão uni ou bilateral é adotado, a saída da face da água e o início da inspiração devem ocorrer ao final da segunda ação propulsiva (empurrada) do braço. Já o retorno da face do nadador na água deve ocorrer antes do início da segunda fase da recuperação (MAGLISCHO, 1999, 2003). Já o padrão em apneia, que compreende longos períodos de bloqueio do ar resulta, numa razão de muitas braçadas sem que seja efetuada uma respiração completa (inspiração, apneia e expiração).

Ainda, visando um nadar eficiente, os nadadores devem rolar o tronco em torno do seu próprio eixo continuamente de um lado para o outro de forma coordenada com os movimentos dos braços (MAGLISCHO, 1999, 2003). Este rolamento é indispensável para a manutenção de um bom alinhamento lateral do corpo e para a redução do arrasto. Em geral, nadando em apneia os nadadores oscilam entre 30 e 45 graus (MAGLISCHO, 1999, 2003) e entre 57 e 66 graus em função da ação respiratória uni ou bilateral (PAYTON et al., 1999). Se tais inclinações forem ótimas, tornam mais eficazes os movimentos dos braços (MAKARENKO, 2001).

Por fim, sobre a interação entre as ações dos braços e pernas é indicado que início e fim de cada pernada para baixo coincida, respectivamente, com o início e fim de cada fase da braçada (MAGLISCHO, 1999, 2003). Esta relação possibilita diferentes ritmos de pernada. $O$ ritmo de pernada refere-se ao número de movimentos para baixo das pernas por ciclo de braços (duas braçadas). Assim podem ocorrer duas, quatro, ou seis pernadas por ciclo de braços, dependendo da distância percorrida (COSTILL, MAGLISCHO \& RICHARDSON, 1992; COUNSILMAN \& COUNSILMAN, 1994; MAGLISCHO, 1999, 2003; MAKARENKO, 2001). Nadadores habilidosos variam o ritmo de pernada, mesmo durante uma única prova (COLWIN, 2002; MAGLISCHO, 1999, 2003). Por isso, nos estudos em que a pernada é uma variável independente, o ritmo de pernada deveria ser previamente estabelecido.

De forma geral, ao comportamento motor habilidoso têm sido conferidas algumas características importantes que devem ser consideradas nos estudos que envolvem habilidades motoras. O próximo capítulo trata destas características. 
Ao observar indivíduos habilidosos praticando esporte supõe-se que estejam repetindo uma série de movimentos idênticos. No entanto, de acordo com BARTLETT (1932) a característica de que o comportamento motor habilidoso é, ao mesmo tempo consistente e variável, não pode ser desconsiderada. Referindo-se à rebatida do tênis de mesa BARTLETT (1932) afirmou que ao executarmos movimentos, na realidade não produzimos algo absolutamente novo e nem repetimos algo velho, pois a bola não cai duas vezes no mesmo lugar, com a mesma rotação, com a mesma velocidade e angulação. Sendo assim, para ter sucesso seria insuficiente repetir exatamente o mesmo movimento. Além disso, existe o problema dos inúmeros graus de liberdade existentes nas articulações, músculos e unidades motoras, o qual também torna a repetição de movimentos improvável no nível microscópico (BERNSTEIN, 1967). Nesse sentido, o que no comportamento motor habilidoso parece idêntico a partir de uma observação geral, macroscópica, quando observado em detalhes, microscopicamente, apresenta variabilidade. Desta forma, o comportamento de executantes habilidosos é consistente em relação a algumas características do movimento e, ao mesmo tempo, variável em relação a outras.

Em sua clássica revisão de estudos sobre o tema, SCHMIDT (1985) concluiu que, mesmo diante de alterações nas condições ambientais, algumas características do comportamento são mantidas invariantes, como o timing relativo, 0 sequenciamento e a força relativa. Enquanto isso, aspectos relacionados a parâmetros como tempo de movimento, força total, e seleção dos músculos variam para atender as demandas específicas da tarefa, dando uma configuração única a cada padrão do movimento.

Esta proposição de existência de aspectos invariantes do comportamento motor foi criticada por GENTNER (1982, 1987), pela falta de rigor na análise estatística. Mas, HEUER $(1988,1991)$ retrucou argumentando que a postulação da existência de aspectos invariantes não se referia à invariância no nível efetor, mas sim no nível central de processamento de informações. Em consequência, pequenos desvios não deveriam ser entendidos como prova de inexistência da invariância, mas 
deveriam ser entendidos de forma relativa, como uma probabilidade de observação desta.

Mesmo assim, nos estudos de comportamento motor até a década de 1990 do século passado, a variabilidade foi tida como sinônimo de erro e, portanto, como algo a ser reduzido ou mesmo eliminado (NEWELL \& CORCOS, 1993). Provavelmente esta visão da variabilidade tem origem na tendência de associar 0 nível de habilidade à consistência do desempenho.

Nesta perspectiva, TANI $(1995,2005)$ verificou a necessidade de diferenciar os tipos de variabilidade, para entender qual o seu papel no comportamento motor. $O$ autor identificou três tipos de variabilidade: a primeira que resulta da inconsistência no padrão do movimento. Este tipo de variabilidade está presente durante o processo de estabilização da performance e deve ser reduzido para que se alcance a consistência. A segunda é a variabilidade presente após a estabilização, que permite que sejam feitos ajustes necessários (parametrização) para fazer frente às mudanças ambientais; e, o terceiro tipo de variabilidade é aquele inerente ao sistema motor (ruído), e não pode ser controlado.

Dessa forma, TANI (2005) considera que a consistência da ação é necessária para alcançar resultados com confiabilidade e a variabilidade (segundo tipo) como fundamental para fazer frente às condições ambientais em constantes mudanças, ou seja, à flexibilidade do comportamento motor habilidoso. Mais especificamente, consistência significa que sempre que necessário, a ação executada implica em resposta apropriada para a solução do problema motor apresentado. Sendo assim, deve-se possuir um controle confiável no sentido de uma possível repetição de seu padrão.

No contexto da teoria de esquema, SCHMIDT (2003) revisitou, entre outras, a questão de quais seriam os aspectos invariantes de habilidades motoras. Nesta retomada, baseado nos estudos realizados, ao mesmo tempo em que afirma ter quase certeza que a proposta de força relativa está incorreta, reforça sua afirmativa de que o timing relativo sim é invariante. Inclusive o autor afirma que, como demonstrado por HEUER, SCHMIDT e GHODSIAN (1995) a invariância no timing relativo pode ser estendida para as ações bimanuais. HEUER et al., (1995), encontraram uma invariância temporal muito forte quando os participantes foram 
solicitados a produzir ações rápidas de forma simultânea, mas diferenciadas para os dois braços. Eles demonstraram que a estrutura temporal de cada membro, bem como a estrutura temporal entre os membros, foi escalonada de forma linear no tempo, isto é, que a invariância do timing relativo esteve presente durante toda a tarefa bimanual. Assim, pode-se considerar que, em comparação com a força relativa, o timing relativo expressa melhor à manutenção de um aspecto relativamente invariante ao longo das tentativas (SCHMIDT, 2003).

Em síntese, o comportamento de executantes habilidosos é consistente em relação a algumas características do movimento, dentre elas, o timing relativo se destaca (aspectos invariantes) e, ao mesmo tempo variável em relação a outras (aspectos variantes). O nadar crawl não é exceção.

\section{$4 \quad$ ESTUDOS DO NADO CRAWL}

Os estudos que envolvem os nados têm sido desenvolvidos predominantemente com o objetivo de determinar qual é o aspecto mais relevante do nadar habilidoso, ou seja, qual é a principal determinante de sua eficiência. Pelo fato de ser o nado mais praticado, a maioria destes estudos envolve o nado crawl.

Freudenheim e colaboradores desenvolveram estudos cujo objetivo foi investigar os aspectos relacionados à consistência e à variabilidade da braçada do nado crawl (FREUDENHEIM et al., 2005; FREUDENHEIM, 2008; MADUREIRA, 2006; SILVA, 2008).

FREUDENHEIM et al., (2005) analisaram a organização temporal da braçada do nado crawl de indivíduos em níveis de habilidade distintos. O objetivo foi verificar se há diferença entre os indivíduos avançados e iniciantes em relação aos aspectos invariantes e variantes da braçada do nadar crawl. Participaram onze crianças, com idade entre 7 e 11 anos, das quais cinco constituíram o Grupo Iniciante e seis o Grupo Avançado. A tarefa consistiu em se deslocar uma distância de dez metros na água, numa velocidade confortável, usando o nado crawl. Foram analisadas as medidas que correspondem aos aspectos invariantes (timing relativo e a variabilidade da fase aérea e aquática do braço direito e esquerdo); e, que correspondem aos aspectos variantes (tempo total da fase aérea e aquática do braço direito e esquerdo, 
tempo total da braçada direita e esquerda, tempo total do ciclo e suas variabilidades), separadamente. Os resultados do estudo mostraram nos aspectos invariantes (braço direito), as crianças mais avançadas permaneceram relativamente mais tempo na fase aquática da braçada, responsável pela propulsão, e o timing relativo nesse componente foi mais consistente. Em relação aos aspectos variantes o grupo avançado executou ciclos mais rápidos, mas a variabilidade do tempo total de ambos os grupos foi à mesma. Portanto, a variabilidade demonstrada pelo grupo de crianças avançadas pode estar associada a uma maior disponibilidade para fazer modificações no ciclo de braçadas, seja para ajustar e manter a frequência de braçada ou para lidar com variações na tarefa. No entanto, os resultados são limitados para compreender o significado da variabilidade que permanece após a estabilização do desempenho (formação de estrutura), pois não foi apresentada nenhuma perturbação.

Para verificar o papel da variabilidade que permanece após a estabilização do desempenho, (MADUREIRA, 2006) investigou o efeito da modificação da tarefa na braçada do nado crawl em indivíduos em níveis de habilidades distintos. Participaram do estudo 42 crianças de ambos os gêneros com idade entre 07 e 10 anos, que nadaram 30 metros em três velocidades: lenta, natural e rápida. Foram utilizadas as mesmas medidas do estudo anterior. Os resultados mostraram que as alterações de desempenho em função das condições experimentais foram efetuadas por ambos os grupos (avançados e iniciantes), exclusivamente a partir de ajustes dos aspectos variantes das braçadas, portanto, via ajustes paramétricos.

Por sua vez SILVA (2008) investigou a consistência (aspectos invariantes) e a variabilidade (aspectos variantes) da braçada do nado crawl, em três velocidades distintas, mas agora, em indivíduos habilidosos (atletas). Participaram do estudo, 16 atletas masculinos das categorias juniores e seniores com idade entre 17 e 32 anos $( \pm 20,6)$ divididos em dois grupos de oito atletas: Grupo Nacional (mais habilidosos) e Grupo Estadual (menos habilidosos). A tarefa foi nadar $6 \times 50$ metros de nado crawl em três condições de nado: $100 \%$, a $90 \%$ e a $80 \%$ de sua velocidade máxima. Os indivíduos mais habilidosos (Nacional) não alteraram os aspectos invariantes da braçada frente às diferentes condições da tarefa, diferentemente do grupo menos habilidoso (Estadual); Em relação aos aspectos variantes da braçada, os nadadores 
mais habilidosos variou mais comparado aos menos habilidosos. A conclusão foi de que a variabilidade nos aspectos variantes da braçada, que permanece após a estabilização do desempenho do nado crawl de nadadores habilidosos, pode ser interpretada como sendo de natureza funcional (MANOEL \& CONNOLLY, 1995; TANI, 1995, 2005).

Os estudos mencionados até aqui foram realizados em situação experimental, ou seja, distante de uma situação real na qual há entre outros, a presença dos adversários. Nesse sentido, seus resultados não necessariamente podem ser generalizados para uma situação real de competição.

Para verificar o poder de generalização dos resultados dos estudos anteriores, FREUDENHEIM (2008) investigou o papel dos aspectos invariantes e variantes da braçada do nado crawl em uma situação real de competição. Participaram do estudo 31 atletas master, de ambos os sexos, com idades entre $21 \mathrm{e}$ 54 anos, que nadaram a prova de 400 metros nado livre em uma competição oficial da Federação Aquática Paulista. Foram registrados o terceiro, sétimo, décimo primeiro e o décimo quinto dos 16 percursos de 25 metros e foram denominadas de partes da prova, respectivamente, partes $1,2,3$ e 4 . Os resultados permitiram concluir que os recursos utilizados pelos nadadores compreenderam alteração do desempenho mediante alteração dos aspectos variantes e manutenção dos aspectos invariantes. Nesse sentido, os resultados revelaram que o nadar crawl habilidoso em situação real de execução também se caracteriza por apresentar consistência aliada à variabilidade, da mesma forma que em contexto artificial.

Estes estudos representaram um avanço, pois permitiram inferir que a braçada do nado crawl é caracterizada por consistência (expressa pelo timing relativo) aliada à variabilidade e ainda, que os ajustes frente às modificações da tarefa (velocidade) são feitos mediante modificações nos aspectos variantes (tempo absoluto). Portanto, estudos que envolvem o nadar crawl habilidoso deveriam possibilitar através das medidas utilizadas a distinção entre os aspectos invariantes, que expressam o padrão de movimento; e, os variantes, que correspondem à parametrização da ação.

Outro conjunto de estudos teve como objetivo investigar o efeito na braçada do nado crawl de variáveis como: nível de habilidade (CHOLLET, PELAYO, 
DELAPLACE, TOURNY \& SIDNEY, 1997); velocidade (CHOLLET et al., 2000; LERDA \& CARDELLI, 2003; MILLET, CHOLLET, CHALIES \& CHATARD, 2002; SEIFERT, BOULESTEIX \& CHOLLET, 2004; SEIFERT, CHOLLET \& ROUARD, 2007); e decorrer do percurso (SEIFERT, BOULESTEIX, CARTER \& CHOLLET, 2005a).

Dentre estes estudos, o de CHOLLET et al., (2000) foi um marco na investigação do nado crawl. Neste estudo os autores propuseram o índice de coordenação do nado crawl (IdC) e verificaram que o IdC varia em função da velocidade de nado e do nível de habilidade. Especificamente, cujos objetivos foram: a) descrever uma nova ferramenta para medir a coordenação entre os braços no nado crawl; e, b) analisar a existência ou não de variações nas sincronizações entre os braços, bem como, braços e pernas para diferentes velocidades e níveis de performance.

Participaram do estudo 43 nadadores (29 homens e 14 mulheres) de 20 anos de idade, de três níveis de habilidade distintos. A tarefa consistiu em nadar três vezes uma distância de 25 metros em velocidade máxima, simulando correspondência, respectivamente com as provas de 800, 100 e 50 metros, em apneia. Ao longo de 10 metros (dos 12,5 metros aos 22,5 metros) os atletas foram instruídos a nadar em apneia para não afetar o IdC. Para evitar o efeito da fadiga houve um período de descanso de 2 minutos e 30 segundos entre as tentativas. Os nadadores foram divididos em 3 grupos (alto, intermediário e baixo nível de habilidade) de acordo com o nível de desempenho nas distâncias nadadas.

Os resultados mostraram que, para a velocidade referente à distância de 800 metros a coordenação encontrada foi a de deslizamento para todos os grupos. Já na simulação das provas de 100 e 50 metros, o grupo mais habilidoso adotou o padrão de sincronização por oposição, o que não ocorreu no grupo de nadadores menos habilidosos. Ainda, com o aumento da velocidade de nado, em função das provas simuladas serem mais curtas, o grupo mais habilidoso aumentou mais o timing relativo das fases propulsivas das braçadas $(40 \%)$ do que o grupo menos habilidoso (24\%). Finalmente, somente o grupo alto nível de habilidade foi capaz de, com o aumento da velocidade, diminuir o comprimento relativo da fase de recuperação. Em conjunto, os resultados indicam que estas modificações na braçada são um recurso 
usado, somente pelos nadadores habilidosos, para gerar períodos mais longos de aplicação de força propulsiva.

Este estudo desencadeou o interesse no meio acadêmico por uma maior compreensão dos ajustes feitos, principalmente no IdC, por indivíduos habilidosos, frente a diferentes condições de deslocamento (LERDA \& CARDELLI, 2003; MILLET et al., 2002; SEIFERT et al., 2004; SEIFERT et al., 2005a; SEIFERT et al., 2007). Em conjunto, os resultados destes estudos mostram que o nível de habilidade associado à velocidade de nado, bem como o decorrer do percurso, afeta a braçada do nado crawl, mais especificamente, frequência e comprimento das braçadas, bem como, a coordenação entre os braços (IdC).

Embora os estudos desenvolvidos por Freudenheim e colaboradores e Chollet e colaboradores tenham representado grandes avanços sobre os conhecimentos do nado crawl, tiveram como foco principal um só componente, a braçada. Esta escolha se justifica, pois ao fazer uso de uma reconhecida estratégia metodológica de redução de variáveis, escolhe-se o componente do crawl com maior contribuição propulsora (a braçada) como principal foco de estudo. No entanto, recentemente, considerando que a respiração é um componente importante do nado crawl, tem-se investigado o efeito da respiração na braçada do nado crawl, tema também do presente estudo.

\subsection{Estudos sobre os efeitos da respiração na braçada do nado crawl}

Dentre os estudos desenvolvidos com o objetivo de determinar quais são os aspectos mais relevantes do nadar habilidoso, tem-se investigado o efeito da respiração na braçada do nado crawl (APOLINÁRIO et al., 2007; LERDA et al., 2001; PAYTON et al., 1999; SEIFERT et al., 2005b; SEIFERT et al., 2008; VEZOS et al., 2007).

PAYTON et al., (1999), realizaram um estudo com o objetivo de investigar o efeito da respiração na braçada e no ângulo de rolamento do tronco. Foram filmados seis nadadores masculinos com média de idade de 21 anos nas condições com inspiração para o lado preferido e em apneia. A tarefa consistiu em nadar 12 tentativas de 25 metros em velocidade máxima simulando uma prova com distância 
de 200 metros. Metade das tentativas foi realizada inspirando para o lado preferido e a outra metade em apneia, nos 15 metros centrais do percurso. As medidas utilizadas foram: comprimento e frequência de braçada, timing relativo das fases das braçadas (entrada e pegada, puxada, empurrada e recuperação) e ângulo de rolamento do corpo. Os resultados mostraram que dos parâmetros analisados, os nadadores somente alteraram o ângulo de rolamento em função da condição de respiração. Os autores concluíram que nadadores de crawl conseguem executar a inspiração sem que esta afete os parâmetros básicos da braçada e que, portanto, são capazes de integrar a ação da respiração com a ação da braçada sem que esta interfira na capacidade de produzir força propulsiva ou no aumento da resistência. Mas, foi feita somente análise descritiva dos dados, a velocidade de nado foi simulada e o nado foi adulterado, pois os nadadores nadaram com uma estrutura de madeira fixada às costas para análise do ângulo de rolamento do corpo. Assim, estes resultados devem ser considerados com cautela. Ainda, provavelmente, por ter sido realizado antes da proposição do IdC (CHOLLET et al., 2000), este estudo não considerou esta importante variável.

Utilizando o IdC, LERDA et al., (2001) investigaram os efeitos da respiração na coordenação da braçada do nado crawl, em função do nível de habilidade e da velocidade de nado. Vinte e quatro nadadores em níveis de habilidades distintos com média de 21 anos de idade foram solicitados a nadar em velocidade máxima simulada para duas distâncias (100 e 800 metros). Participantes dos dois grupos nadaram 2 séries de 4 tentativas de 25 metros em duas condições: com inspiração a cada ciclo de braçada e em apneia. Acrescido o IdC, e com exceção do ângulo de rolamento do corpo, as medidas foram as mesmas utilizadas em (PAYTON et al., 1999). Como em PAYTON et al., (1999), os resultados mostraram que os nadadores mais habilidosos não alteraram velocidade, frequência e comprimento de braçada em função da condição de respiração (em apneia e com inspiração) na velocidade máxima simulada comparado aos menos habilidosos. Mas, ambos os grupos apresentaram IdC maior na condição em apneia comparado a condição com inspiração a cada ciclo de braçada. Portanto, concluíram que inspirar enquanto se nada aumenta a descontinuidade das ações propulsivas dos braços. Em relação ao timing relativo, os dois grupos de nadadores apresentaram modificação na fase de 
puxada na condição com inspiração a cada ciclo de braçada. Esses resultados se diferenciam daqueles obtidos por (PAYTON et al., 1999), a respeito do tempo das fases das braçadas de nadadores não terem sido afetados pela ação da respiração. Nesse sentido, apontam para o fato de a respiração interferir sim na braçada, e reforça a importância de se considerar o IdC nos estudos que visam investigar a interação entre a respiração e a braçada. Mas, este estudo foi em velocidades simuladas. Por isso a interpretação dos seus resultados, como no caso de (PAYTON et al., 1999), também merece cautela.

SEIFERT et al., (2005b) investigaram a relação entre a simetria na coordenação da braçada, dominância lateral e lateralidade respiratória, em função do nível de habilidade. Participaram deste estudo jovens nadadores, todos de gênero masculino (média de idade de 20 anos) dos quais 10 de elite (G1), 10 de nível médio (G2) e 8 nadadores não peritos (G3). Todos os nadadores foram solicitados a percorrer 100 metros nadando crawl em velocidade máxima simulada da prova de 200 metros. Todos nadaram usando seu padrão respiratório preferido, obtido através da aplicação de um questionário desenvolvido para este fim. Portanto alguns nadaram usando o padrão unilateral e outros o bilateral, sempre inspirando conforme lado e frequência de sua preferência. A dominância lateral foi identificada a partir de um inventário. Para análise foram considerados os 15 metros centrais das quatro parciais de 25 metros. As medidas foram as mesmas utilizadas por (LERDA et al., 2001) acrescido o índice de coordenação do braço esquerdo (IdCe), o índice de coordenação do braço direito (IdCd), e o índice de simetria (IS), ou seja, a diferença entre $\mathrm{IdCe}$ e IdCd. Os resultados indicaram que a velocidade e frequência de braçada diminuíram da primeira para a segunda parte do trajeto para G1 e G2. Para G3 a velocidade diminuiu ao longo de todo o trajeto e frequência da mesma forma que para os demais grupos. Somente para o G3 o comprimento da braçada não mudou ao longo do percurso. Em relação à assimetria, os resultados indicaram que a maior parte dos nadadores apresentou assimetria na coordenação entre os braços, com IDC indicando descontinuidade em um dos braços e sobreposição no outro. Esta assimetria foi mais acentuada aos participantes que usaram o padrão de respiração unilateral, em comparação com aqueles com preferência pela inspiração bilateral, que apresentaram maior simetria entre as braçadas direita e esquerda. 
Ainda, somente no caso dos nadadores não peritos, a ação da respiração em si, mais do que o padrão respiratório adotado, amplificou a assimetria no lado da inspiração. Estes resultados reforçam os do estudo anterior no que diz respeito ao padrão de respiração, mesmo sendo o preferido, interferir na braçada de jovens nadadores e a importância de se considerar, o nível de habilidade dos participantes e o IdC nos estudos que visam investigar a interação entre a respiração e a braçada.

Por sua vez, VEZOS et al., (2007) investigaram o efeito da ação respiratória nas fases da braçada do nado crawl em atletas de gênero feminino. Vale ressaltar que este estudo como o de (SEIFERT et al., 2005b), abordou somente o lado preferido de inspiração. Dez jovens nadadoras (média de idade de 15 anos) foram solicitadas a percorrer nadando crawl duas tentativas de 25 metros, em velocidade submáxima simulada ( $80 \%$ do melhor tempo na distância de $100 \mathrm{~m})$, em duas condições: com inspiração para o lado preferido e em apneia. Foram somente utilizadas medidas que correspondem aos tempos das fases das braçadas: recuperação, entrada e pegada, puxada e empurrada. Portanto, o IdC não foi considerado para análise. Os resultados mostraram que as nadadoras apresentaram maior tempo nas fases das braçadas na condição com inspiração, comparado a condição em apneia e que também modificaram os parâmetros dos subcomponentes da braçada em função do padrão respiratório. Assim, podemos observar que esses resultados não corroboram os de (PAYTON et al., 1999) e de (LERDA et al., 2001) no que se refere ao efeito da inspiração nos parâmetros básicos da braçada.

Mais recentemente SEIFERT et al., (2008) investigaram a relação entre o padrão respiratório e a simetria da coordenação da braçada do nado crawl, incluindo como condição o lado não preferido de inspiração. Participaram do estudo 11 jovens nadadores homens (média de idade de 18,6 anos) especialistas no nado crawl. A tarefa consistiu em nadar 25 metros em ritmo correspondendo à prova de 100 metros do nado livre. Foram utilizados os padrões de respiração unilateral, bilateral e em apneia. O padrão unilateral compreendeu as condições, duas braçadas: com uma inspiração para o lado preferido (2p); com uma inspiração para o lado não preferido (2np); simulando inspiração para o lado preferido (simulação 2p); e, com snorkel frontal, sem virar a cabeça, respeitando a inspiração em todas as braçadas para o lado preferencial de inspiração (snorkel $2 p$ ). Os demais padrões de respiração foram: 
Lado e frequência inspiratória livre com snorkel frontal (snorkel); Em apneia; e, Três braçadas para uma respiração (bilateral). Com a justificativa de evitar qualquer influência das pernas na coordenação entre os braços, neste estudo os nadadores usaram flutuador e tiveram as pernas atadas. Para análise, foram utilizadas as mesmas medidas que em (SEIFERT et al., 2005b). Semelhante a (PAYTON et al., 1999) e (LERDA et al., 2001), os resultados mostraram que não houve diferença significante na velocidade de nado, frequência e comprimento de braçada em função da condição da respiração. Em relação ao índice de simetria os resultados indicaram assimetria nos 7 padrões de respiração. Mas, em comparação aos demais, os padrões respiratórios com snorkel, apneia e bilateral apresentaram maior simetria, sendo, como no estudo de (SEIFERT et al., 2005b), o padrão bilateral o que obteve o menor efeito dos sete padrões analisados.

No entanto, como na maioria deles, a velocidade neste estudo também foi simulada e, no caso especifico, um agravante é que as pernas foram atadas para anular a sua ação. Esse recurso pode significar mudança na manutenção da estabilidade do corpo do nadador. Nesse sentido, neste estudo, o nado crawl foi descaracterizado, o que faz com que os resultados também devam ser considerados com muita cautela.

Em suma, os resultados deste conjunto de estudos avançam no que diz respeito à compreensão dos efeitos da respiração na braçada do nado crawl. Embora os resultados não sejam convergentes quanto ao efeito do padrão respiratório nos parâmetros básicos da braçada (frequência, comprimento e tempo), mostram que o padrão respiratório afeta o IdC e a simetria na coordenação da braçada, principalmente de nadadores não peritos.

No entanto, na maioria dos estudos a tarefa consistiu em nadar um trajeto curto em velocidade máxima simulada, de acordo com diferentes provas e suas correspondentes distâncias. Assim, na maioria destes estudos o desempenho na denominada velocidade máxima foi também fruto de simulação. Chama a atenção também no caso deste conjunto de estudos, a não consideração diferenciada dos aspectos invariantes e variantes da braçada do nado crawl, característica essencial do nadar habilidoso. Nesse sentido, os aspectos que são mantidos relativamente invariantes ao longo das tentativas e condições de realização da tarefa, que 
garantem a consistência do comportamento motor habilidoso, não foram diferenciados dos aspectos que variam para atender as demandas específicas da tarefa e assim assegurar a flexibilidade do nado.

Em um estudo exploratório, APOLINÁRIO et al., (2007) investigaram os efeitos do lado inspiratório - lado não preferido e preferido na consistência e variabilidade da braçada do nado crawl. Dois nadadores, sendo um atleta e o outro não atleta, foram filmados nadando 25 metros do nado crawl, em velocidade lenta em duas condições de inspiração: lado preferido (LP) e lado não preferido (LNP). Para a análise descritiva, foram utilizadas as medidas referentes aos aspectos invariantes e variantes da braçada. Para manter-se em velocidade lenta e passar da condição LP para a LNP, o atleta parece ter mantido a organização temporal da braçada e se adaptado à mudança para o lado não preferido a partir, exclusivamente, de ajustes nos aspectos variantes. Por sua vez, a mudança parece ter afetado o nadar do não atleta em relação aos aspectos invariantes (variabilidade do timing relativo) e variantes (variabilidade do tempo absoluto). Dentro das limitações inerentes a um estudo exploratório, os resultados indicam que os nadadores atletas se adaptam à mudança para o lado não preferido de inspiração, excluisvamente, a partir de ajustes nos aspectos variantes devido á redundância (folga) no sistema. Contudo, esses resultados e sua interpretação devem ser considerados com cautela, devido às limitações referentes ao número limitado de sujeitos, por se tratar de uma análise descritiva e também pelo fato da tarefa ter sido realizada em velocidade lenta, que não representa desafio para os participantes. Além disso, neste estudo o IdC não foi considerado.

Em resumo, pode-se dizer que os resultados obtidos nas pesquisas que tiveram como objetivo investigar os efeitos da respiração na braçada do nado crawl, não foi suficientemente conclusivo. Nesse sentido, eles indicaram que os efeitos de diferentes padrões respiratórios no desempenho e na consistência e variabilidade na braçada do nado crawl deveriam ser abordados para que se pudessem obter dados mais esclarecedores. 
O objetivo do presente estudo foi investigar os efeitos de diferentes padrões respiratórios no desempenho e na braçada do nado crawl.

\subsection{Amostra}

Participaram do estudo, mediante assinatura do termo de consentimento, 21 atletas masculinos das categorias infantis e juvenis, ou seja, com idade entre 13 e 16 anos $( \pm 14,52)$, respectivamente, vice campeões Paulista e Brasileiro e campeões Paulista e Brasileiro de 2009. Para minimizar o efeito da preferência por algum padrão respiratório específico, foi utilizado como critério de inclusão da amostra ter preferência pelo padrão com inspiração unilateral para o lado direito ou esquerdo, identificado através da aplicação de questionário específico (SEIFERT et al., 2005b).

\subsection{Tarefa}

A tarefa, definida com base no estudo exploratório realizado por (APOLINÁRIO et al., 2007), foi nadar 4 tentativas de 25 metros do nado crawl em velocidade máxima em quatro condições de forma aleatória e contrabalanceada:

LP: Inspiração para lado preferido a cada ciclo de braçada

LNP: Inspiração para lado não preferido a cada ciclo de braçada

S: Sem inspiração - em apneia

B: Inspiração bilateral

O experimento foi realizado em uma piscina de 25 metros de comprimento por 12,5 de largura aberta e aquecida com profundidade de 5 metros. Para análise, foram consideradas seis braçadas (três direita e três esquerda) consecutivas nos 10 metros centrais do percurso de 25 metros nas quatro condições. 


\subsection{Procedimentos}

A coleta de dados foi realizada em duas etapas. Na primeira, os atletas foram conduzidos a uma sala onde receberam as informações sobre o estudo, preencheram o questionário (ANEXO I) e assinaram o termo de consentimento livre e esclarecido (ANEXO II).

A segunda etapa ocorreu no ambiente da piscina (FIGURA 2) e compreendeu familiarização com o ambiente, marcação de pontos anatômicos, identificação com toucas, fornecimento de instrução, posicionamento e execução da tarefa experimental. A coleta de dados foi realizada por 6 experimentadores, sendo 4 deles membros de grupos de estudos em Comportamento Motor e 2 especialistas em natação, todos com experiência em coleta de dados e com mais de 10 anos de experiência em natação.

A familiarização com o ambiente (piscina), ocorreu mediante aquecimento individualizado dos atletas de acordo com especificações de seu técnico de, no mínimo, 10 minutos. Após a familiarização, os atletas foram conduzidos para a lateral da piscina onde um experimentador efetuou a marcação nos seus punhos com fita velcro branca ou preta (de acordo com a cor da pele) e foram identificados com toucas brancas e amarelas numeradas de 1 a 12. A marcação nos punhos teve como objetivo facilitar a visualização das ações dos braços, e a touca para controlar 0 padrão de respiração realizado.

Em seguida um experimentador forneceu a instrução coletiva detalhada sobre a tarefa. Foi Ihes informado que a posição inicial deveria ser com o corpo na horizontal e com os pés na parede; a partida seria iniciando o nado sem impulsão da borda; após o sinal de partida dado por um apito, eles deveriam nadar 25 metros do nado crawl em velocidade máxima na condição de respiração requisitada pelo experimentador, e a chegada seria com uma das mãos. Após a instrução fornecida coletivamente, os nadadores foram divididos em atletas pares e ímpares conforme a numeração das toucas. Os atletas pares foram posicionados de um lado da piscina e os atletas ímpares do outro lado da piscina para aguardar o início das execuções, sendo um experimentador responsável pelos atletas ímpares e outro para os atletas pares. Eles foram solicitados a permanecer sentados nas cadeiras, organizados em 
ordem numérica, até serem chamados. Os atletas eram chamados um de cada vez para, próximos à raia de execução, receber a instrução individual que consistiu da informação sobre a condição respiratória a ser adotada na execução: Duas braçadas para uma respiração do lado direito; Duas braçadas para uma respiração do lado esquerdo; Três braçadas para uma respiração (bilateral); ou Em apneia. Após receber a instrução individual, o atleta entrava na água e aguardava o sinal de saída (apito) na posição inicial. Após o apito, o nadador iniciava a execução da tarefa. Assim que os pés saíssem da parede, deveria nadar 25 metros crawl em velocidade máxima na condição informada pelo experimentador. Ao terminar sua execução, o atleta deveria sair pela raia ao lado (vide FIGURA 2) para liberar a raia de execução para o atleta seguinte. Após todos os atletas terem realizado a primeira execução, os procedimentos para a segunda tinham início e assim sucessivamente, até a quarta e última execução da tarefa.

Entre as execuções houve intervalo de, aproximadamente, 5 a 10 minutos, tempo correspondente a execução da tarefa por parte dos atletas seguintes. $O$ intervalo foi dado com a finalidade de minimizar o efeito da fadiga e para preparar a próxima filmagem.

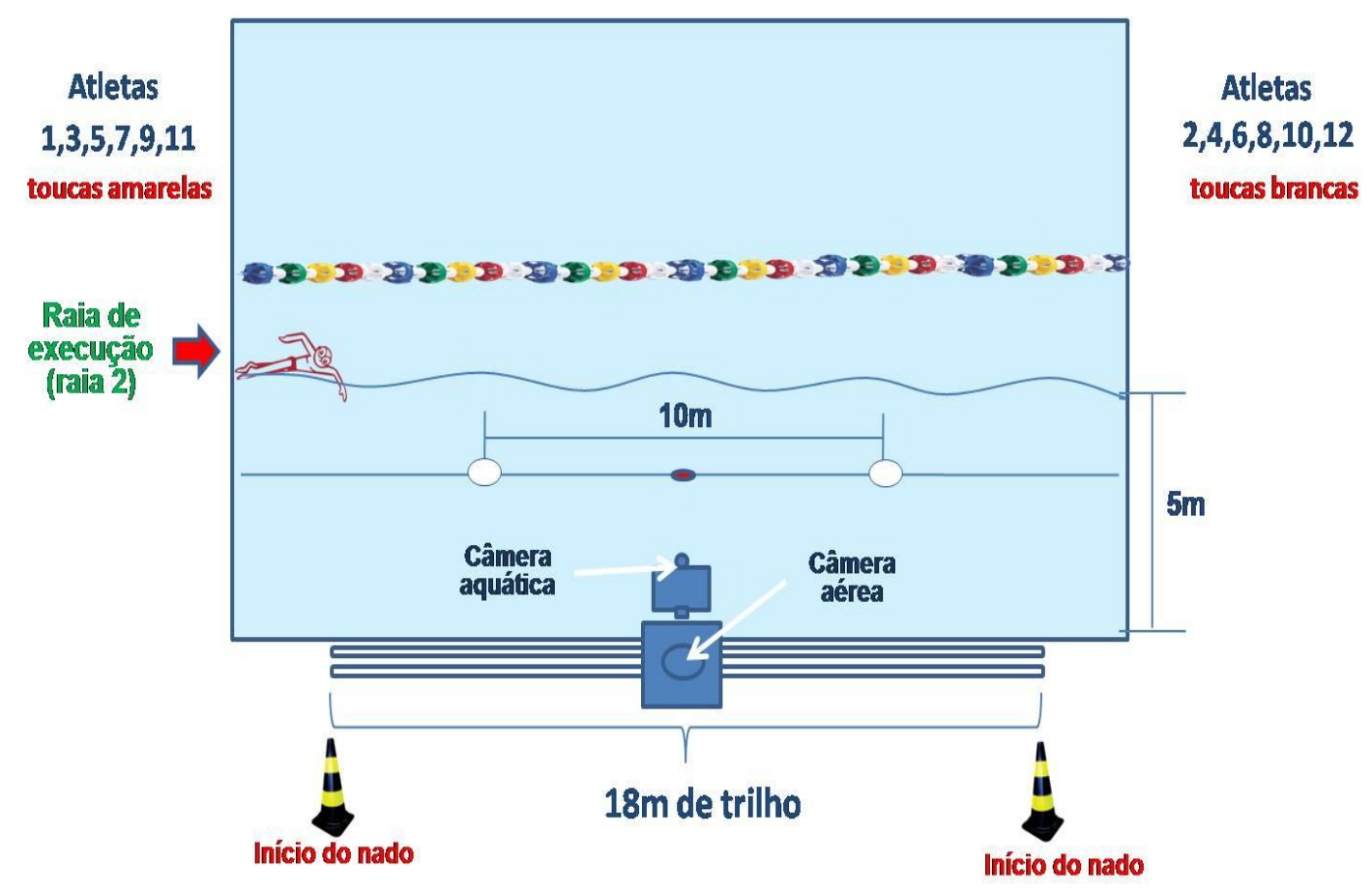

FIGURA 2 - Ambiente de coleta de dados. 
Para a realização da filmagem, um experimentador conduziu o carrinho de filmagem acompanhando o nadador na lateral da piscina visualizando a imagem da câmera aérea apresentada no monitor do notebook.

O presente estudo foi aprovado pela Comissão de Ética e Pesquisa (CEP) da Escola de Educação Física e Esporte da Universidade de São Paulo (EEFE-USP).

\subsection{Instrumentos}

\subsubsection{Filmagem}

Para a realização do estudo houve a necessidade da construção de um carrinho com uma barra vertical de ferro galvanizado para possibilitar a filmagem por cima e por baixo da água. Este carrinho foi colocado sobre um trilho de alumínio com 18 metros de comprimento na lateral da piscina para acompanhar o nadador em velocidade máxima perpendicularmente nos 10 metros centrais do percurso, com o mínimo de trepidação (ANEXO III). Foi montada e instalada na piscina uma raia de 25 metros com dois pontos brancos de referência para delimitar o espaço dos 10 metros utilizados nas análises (FIGURA 2).

Para a captação das imagens aérea e aquática foram utilizadas duas filmadoras da marca Sony (60fps), alinhadas verticalmente e sincronizadas através de um flash emitido por uma câmera fotográfica também da marca Sony (modelo DSC W50). A filmadora aérea, de modelo hdr xr 100 gravou a imagem que era enviada diretamente para o notebook da marca Toshiba através de uma placa de captura easy cap 2.0 que possibilitou a captura da imagem e o acompanhamento do nadador através do software Ulead VídeoStudio 10. Para a filmagem aquática, foi utilizada uma filmadora de modelo hdr sr11 que gravou a imagem aquática utilizada para a análise do índice de coordenação.

Para a fixação da filmadora aérea, foi utilizado um suporte de GPS na parte superior da barra vertical para possibilitar ajustes no ângulo de filmagem. Já para a fixação da filmadora aquática foi necessária a construção de um olho aquático de ferro galvanizado, conforme ilustrado no ANEXO III, para facilitar o deslocamento do carro de filmagem em velocidade máxima. Uma caixa estanque da marca Sony SPK- 
HCE foi utilizada para inserir a filmadora aquática e possibilitar a filmagem sem danos no equipamento;

\subsubsection{Edição de vídeo e análise}

Para sincronizar as imagens das filmadoras aérea e aquática, foi utilizado o Software Ulead VídeoStudio 11. A partir das imagens geradas, para a obtenção dos tempos de desempenho e dos tempos em milissegundos de cada fase da braçada mediante a contagem do número de quadros, foi utilizado o Software Kinovea 0.8.7. Para facilitar a identificação e análise dos tempos das fases das braçadas, foi utilizada uma fita velcro, para marcação do punho (cabeça da ulna).

Foram utilizadas doze toucas de cor branca e amarela numeradas de 1 a 12 para identificação dos nadadores nas análises e para facilitar a organização da coleta.

\subsubsection{Identificação da preferência do lado inspiratório}

Para determinar a preferência do lado inspiratório e possibilitar a organização dos nadadores nas diferentes condições experimentais foi aplicado o questionário para determinação do lado preferido adaptado de (SEIFERT et al., 2005b). Este questionário é composto por cinco questões: 1) Qual lado e frequência respiratória você utiliza durante uma competição de 50 metros?; 2) Qual o lado e frequência respiratória utilizada durante uma competição de 100 e 200 metros?; 3) Qual o lado e frequência respiratória utilizada durante as competições de 400, 800 e 1500 metros?; 4) Qual o lado e frequência respiratória utilizada durante treinamento pesado?; e, 5) Qual o lado e frequência respiratória utilizada durante treinamento leve?

\section{$6.5 \quad$ Medidas}

Foram utilizadas medidas que correspondem ao desempenho, aos aspectos invariantes da braçada, aos aspectos variantes da braçada e à coordenação entre os braços. 
As medidas de desempenho utilizadas foram aquelas que, reconhecidamente, expressam a eficiência do nado, ou seja, tempo gasto para percorrer o percurso, velocidade, frequência de braçada, e comprimento de braçada (COLWIN, 2000; MAGLISCHO, 1999, 2003). Foram consideradas medidas dos aspectos invariantes da braçada, aquelas que melhor expressam a organização temporal da própria estrutura do movimento: timing relativo e a variabilidade do timing relativo (SCHMIDT, 2003). Especificamente, no caso do nadar, o timing relativo das fases aérea e aquática das braçadas direita e esquerda (FREUDENHEIM et al., 2005). Por sua vez medidas dos aspectos variantes da braçada foram considerados a magnitude e a variabilidade do tempo absoluto de movimento.

Operacionalmente, neste estudo, a fase aérea (recuperação) consiste da saída do punho da água até a entrada do punho para próxima braçada; a fase aquática na entrada do punho na água até a saída do punho da água. A braçada foi considerada como início entrada do punho na água e a próxima entrada do punho do mesmo braço.

Ainda, o IdC foi considerado como medida de interação entre os braços pois corresponde a proporção do tempo médio entre a ação propulsiva do braço direito e esquerdo sobre a média do tempo total da braçada direita e esquerda.

Para mensurar o IdC foi necessário analisar a fase aquática de entrada e pegada do braço direito e esquerdo. Esta fase consiste da entrada do punho na água até o início do movimento da mão para trás. O início do movimento da mão para trás caracteriza o início do movimento propulsivo dos braços (CHOLLET et al., 2000).

Considerando estas correspondências e definições operacionais, em síntese, no presente estudo foram utilizadas as seguintes medidas:

\section{Desempenho:}

Tempo total (Tt): tempo gasto para nadar a distância de 10 metros em velocidade máxima;

Velocidade média $(\mathrm{Vm})$ : razão entre a distância percorrida e o tempo gasto para percorrê-la $(\mathrm{Tt})$.

Frequência de braçada $(\mathrm{Fb})$ : número de braçadas realizadas em 10 metros; 
Comprimento de braçada $(\mathrm{Cb})$ : razão entre a distância nadada e o número de braçada.

Aspectos invariantes da braçada do nado crawl:

Distribuição e variabilidade do timing relativo da fase aérea ( $\operatorname{Tr} A e$ e $\operatorname{Vtr} \mathrm{Ae})$ e da fase aquática ( $\operatorname{Tr}$ Aq e VTr Aq) dos braços direito e esquerdo.

Para calcular estas variáveis, tivemos que decompor o tempo total da braçada (direita e esquerda). A duração total da braçada foi caracterizada como a somatória das fases aérea e aquática (tempo absoluto). Desta forma, com a duração total de cada braçada e de cada fase foi possível calcular o timing relativo das mesmas, variável esta que consiste na porcentagem do tempo total de movimento (duração total da braçada) gasto em cada fase.

Estas medidas tiveram como finalidade permitir a análise da consistência no padrão temporal das braçadas, bem como, a variabilidade desta consistência.

Aspectos variantes da braçada do nado crawl:

Tempo total e variabilidade do tempo total da fase aérea (Tt Ae e VTt Ae) e aquática (Tt Aq e VTt Aq) dos braços direito e esquerdo. A fase aérea (recuperação) consiste na saída do punho da água e a entrada do punho para próxima braçada. A fase aquática consiste na entrada do punho na água e seu final com a saída do punho da água. Tempo total e variabilidade do tempo total da braçada direita (Tt Bd e VTt Bd) e braçada esquerda ( $T t$ Be e VTt Be). O tempo total da braçada é a soma do tempo para executar a fase aérea e a fase aquática. Estas medidas permitiram a análise da variabilidade das braçadas.

Para cálculo das variáveis relacionadas aos aspectos invariantes e variantes, foram considerados três ciclos de braçadas consecutivos realizados nos 10 metros centrais do percurso. Isso foi determinado para evitar o efeito que a saída para o nado e a sua finalização, poderia exercer sobre a organização temporal da braçada. 
Coordenação entre os braços:

O índice de coordenação entre os braços (IdC) corresponde a média do IdCe e IdCd expressos em porcentagem da média do tempo total das braçadas direita e esquerda. O índice de coordenação esquerdo (IdCe) corresponde ao tempo entre o fim da propulsão do primeiro braço esquerdo e início da propulsão do primeiro braço direito. O índice de coordenação direito (IdCd) corresponde ao tempo entre o fim da propulsão do primeiro braço direito e início da propulsão do segundo braço esquerdo, conforme o exemplo do índice de coordenação por oposição (média do IdCe e IdCd $=0 \%$ ) representado na FIGURA 3 . Esta medida permite a análise da interação das ações dos braços direito e esquerdo.

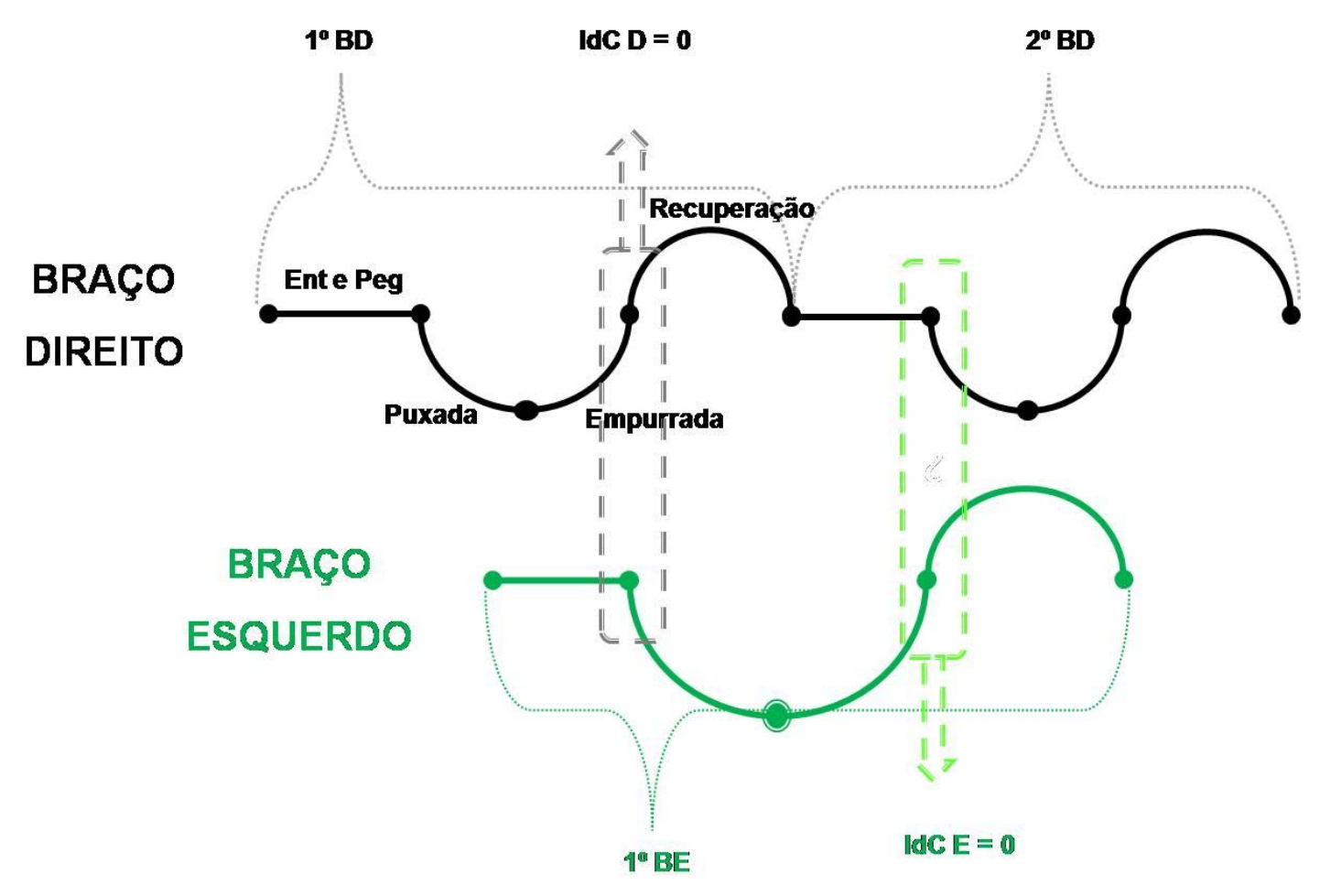

FIGURA 3 - Representação do índice de coordenação por oposição (adaptado de CHOLLET et al., 2000). 


\subsection{Análise estatística}

Considerando que todas as medidas utilizadas são de natureza intervalar e são 21 participantes sendo analisados em quatro condições, foram realizados testes de normalidade para verificar se os pressupostos da análise paramétrica seriam atendidos. Quando encontrada normalidade para todas as condições envolvidas $(p \geq 0,05)$, foi realizada uma análise de variância (ANOVA one-way) com medidas repetidas. Para localizar as diferenças apontadas pela ANOVA, foi aplicado o teste de post hoc de Bonferroni.

Os participantes realizaram uma tentativa em cada condição para a obtenção das medidas de desempenho. Enquanto as medidas de organização temporal foram calculadas pela média de 3 ciclos de braçada (três ciclos por tentativa) em cada condição.

$7 \quad$ RESULTADOS

7.1 Desempenho 


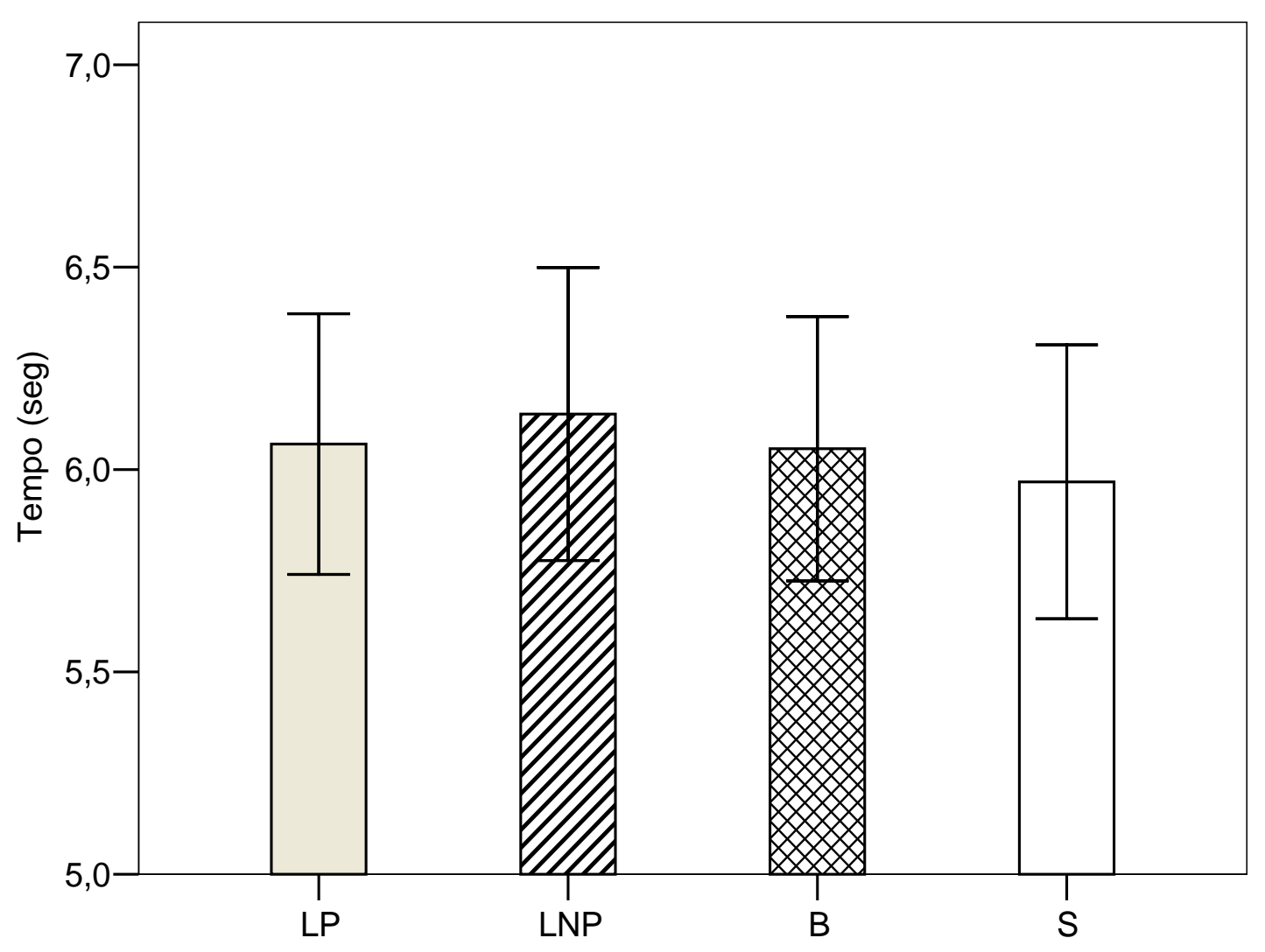

FIGURA 4 - Tempo para percorrer 10 metros nadando crawl em velocidade máxima nas condições de inspiração para o lado preferido (LP), lado não preferido (LNP), bilateral (B) e sem inspiração (S).

Podemos verificar na FIGURA 4 que o tempo de deslocamento parece menor na condição em apneia (S) comparado com as condições do lado preferido (LP), lado não preferido (LNP) e bilateral (B). Confirmando a descrição, a análise estatística detectou diferença significativa entre as condições experimentais $\left[F_{(3 ; 60)}=13,313\right.$; $\mathrm{p}=0,001]$. $\mathrm{O}$ teste de post hoc de Bonferroni indicou diferenças entre a condição $\mathrm{S} e$ as condições LP, LNP e $B$ (respectivamente, $p=0,022 ; p=0,032$ e $p=0,021$ ). 


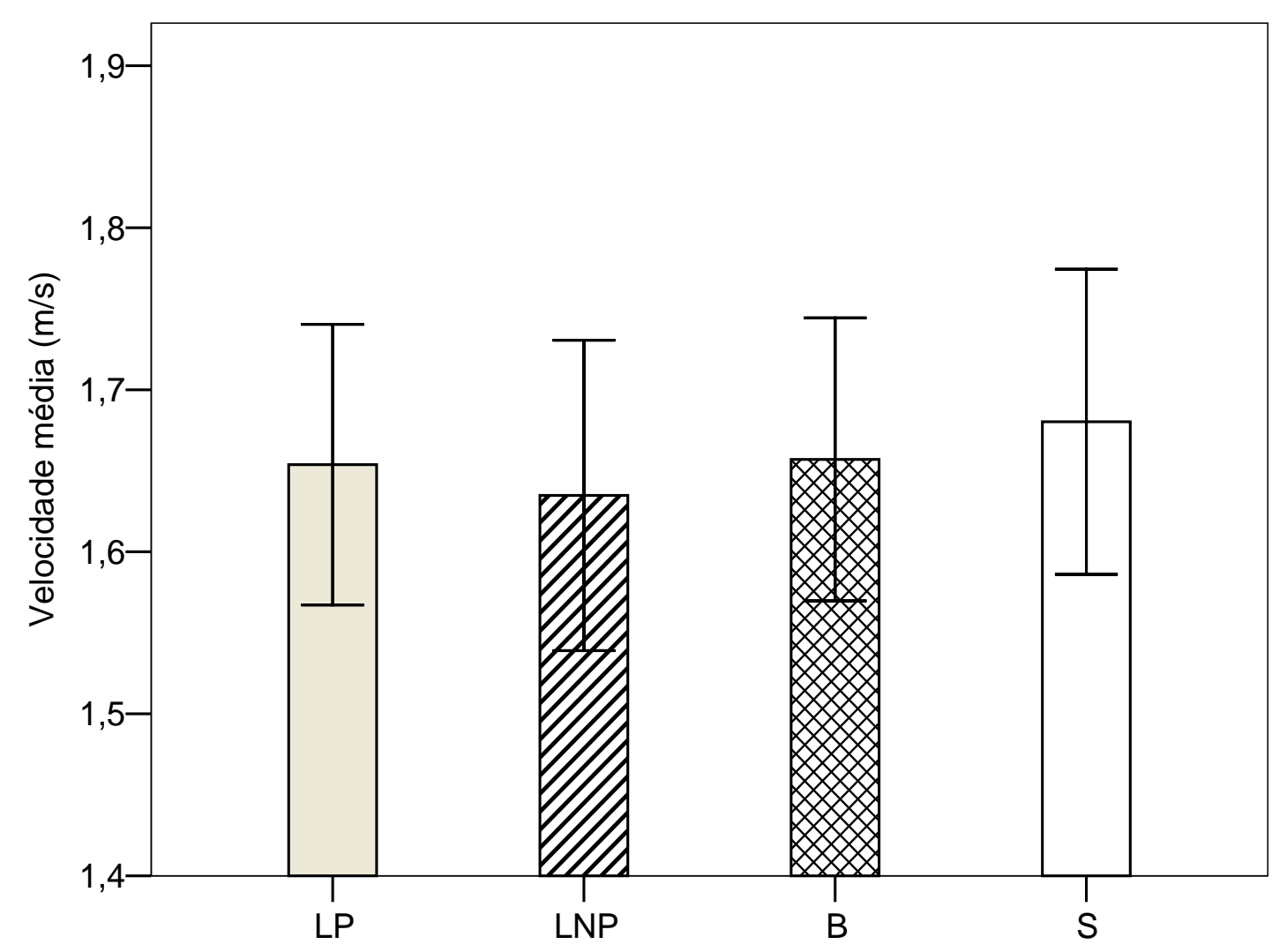

FIGURA 5 - Velocidade média para percorrer 10 metros nadando crawl em velocidade máxima nas condições de inspiração para o lado preferido (LP), lado não preferido (LNP), bilateral (B) e sem inspiração (S).

A partir da FIGURA 5 pode-se observar que a velocidade média na condição $S$ tende a ser maior comparada com as condições LP, LNP e B. A análise estatística confirmou a análise descritiva, detectando diferença significativa entre as condições $\left[F_{(3 ; 60)}=12,601 ; p=0,001\right]$. $O$ teste de post hoc de Bonferroni indicou diferenças entre a condição $S$ e as condições LP, LNP e $B$ (respectivamente, $p=0,003 ; p=0,001$ e $\mathrm{p}=0,005$ ). 


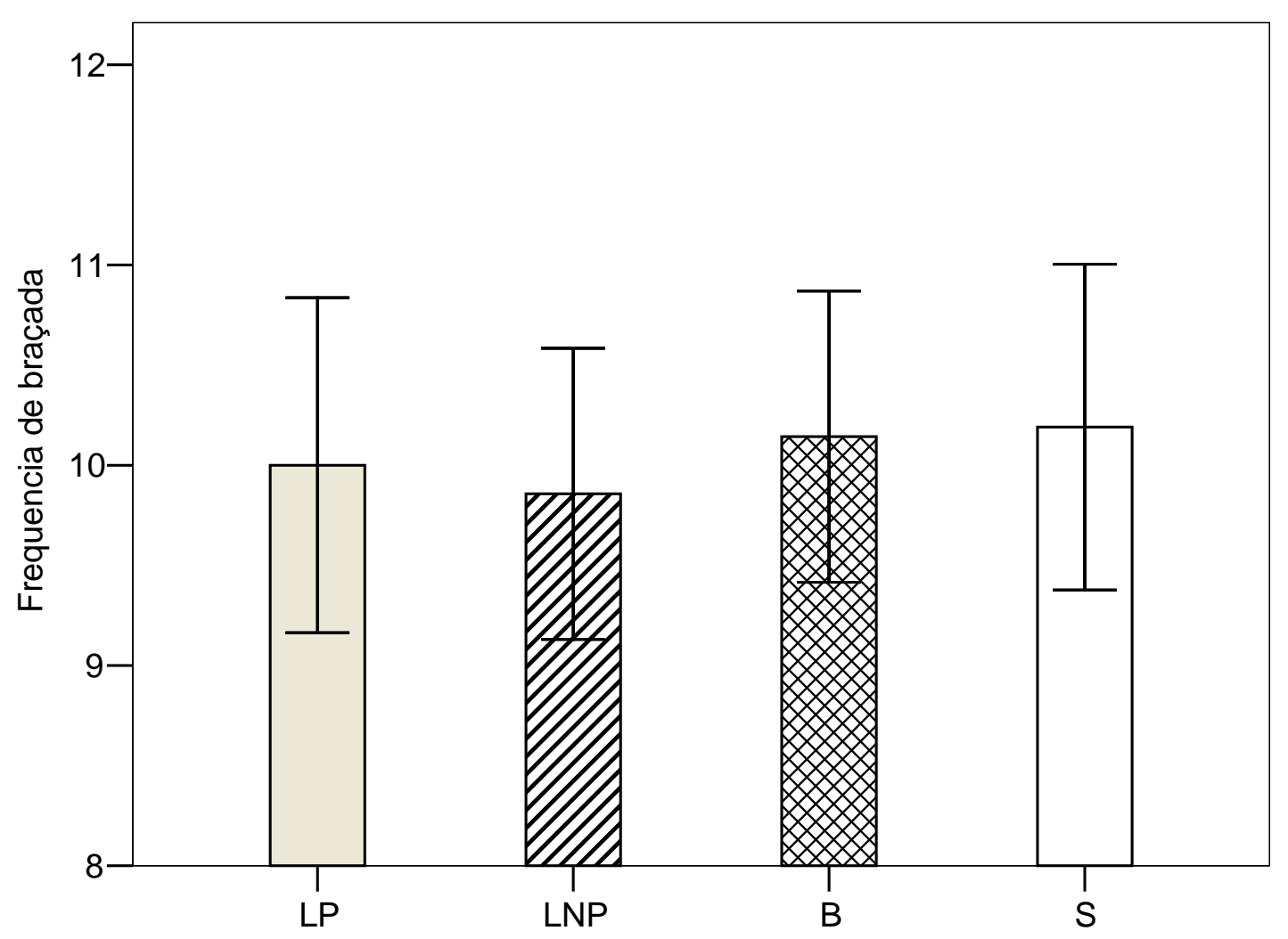

FIGURA 6 - Frequência de braçadas para percorrer 10 metros nadando crawl em velocidade máxima nas condições de inspiração para o lado preferido (LP), lado não preferido (LNP), bilateral (B) e sem inspiração (S).

Pode se observar na FIGURA 6 que a frequência de braçadas nas condições $S$ e $B$ tende a ser ligeiramente maior comparada com a da condição LNP. A análise estatística confirmou a análise descritiva, detectando diferença significativa entre as condições experimentais $\left[F_{(3 ; 60)}=2,837 ; p=0,046\right]$. $O$ teste de post hoc de Bonferroni não detectou diferenças entre as condições analisadas, desta forma a tendência será considerada como diferença significativa. 


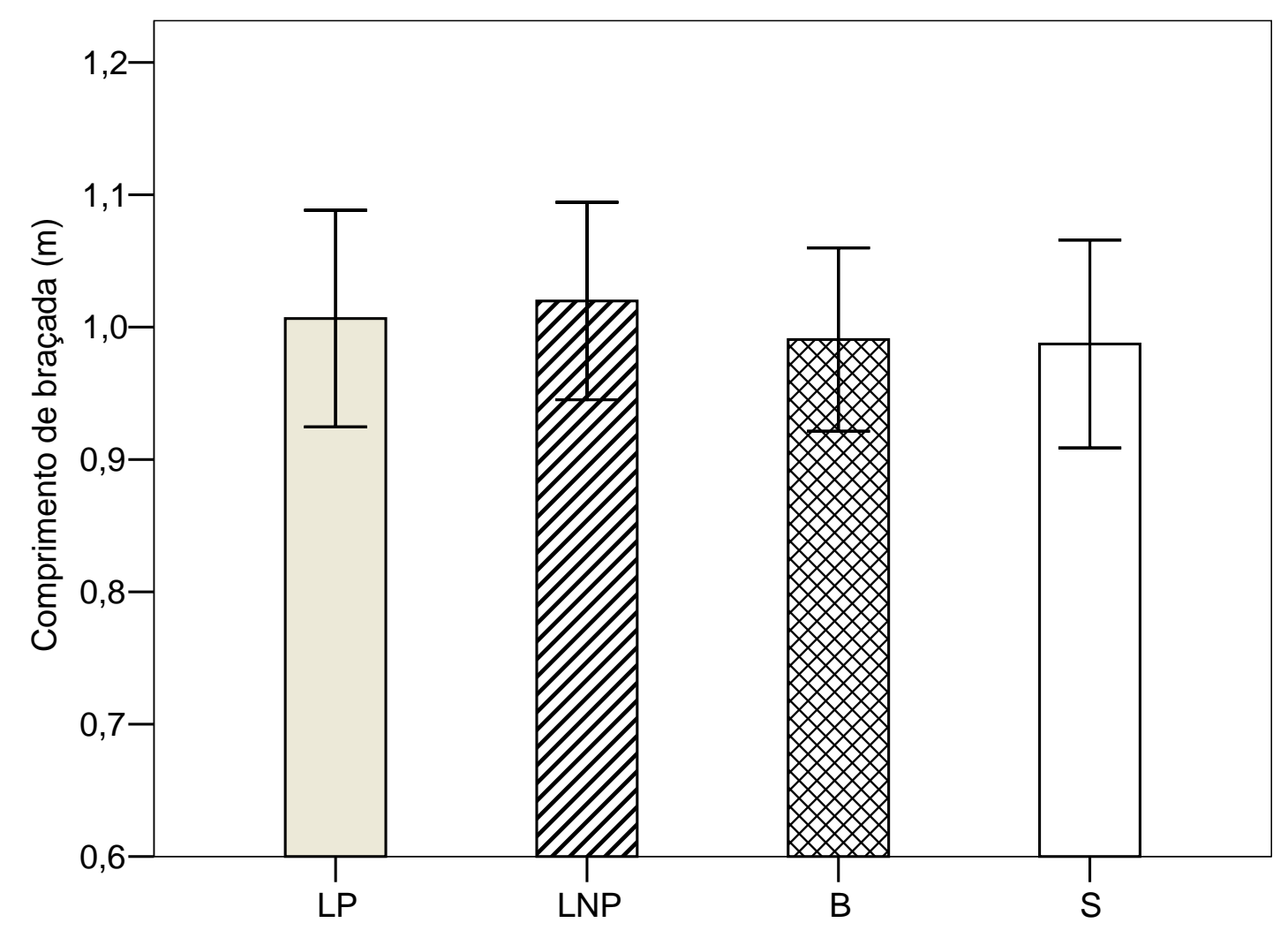

FIGURA 7 - Comprimento de braçada para percorrer 10 metros nadando crawl em velocidade máxima nas condições de inspiração para o lado preferido (LP), lado não preferido (LNP), bilateral (B) e sem inspiração (S).

A FIGURA 7 indica menor comprimento de braçada nas condições $S$ e $B$ comparado às condições LP e LNP. A análise estatística detectou diferença significativa entre as condições $\left[F_{(3 ; 60)}=2,864 ; p=0,044\right]$. O teste de post hoc de Bonferroni não detectou diferenças entre as condições experimentais. Desta forma as tendências serão consideradas como apresentando diferença significativa.

7.2 Aspectos invariantes da braçada 


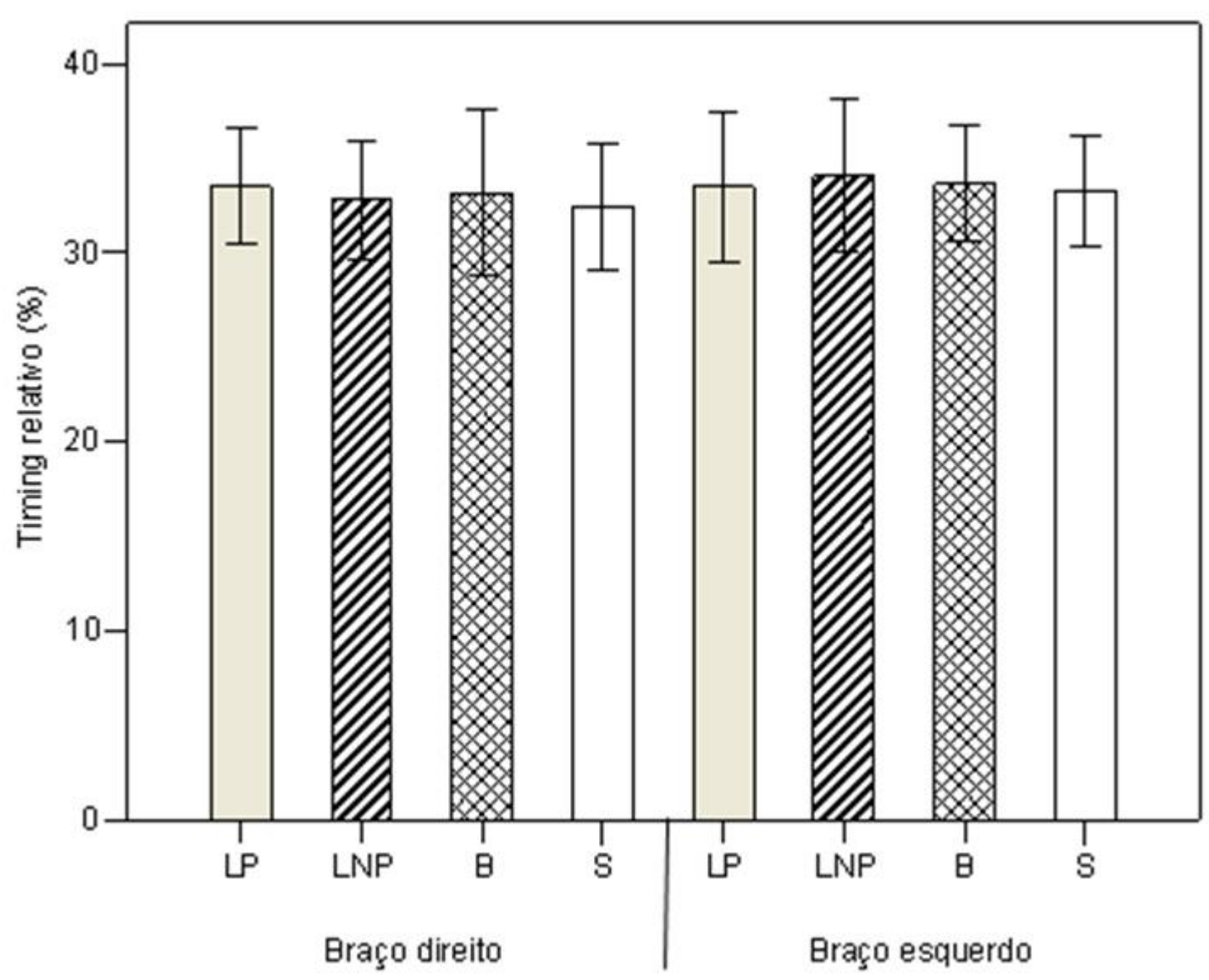

FIGURA 8 - Timing relativo aéreo dos braços direito e esquerdo nadando crawl em velocidade máxima nas condições de inspiração para o lado preferido (LP), lado não preferido (LNP), bilateral (B) e sem inspiração (S).

Na FIGURA 8 pode se verificar que o timing relativo aéreo do braço direito e esquerdo parecem semelhantes entre as condições experimentais. Confirmando a análise descritiva, a inferencial não detectou diferença significativa entre as condições experimentais para o braço direito $\left[F_{(3 ; 60)}=0,636 ; p=0,595\right]$ e para o braço esquerdo $\left[F_{(3 ; 60)}=0,314 ; p=0,815\right]$. 


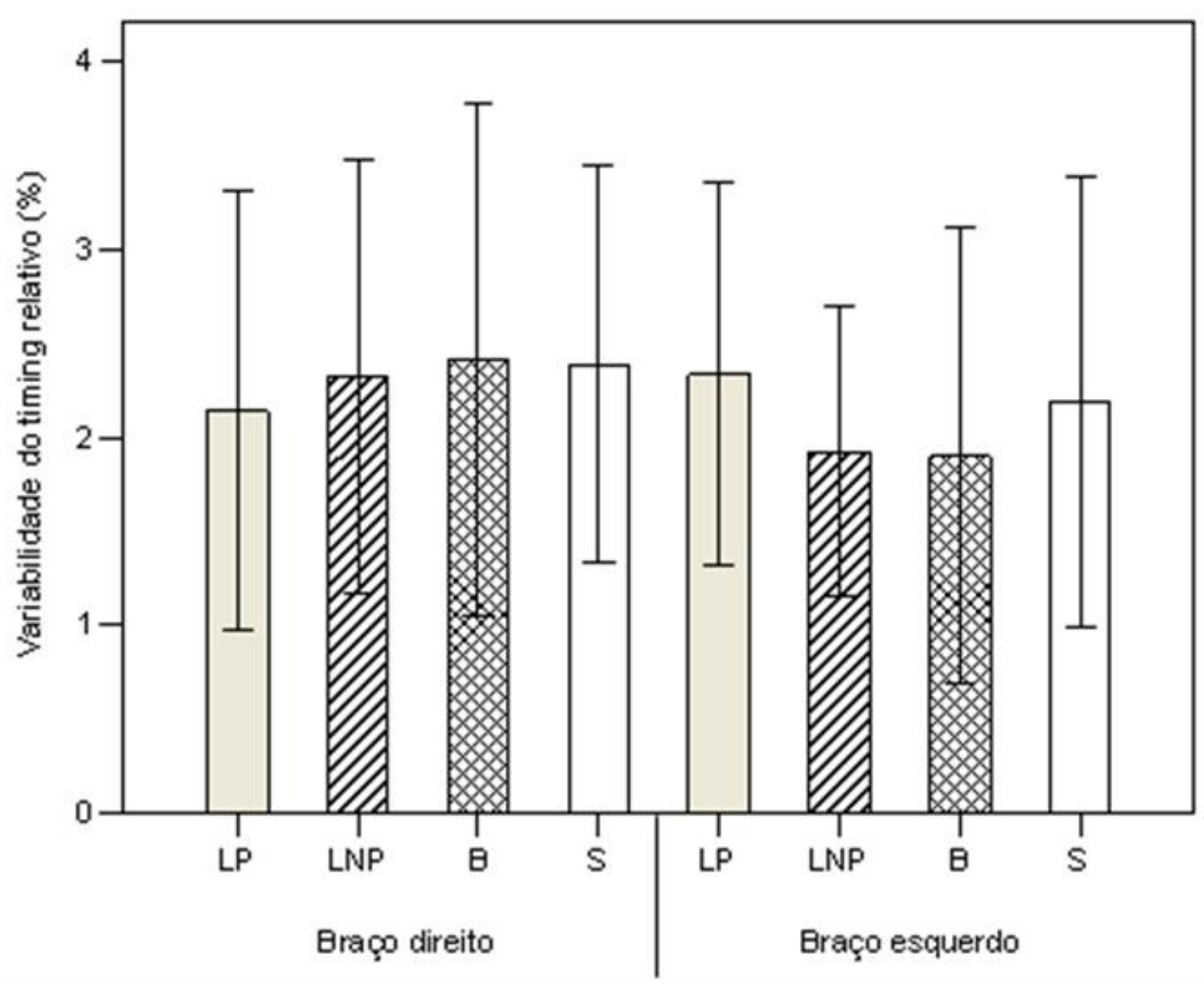

FIGURA 9 - Variabilidade do timing relativo aéreo dos braços direito e esquerdo nadando crawl em velocidade máxima nas condições de inspiração para o lado preferido (LP), lado não preferido (LNP), bilateral (B) e sem inspiração (S).

A partir da FIGURA 9, pode se verificar que a variabilidade do timing relativo aéreo para o braço direito tende a aumentar da condição LP para as condições LNP, $B$ e $S$. No entanto, a análise inferencial não confirmou essa tendência $\left[F_{(3 ; 60)}=0,608\right.$ $p=0,613]$. Para o braço esquerdo, a variabilidade do timing relativo nas condições LNP e B tende a ser menor comparada com as condições LP e S. No entanto, mais uma vez, a análise inferencial não detectou diferença significativa entre as condições experimentais $\left[F_{(3 ; 60)}=0,625 ; p=0,602\right]$. 


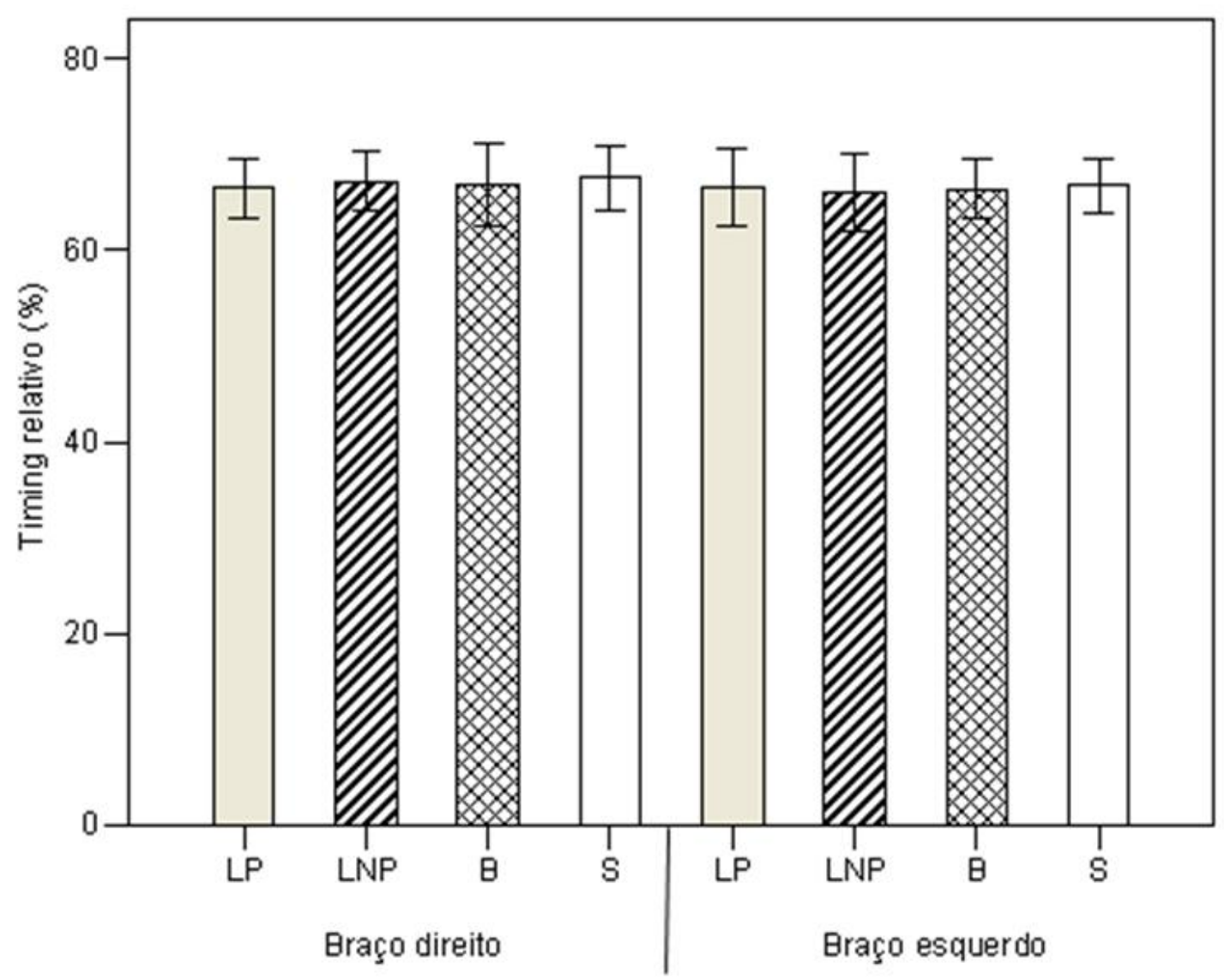

FIGURA 10 - Timing relativo aquático dos braços direito e esquerdo nadando crawl em velocidade máxima nas condições de inspiração para o lado preferido (LP), lado não preferido (LNP), bilateral (B) e sem inspiração (S).

Como pode ser observado na FIGURA 10, o timing relativo aquático parece ser semelhante em todas as condições experimentais para os braços direito e esquerdo. Confirmando a descritiva, a análise inferencial não detectou diferença significativa para os braços direito $\left[F_{(3 ; 60)}=0,636 ; p=0,595\right]$ e esquerdo $\left[F_{(3 ; 60)}\right.$ $=0,314 ; p=0,815]$ em função das condições experimentais. 


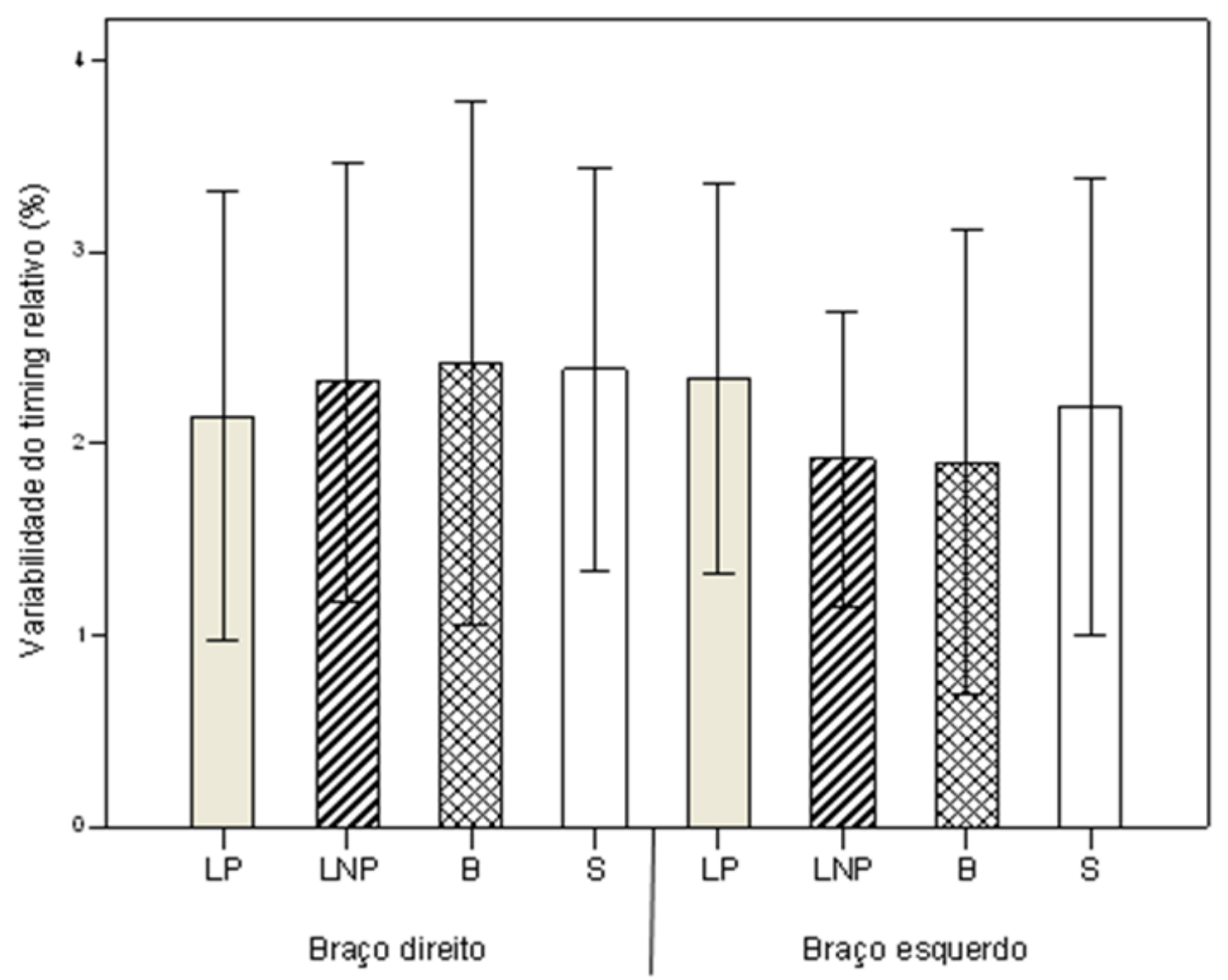

FIGURA 11 - Variabilidade do timing relativo aquático dos braços direito e esquerdo nadando crawl em velocidade máxima nas condições de inspiração para o lado preferido (LP), lado não preferido (LNP), bilateral (B) e sem inspiração (S).

$\mathrm{Na}$ FIGURA 11, podemos verificar que a variabilidade do timing relativo aquático do braço direito na condição LP parece menor comparado com o das condições LNP, B e S. Por sua vez, para o braço esquerdo, a variabilidade do timing relativo tende a ser menor nas condições LNP e B comparado com as condições LP e $S$. No entanto, essa tendência não foi confirmada para os braços direito $\left[F_{(3 ; 60)}\right.$ $=0,608 ; p=0,613]$ e esquerdo $\left[F_{(3 ; 60)}=0,625 ; p=0,602\right]$.

7.3 Aspectos variantes da braçada 


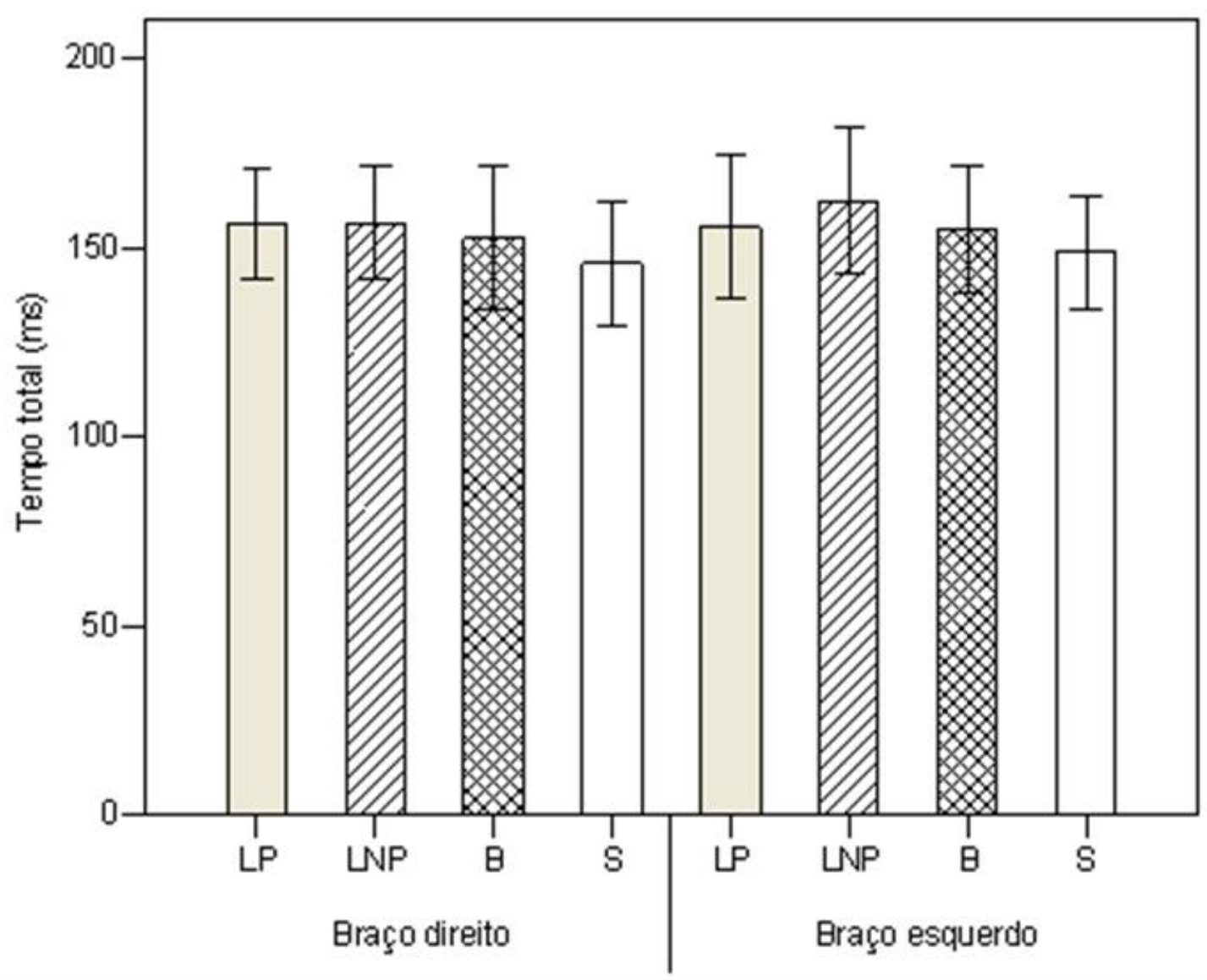

FIGURA 12 - Tempo total aéreo dos braços direito e esquerdo nadando crawl em velocidade máxima nas condições de inspiração para o lado preferido (LP), lado não preferido (LNP), bilateral (B) e sem inspiração (S).

No que diz respeito ao tempo total aéreo do braço direito e esquerdo (FIGURA 12) nota-se que os nadadores permanecem menos tempo na condição $S$ comparado com as condições LP, LNP e B. Confirmando a descrição, foi detectada diferença significativa entre as condições experimentais $\left[F_{(3 ; 60)}=3,867 ; p=0,014\right]$. $O$ teste de post hoc de Bonferroni localizou diferenças entre a condição $S$ e as condições LNP e LP para o braço direito (respectivamente, $p=0,028$ e $p=0,001$ ) e, para o braço esquerdo, entre as condições $S$ e LNP $(p=0,023)$. 


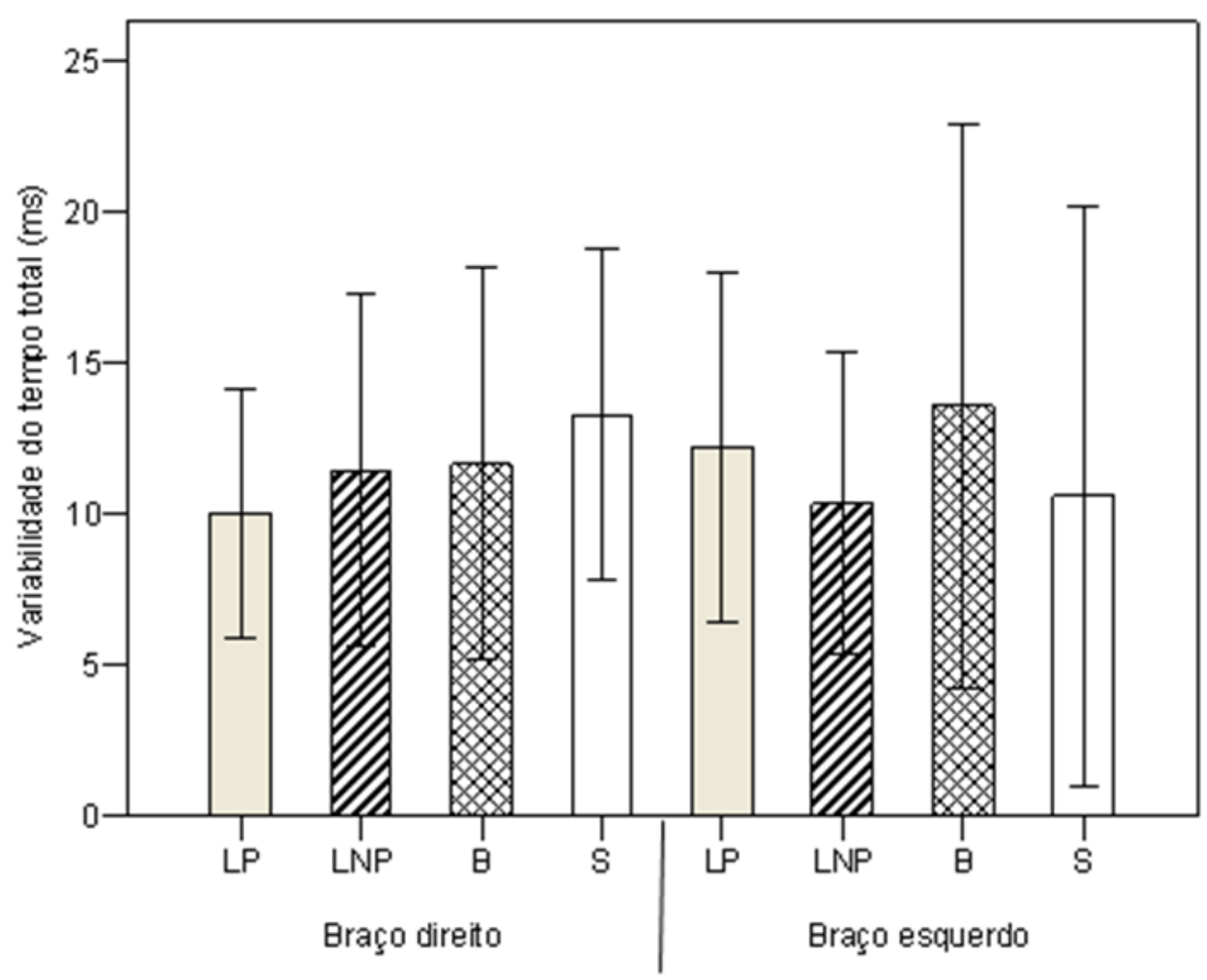

FIGURA 13 - Variabilidade do tempo total aéreo dos braços direito e esquerdo nadando crawl em velocidade máxima nas condições de inspiração para o lado preferido (LP), lado não preferido (LNP), bilateral (B) e sem inspiração (S).

Podemos verificar na FIGURA 13 que a variabilidade do tempo total aéreo para o braço direito tende a aumentar gradativamente da condição LP para as condições LNP, B e S. Para o braço esquerdo, a variabilidade do tempo total aéreo tende a ser menor nas condições LNP e S comparado com as condições LP e B. No entanto, não foram detectadas diferenças significativas entre as condições experimentais para o braço direito $\left[F_{(3 ; 54)}=1,586 ; p=0,302\right]$ e para o esquerdo $\left[F_{(3 ; 57)}\right.$ $=0,623 ; p=0,603]$. 


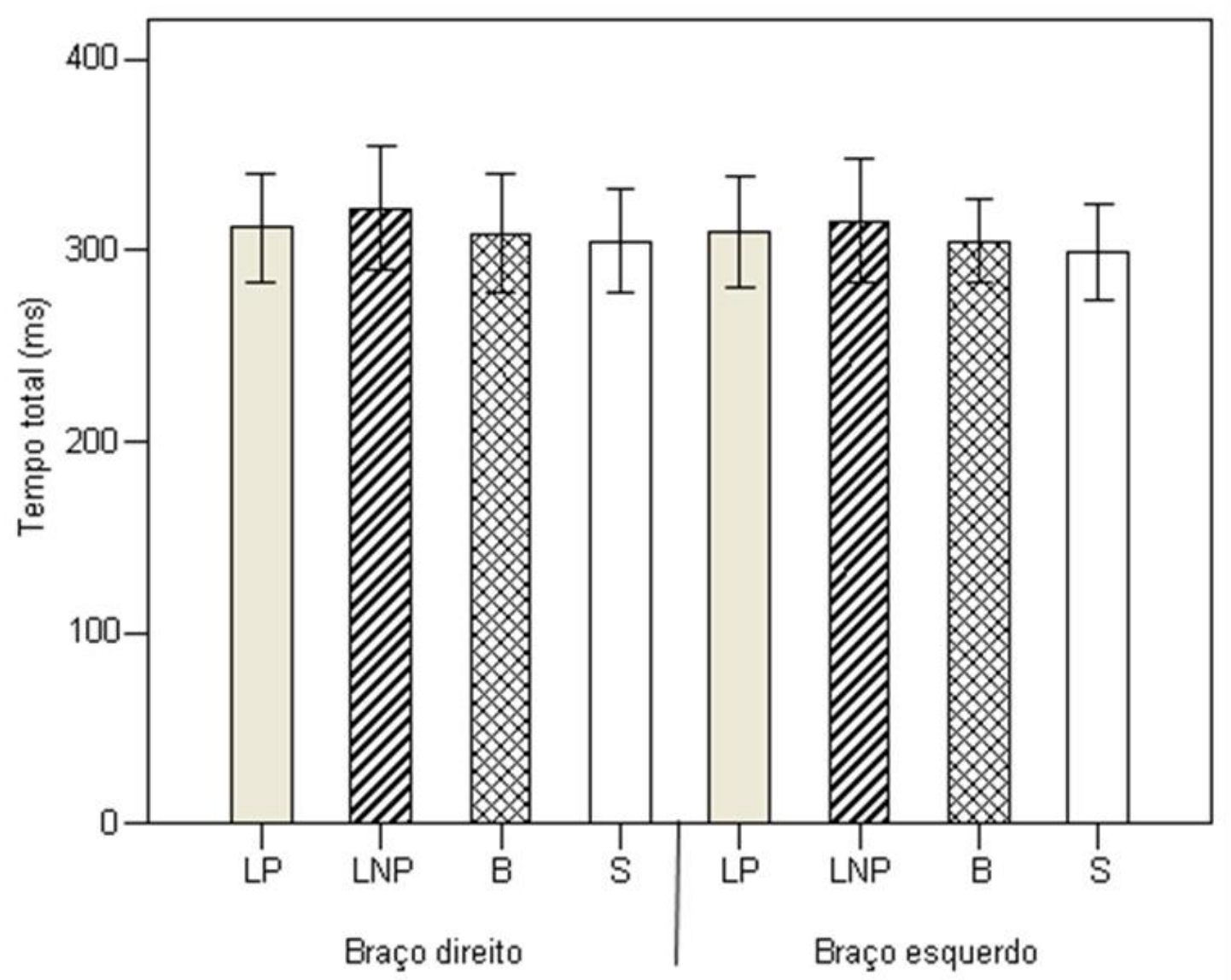

FIGURA 14 - Tempo total aquático dos braços direito e esquerdo nadando crawl em velocidade máxima nas condições de inspiração para o lado preferido (LP), lado não preferido (LNP), bilateral (B) e sem inspiração (S).

Na FIGURA 14 observamos que o tempo total aquático dos braços direito e esquerdo tende a ser ligeiramente maior na condição LNP comparado com as condições LP, B e S. A análise estatística não confirmou essa tendência, para 0 braço direito $\left[F_{(3 ; 60)}=2,710 ; p=0,053\right]$ e para o braço esquerdo $\left[F_{(3 ; 60)}=2,449\right.$; $p=0,072]$. 


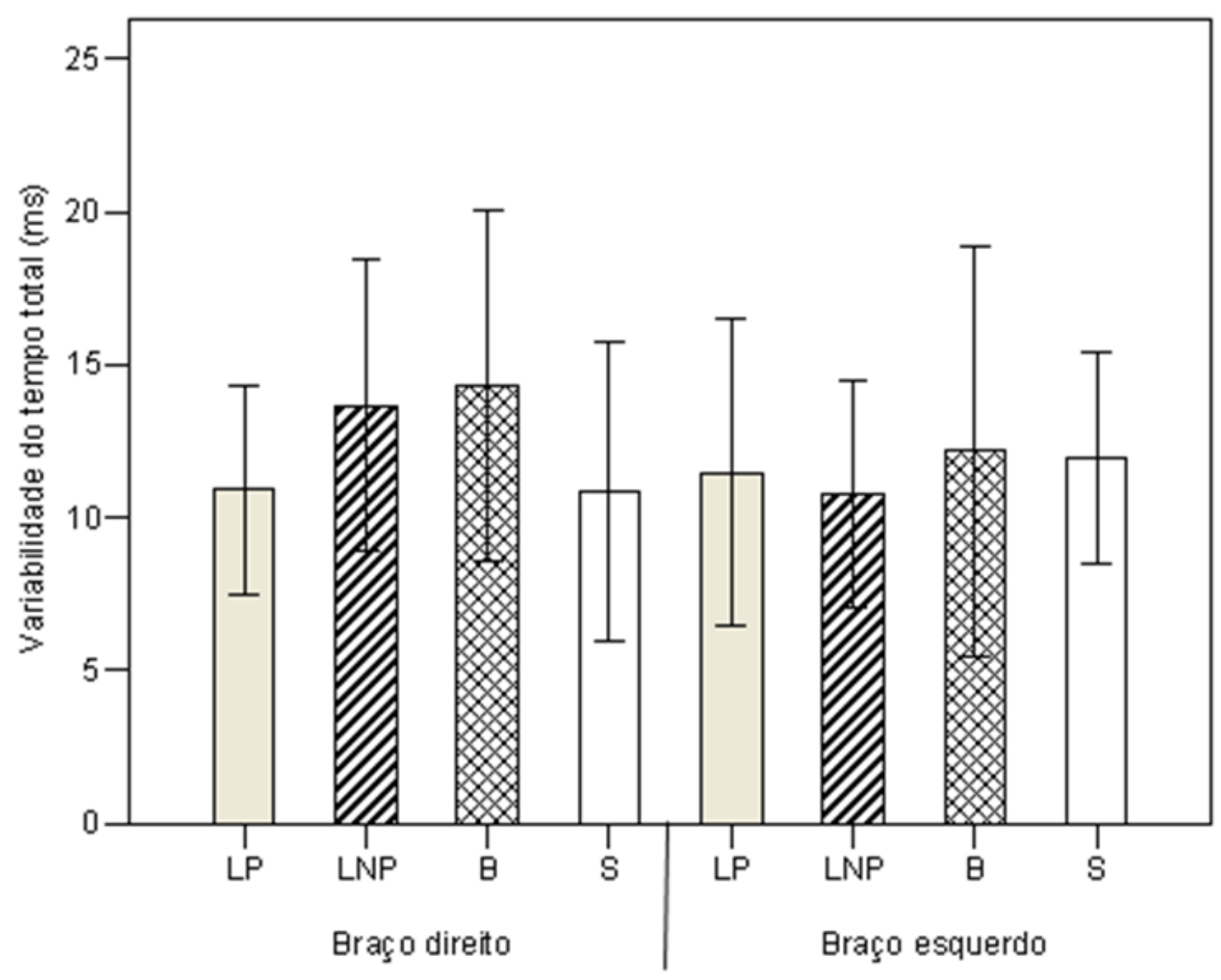

FIGURA 15 - Variabilidade do tempo total aquático dos braços direito e esquerdo nadando crawl em velocidade máxima nas condições de inspiração para o lado preferido (LP), lado não preferido (LNP), bilateral (B) e sem inspiração (S).

A variabilidade do tempo total aquático do braço direito tende a ser menor nas condições LP e S comparada com as condições LNP e B. Já para o braço esquerdo a variabilidade do tempo total aquático parece ser ligeiramente menor na condição LNP comparada com as condições LP, B e S (FIGURA 15). No entanto, a análise estatística não detectou diferença significativa entre as condições para 0 braço direito $\left[F_{(3 ; 51)}=2,586 ; p=0,063\right]$ e para o braço esquerdo $\left[F_{(3 ; 51)}=1,313\right.$; $p=0,280]$. 


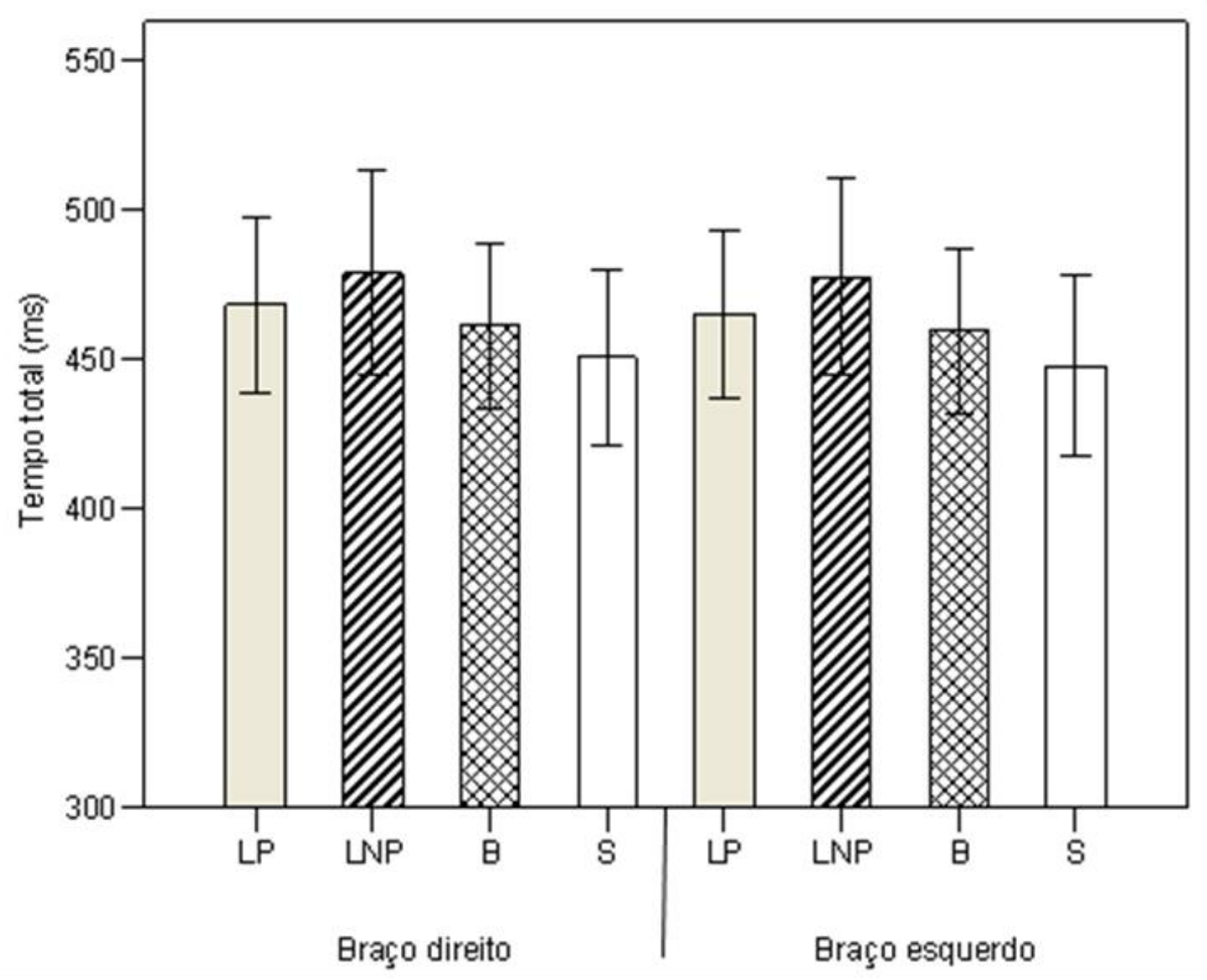

FIGURA 16 - Tempo total dos braços direito e esquerdo nadando crawl em velocidade máxima nas condições de inspiração para o lado preferido (LP), lado não preferido (LNP), bilateral (B) e sem inspiração (S).

Pode-se notar na FIGURA 16, que o tempo total dos braços direito e esquerdo tende a ser maior na condição LNP comparado com as condições LP, B e S. A análise estatística detectou diferença significativa para o braço direito $\left[F_{(3 ; 60)}\right.$ $=8,144 ; p=0,000]$ e braço esquerdo $\left[F_{(3 ; 60)}=9,243 ; p=0,000\right]$. $O$ post hoc de Bonferroni detectou diferença significativa entre a condição LNP e $B$ e entre as condições LNP e S para o braço direito (respectivamente, $p=0,020, p=0,004$ ) e braço esquerdo (respectivamente, $p=0,016, p=0,002$ ). 


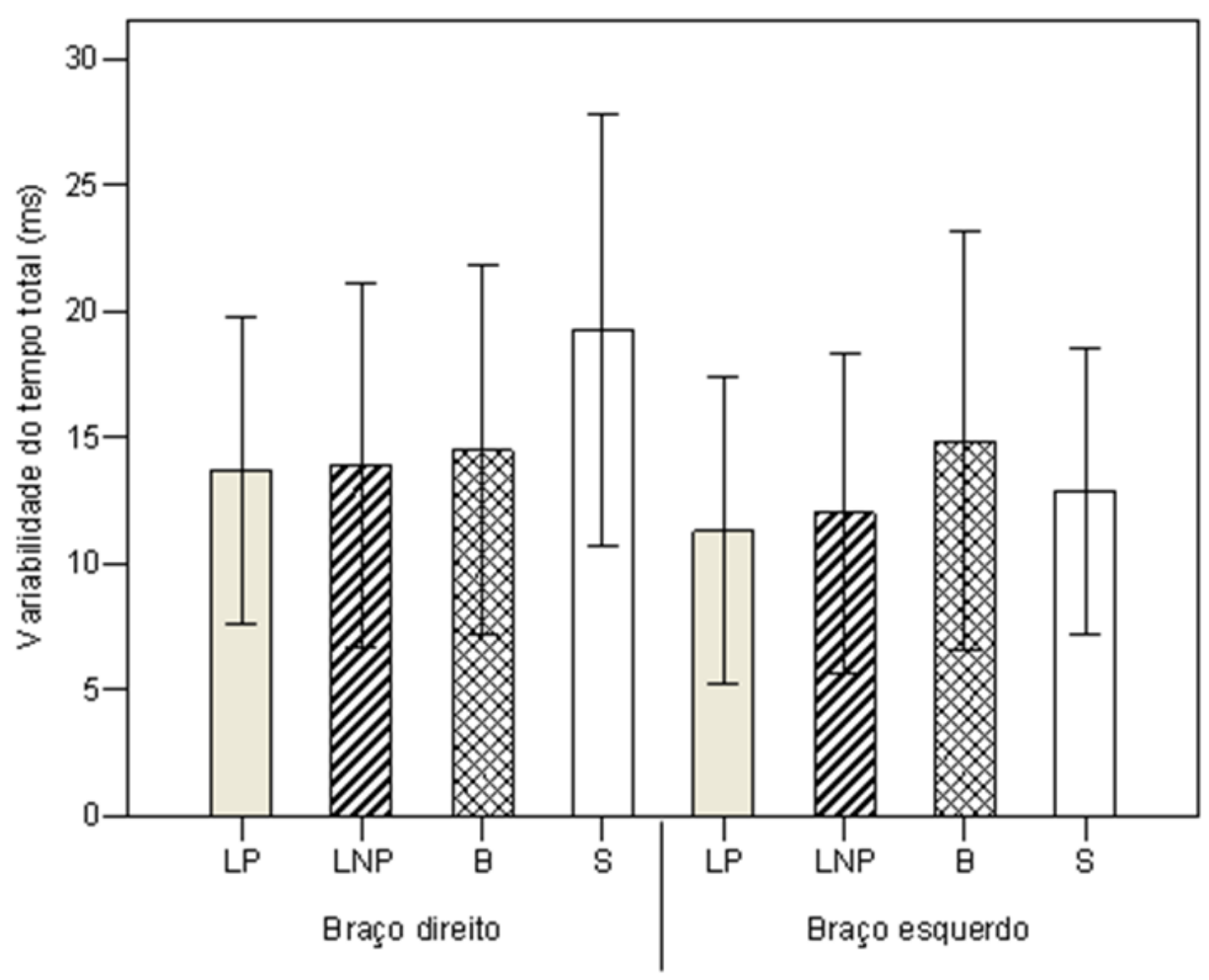

FIGURA 17 - Variabilidade do tempo total dos braços direito e esquerdo nadando crawl em velocidade máxima nas condições de inspiração para o lado preferido (LP), lado não preferido (LNP), bilateral (B) e sem inspiração (S).

Na FIGURA 17, verifica-se que a variabilidade do tempo total do braço direito tende a ser maior na condição $S$ comparado com as condições LP, LNP e B. Esta tendência foi parcialmente confirmada, pois foi detectada diferença significativa entre as condições $\left[F_{(3 ; 60)}=5,724 ; p=0,002\right]$. O teste de post hoc de Bonferroni localizou as diferenças como estando entre a condição $S$ e as condições LP e LNP ( $p=0,002$ e $p=$ 0,030 ), portanto, não em relação à condição $B$. Para o braço esquerdo, variabilidade tende a ser maior na condição $B$ comparado as condições LP, LNP e S. A análise estatística não confirmou essa tendência $\left[F_{(3 ; 45)}=1,081 ; p=0,360\right]$.

\subsection{Coordenação entre os braços}




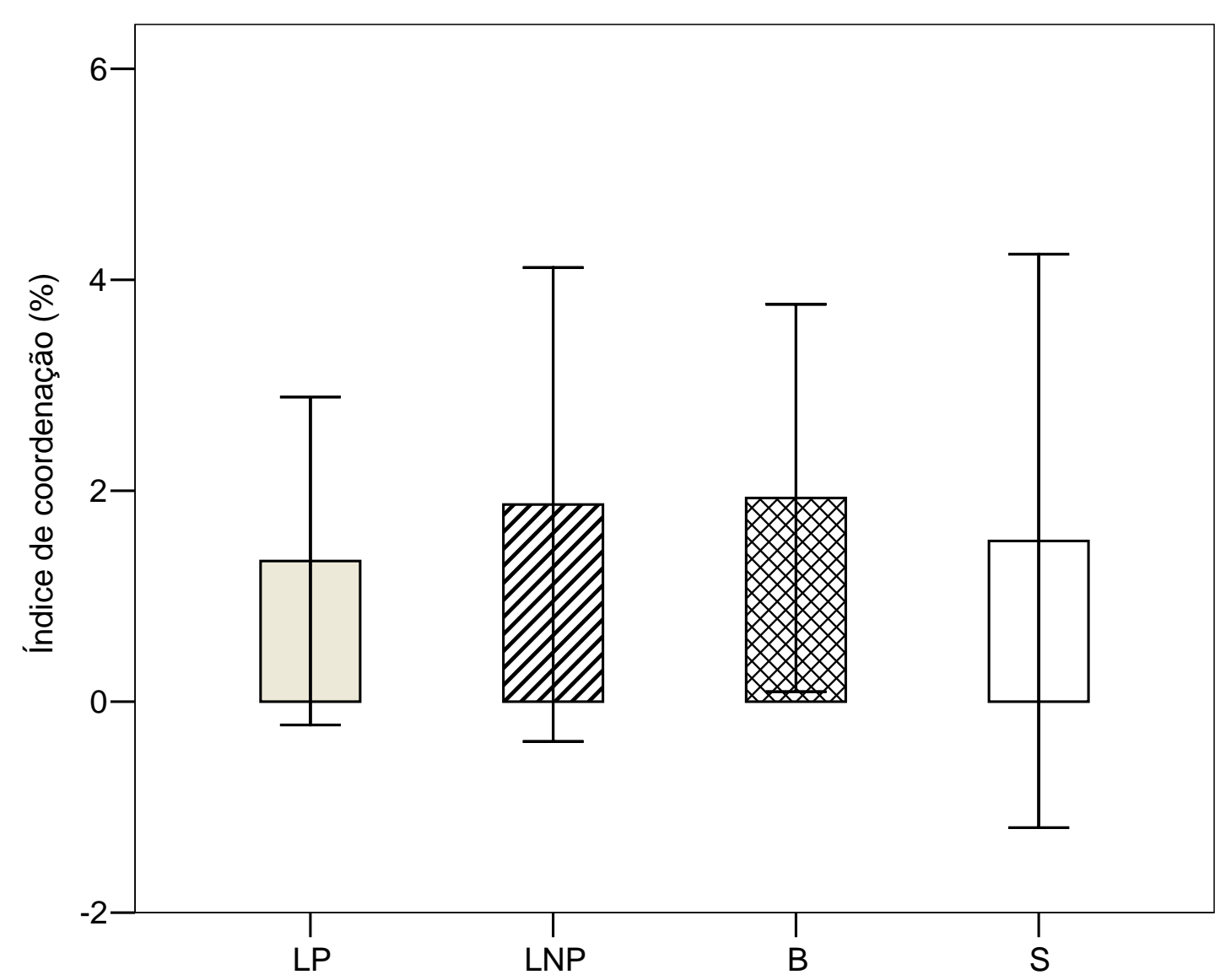

FIGURA 18 - Índice de coordenação nadando crawl em velocidade máxima nas condições de inspiração para o lado preferido (LP), lado não preferido (LNP), bilateral (B) e sem inspiração (S).

Com relação ao índice de coordenação (IdC) da braçada do nado crawl, (FIGURA 18) pode-se notar que tende a ser menor nas condições LP e $S$ comparado com as condições LNP e B. Mas, esta tendência não foi confirmada $\left[F_{(3 ; 60)}=0,399\right.$; $\mathrm{p}=0,774]$.

8

DISCUSSÃO E CONCLUSÃO

O objetivo do presente estudo foi investigar se o desempenho e a braçada do nado crawl são afetados pelos padrões respiratórios: sem inspiração (apneia), com inspiração unilateral (LP e LNP) e bilateral. A amostra compreendeu atletas 
masculinos das categorias infantis e juvenis, todos com preferência pelo padrão respiratório unilateral.

Para a análise foram consideradas medidas que correspondem ao desempenho (tempo gasto para percorrer a distância de 10 metros em velocidade máxima, velocidade média, frequência e comprimento de braçada); aos aspectos invariantes (timing relativo das fases aérea e aquática dos braços direito e esquerdo) e variantes (tempo total da fase aérea e aquática do braço direito e esquerdo, tempo total do braço direito e esquerdo) da organização temporal da braçada, e a interação entre os braços (índice de coordenação da braçada) do nado crawl.

Os resultados mostraram que o padrão respiratório afetou o desempenho dos atletas jovens. Eles precisaram de menos tempo e, portanto, foram também mais velozes para percorrer 10 metros na condição $S$ (sem inspiração) que nas demais condições. Dessa forma, mesmo no caso de nadadores peritos jovens, podemos observar que, em relação a permanecer em apneia, efetuar a inspiração, independente do padrão adotado, afeta velocidade e tempo de nado. Assim, em termos de velocidade e tempo para percorrer 10 metros em velocidade máxima, é mais vantajosa a condição de nadar crawl em apneia que em qualquer das condições com inspiração.

Importante ressaltar que não há na literatura estudos que tenham apresentado dados em relação aos efeitos de padrões de respiração no tempo e velocidade de nadadores. Na maior parte dos estudos até então desenvolvidos, a velocidade foi variável independente, pois os atletas foram solicitados a nadar simulando velocidade empregada em determinadas provas (LERDA et al., 2001; PAYTON et al., 1999; VEZOS et al., 2007). No único estudo em que a velocidade foi variável dependente (SEIFERT et al., 2008), não foi verificada diferença na velocidade dos nadadores em função das condições sem e com inspiração. Mas, neste estudo o nado crawl foi descaracterizado, pois os nadadores nadaram com as pernas atadas. O presente estudo é o único que investigou o efeito do padrão de respiração no desempenho do nado crawl, em situação mais próxima do real, ou seja, em velocidade máxima real e sem descaracterizar o nado. Talvez por isso, os resultados do presente estudo não corroborem com os encontrados por SEIFERT et al., (2008). 
Os resultados encontrados, que em termos de velocidade e tempo, é mais vantajosa a condição de nadar em apneia, podem ser explicados em função do arrasto ativo causado pela movimentação do corpo em função da ação respiratória, e consequentemente, resultando num aumento significativo no tempo de deslocamento dos nadadores. Fortalece este argumento o fato de que nadar em apneia resulta numa menor oscilação do tronco (MAGLISCHO, 1999, 2003).

Ainda a respeito das variáveis de desempenho, verificou-se nesse estudo que no padrão de inspiração LNP os atletas apresentaram menor frequência e maior comprimento da braçada que no padrão de inspiração B. No caso destas variáveis a condição B não se diferenciou da S. Assim, embora a condição $S$ tenha sido a mais vantajosa em termos de tempo e velocidade, em relação à eficiência da braçada, mensurada pela sua frequência e comprimento, se igualou à condição $B$. Portanto, a condição em si de inspiração (LP, LNP, B) afetou o desempenho no que diz respeito à frequência e comprimento da braçada, sendo a condição $\mathrm{B}$ a mais eficiente, e a LNP a menos eficiente dentre as três. A condição LP não se diferenciou das demais nestas variáveis.

Portanto os resultados deste estudo indicam que os padrões respiratórios bilateral, unilateral (para o lado preferido e não preferido) além de serem usados para manter a difusão pulmonar do nadador (respiração), podem também servir como estratégia tática na observação de seus adversários durante a prova, sem que haja prejuízo na velocidade do nado. No entanto, no que se refere ao desempenho, mesmo que declaradamente não seja o padrão preferido, dentre eles, o mais eficiente é o nado com padrão bilateral. Este resultado tem implicações para a intervenção: o padrão do lado preferido de inspiração, não necessariamente, corresponde ao mais vantajoso em termos do desempenho.

Este estudo também teve como objetivo investigar os efeitos de diferentes padrões respiratórios na braçada do nado crawl. Nesse sentido, foram consideradas medidas correspondentes à consistência e variabilidade da organização temporal dos braços direito e esquerdo; e, o índice de coordenação entre os braços (IdC).

Os resultados mostraram que o padrão respiratório não afetou a consistência da braçada, mas que afetou sua variabilidade, ou seja, as medidas correspondentes aos aspectos variantes. 
No que diz respeito à consistência, nas medidas que corresponde aos aspectos invariantes da braçada do nado crawl (consistência), timing relativo das fases aérea e aquática dos braços direito e esquerdo, bem como sua variabilidade, não houve efeito das condições experimentais. Dessa forma pode-se considerar que, diante da modificação do padrão respiratório, nadadores peritos jovens mantêm a estrutura temporal do movimento (padrão) da braçada inalterada. Portanto, as diferenças observadas no desempenho não podem ser atribuídas à reorganização da estrutura temporal da ação dos braços esquerdo e direito.

Neste aspecto, os resultados desse estudo corroboram com os obtidos com modificação na velocidade de nado (SILVA, 2008). Com base nesses resultados, podemos observar que os nadadores apresentam organização temporal da braçada do nado crawl similares e estáveis, ou seja, mantém os aspectos invariantes frente à modificação também do padrão respiratório. Esse resultado mostra que, em se tratando de atletas, uma modificação no parâmetro bem como uma modificação na estrutura da tarefa pode resultar, igualmente, na manutenção do padrão em si no movimento.

Por sua vez, nas medidas correspondentes aos aspectos variantes, especificamente, somente foram encontradas diferenças nas medidas de tempo total da fase aérea, entre a condição $S$ e as condições LNP e LP para o braço direito, e entre as condições S e LNP, para o braço esquerdo. Dessa forma, podemos afirmar que, a ação respiratória afeta a fase aérea da braçada dos nadadores jovens, mas não a fase aquática, nem a variabilidade de ambas.

Assim, o melhor desempenho na condição $S$, quando comparado às condições LP e LNP, pode ser atribuído à diferença no tempo total da fase aérea da braçada. Esta sensibilidade da fase aérea às modificações da tarefa corrobora a observada nos resultados obtidos em MADUREIRA (2006) e SILVA (2008). Ainda, em relação à fase aérea dos braços direito e esquerdo, observamos que, nesta variável, somente a condição B não se diferenciou das demais. Neste sentido, a maior eficiência da braçada (frequência e comprimento) na condição B sobre as demais condições com inspiração (LP e LNP), pode ser explicada pelo fato de os nadadores terem efetuado a ação dos braços com um tempo total da fase aérea, mais semelhante ao da condição S. 
Em relação ao tempo total das braçadas, os resultados mostram que houve aumento em ambos os braços da condição $S$ para a LNP e que para o braço direito, além desta diferença, houve aumento também de B para LNP. Estes resultados permitem afirmar que a ação respiratória unilateral para o lado não preferido (LNP) causa aumento do tempo total da ação dos braços (direito e esquerdo) dos nadadores e, consequentemente, prejudica o desempenho dos mesmos nesta condição. A condição LP, nesta variável, não se diferenciou das demais. Este é mais um indicativo de vantagem da adoção da condição de inspiração $B$, sobre as demais, inclusive daquela (LP), declarada de preferência pelos nadadores.

Em síntese, os resultados referentes às medidas dos aspectos variantes, em conjunto com os dos aspectos invariantes, permitem inferir que as alterações de desempenho entre as condições ocorreram por meio da flexibilidade do comportamento, ou seja, só de ajustes mediante os aspectos variantes da braçada do nado crawl. Esses resultados corroboram com os encontrados em MADUREIRA (2006), SILVA (2008) e FREUDENHEIM (2008). As diferenças no desempenho podem ser explicadas pelas alterações no tempo total da fase aérea dos braços direito e esquerdo.

Por último, na medida em que expressa a interação entre os braços, os resultados mostraram que não houve diferença significativa entre as condições experimentais. Nesse sentido, esses resultados, não corroboram com os de LERDA et al., (2001) em que houve diferença no IdC em função do padrão inspiratório. Portanto, os resultados do presente estudo, indicam que independente do padrão respiratório utilizado, atletas jovens mantém o padrão de coordenação entre os braços, bem como seu tempo de desempenho em velocidade máxima real. Esta diferença de resultados pode ser explicada, pois em LERDA et al., (2001) a velocidade foi simulada e pela diferença de idade o que normalmente, está associado à experiência de nado dos participantes.

Com base nos resultados obtidos e considerando as delimitações da presente pesquisa, pode-se concluir que:

1) O padrão respiratório afeta o desempenho dos atletas jovens. Em termos de velocidade e tempo, é mais vantajosa a condição de nadar crawl em apneia que em qualquer das condições com inspiração. No que diz respeito à frequência e 
comprimento da braçada a condição $B$ (bilateral) é a mais eficiente e a LNP (unilateral para o lado não preferido), a menos eficiente dentre as três condições com inspiração utilizadas no presente estudo. Portanto, o padrão preferido de respiração, não necessariamente, corresponde ao mais eficiente em termos do desempenho.

2) Diante da modificação do padrão respiratório, nadadores peritos jovens mantém a estrutura temporal do movimento (padrão) das braçadas direita e esquerda (aspectos invariantes da braçada) bem como a interação entre os braços inalteradas enquanto efetuam ajustes na fase aérea da braçada (aspectos variantes). 
REFERÊNCIAS

ANJOS, M.; FERREIRA M. B. Novo dicionário Aurélio. São Paulo: Positivo, 2004.

APOLINÁRIO, M. R.; SILVA, C. G. S.; TERTULIANO, I. W.; OLIVEIRA, T.A. C.; MARQUES, M. T.; FREUDENHEIM, A. M. Efeito da modificação estrutural na braçada do nado crawl: um estudo exploratório. In: XXX Simpósio Internacional de Ciências do Esporte, 15, 2007. Anais. São Paulo, 2007. p. 248.

BARTLETT, F. C. Remembering: A study in experimental and social psychology. Cambridge: Cambridge University Press. 1932.

BERNSTEIN, N. The coordination and regulation of movements. New York: Pergamon, 1967.

CHOLLET, D.; CHALIES, S.; CHATARD, J. C. A new index of coordination for the crawl: description and usefulness. International Journal of Sports Medicine, Stuttgart, v. 21, p. $54-59,2000$.

CHOLLET, D.; PELAYO, P.; DELAPLACE, C.; TOURNY, C.; SIDNEY, M. Stroking characteristic variations in the $100-\mathrm{m}$ freestyle for males of differing skill. Perceptual and Motor Skills, Missoula, v. 85, p. 167-177, 1997.

COLWIN, C. M. Breakthrough swimming. Champaign: Human Kinetics, 2002.

COLWIN, C. M. Nadando para o século XXI. São Paulo, Manole, 2000.

COSTILL, D. L.; MAGLISCHO, E. W.; RICHARDSON, A. B. Handbook of Sports Medicine and Science Swimming. Blacwell science, 1992.

COUNSILMAN, J. E.; COUNSILMAN, B. E. The new science of swimming. PrenticeHall, 1994. 
DESCHODT, V. J.; ARSAC, L. M.; ROUARD, A. H. Relative contribution of arms and legs in humans to propulsion in $25 \mathrm{~m}$ sprint front-crawl swimming. European Journal of Applied Physiology, v. 80, n. 3, p. 192-199, 1999.

FREUDENHEIM, A. M. O Nadar: uma habilidade motora revisada. São Paulo: CEPEUSP, 1995.

FREUDENHEIM, A. M. Programa de ação hierárquico e validade ecológica. 2008, 93f. Tese (Livre Docência) - Escola de Educação Física e Esporte, Universidade de São Paulo, São Paulo.

FREUDENHEIM, A. M.; BASSO, L.; XAVIER FILHO, E; SILVA, C. G; MADUREIRA, F; MANOEL, E. J. Organização temporal da braçada do nado crawl: iniciantes "versus" avançados. Revista Brasileira de Ciência e Movimento, v. 15, n. 2, p. 75-84, 2005.

FREUDENHEIM, A. M.; GAMA, R.; MOISÉS, M. La habilidad nadar: (re) visión. Ciências de la Actividad Física, v. 4, n. 8, p. 139-155, 1996.

FREUDENHEIM, A. M.; MADUREIRA, F. Natação: análise e ensino do nado crawl. In: TANI, G.; BENTO, J. O.; PETERSEN, R. D. S. Pedagogia do desporto. Guanabara Koogan, Rio de Janeiro, 2006. Cap. 29, p. 372-383.

GENTNER, D. R. Evidence against a central control model of timing in typing. Journal of Experimental Psychology: Human Perception and Performance, Washington, v. 8, p. 793-810, 1982.

GENTNER, D. R. Timing of skilled motor performance: Tests of the proportional duration model. Psychological Review, Princeton, v. 94, p. 255-276, 1987.

HEUER, H. Testing the invariance of relative timing: comment on GENTNER (1987). Psychological Review, Princeton, v. 95, p. 552-557, 1988. 
HEUER, H. Invariant relative timing in motor program theory. In: FAGARD, J.; WOLFF, P. H. (Eds.). The development of timing control and temporal organization in coordinated action: invariant relative timing, rhythms and coordination. Amsterdam: North-Holland, 1991. p. 37-68.

HEUER, H.; SCHMIDT, R. A.; GHODSIAN, D. Generalized motor programs for rapid bimanual tasks: A two level multiplicative-rate model. Biological Cybernetics, v. 73, p. 343-356, 1995.

LERDA, R.; CARDELLI, C. Breathing and propelling in crawl as a function of skill and swim velocity. International Journal of Sports Medicine, Stuttgard, v. 24, p. 75-80, 2003.

LERDA, R.; CARDELLI, C.; CHOLLET, D. Analysis of interaction between breathing and arm actions in front crawl. Journal of Human Movement Studies, London, v. 40, p. 129-44, 2001.

MADUREIRA, F. B. Efeito da modificação da tarefa na braçada do nado crawl em indivíduos com níveis de habilidades distintos. 2006, 76f. Dissertação (Mestrado) Escola de Educação Física e Esporte da Universidade de São Paulo, São Paulo.

MAGILL, R. A. Aprendizagem motora: conceitos e aplicações. 5a. ed. São Paulo: Edgard Blücher, 2000.

MAGLISCHO, E. W. Nadando ainda mais rápido. São Paulo, Manole, 1999.

MAGLISCHO, E. W. Swimming Fastest. Champaign: Human Kinetics, 2003.

MAKARENKO, L. P. Natação: seleção de talentos e iniciação desportiva. São Paulo, Artmed, 2001. 
MANOEL, E. J.; CONNOLLY, K. J. Variability and the development of skilled actions. International Journal of Psychophysiology, New York, v. 19, p. 129-147, 1995.

MILLET, G. P.; CHOLLET, D.; CHALIES, S.; CHATARD, J. C. Coordination in front crawl in Elite Triathletes and Elite Swimmers. International Journal Sports Medicine; v.23, p.99-104, 2002.

NEWELL, K. M.; CORCOS, D. M. Variability and motor control. Champaign, IL: Human Kinetics, 1993.

OLIVEIRA, T. A. C.; APOLINÁRIO, M. R.; FREUDENHEIM, A. M.; CORRÊA, U. C. Análise sistêmica do nado crawl. Brazilian Journal of Motor Behavior, v. 4, n. 1, p. 1521, 2009.

PAYTON, C. J.; BARTLETT, R. M.; BALTZOPOULOS, V.; COOMBS, R. Upper extremity kinematics and body roll during preferred side breathing and breath-holding front crawl swimming. Journal of Sports Sciences, v. 17, p. 689-696, 1999.

SCHMIDT, R. A. Motor schema theory after 27 years: Reflections and implications for a new theory. Research_Quarterly for Exercise and Sport. v. 74, n. 4, p.366-375, 2003.

SCHMIDT, R. A. Past and future issues in motor programming. Research Quaterly for Exercise and Sport, Washington, v. 51, p. 122-140, 1980.

SCHMIDT, R. A. The search for invariance in skilled movement behavior. Research Quarterly for Exercise and Sport, Washington, v. 56, n. 2, p.188-200, 1985.

SCHMIDT, R.; WRISBERG, C. Aprendizagem e performance motora: uma abordagem da aprendizagem baseada no problema. Porto Alegre, Artmed, 2001. 
SEIFERT, L.; BOULESTEIX, L.; CARTER, M.; CHOLLET, D. The spatial-temporal and coordinative structures in elite male $100-\mathrm{m}$ front crawl swimmers. International Journal of Sports Medicine, Stuttgart, v. 26, p. 286-93, 2005a.

SEIFERT, L.; BOULESTEIX, L.; CHOLLET, D. Effect of gender on the adaptation of arm coordination in front crawl. International Journal of Sports Medicine, Stuttgart, v. 25, p. 217-23, 2004.

SEIFERT, L.; CHEHENSSE, A.; CHOLLET, C. T.; LeMAITRE, F.; CHOLLET, D. Effect of breathing pattern on arm coordination symmetry in front crawl. Journal of Strength and Conditioning Research, v. 22, p. 1670-1676, 2008.

SEIFERT, L.; CHOLLET, D.; ALLARD, P. Arm coordination symmetry and breathing effect in front crawl. Human Movement Science, v. 24, p. 234-256, 2005b.

SEIFERT, L.; CHOLLET, D.; ROUARD, A. Swimming constraints and arm coordination. Human Movement Science, v. 26, p. 68-86, 2007.

SILVA, C.G.S. Consistência e variabilidade do nado crawl em indivíduos habilidosos. 2008, 75f. Dissertação (Mestrado) - Escola de Educação Física e Esporte, Universidade de São Paulo, São Paulo.

STAGER, J. M.; TANNER, D. A. Natação: Manual de medicina e ciência do esporte. São Paulo, Manole, 2008.

TANI, G. (Ed.). Comportamento motor: aprendizagem e desenvolvimento. Rio de Janeiro, Guanabara Koogan, 2005.

TANI, G. Hierarchical organization of human motor behaviour. Sheffield, University of Sheffield, 1995. (Unpublished Technical Report). 
VEZOS, N.; GOURGOULIS, V.; AGGELOUSSIS, N.; KASIMATIS, P.; CHRISTOFORIDIS, C.; MAVROMATIS, G. Underwater stroke kinematics during breathing and breath-holding front crawl swimming. Journal Sports Science and Medicine, v. 6, p. 58-62, 2007.

VORONTSOV, A. R.; RUMYANTSEV, V. A. Forças resistivas na natação. In: ZATSIORSKY, V. M. (Ed.) Biomecânica do esporte: performance do desempenho e prevenção de lesão. Rio de Janeiro: Guanabara Koogan, 2004. Cap. 9, p. 143-158.

YANAI, T. Buoyancy is the primary source of generating bodyroll in front-crawl swimming. Journal of Biomechanics, v. 37, p. 605-612, 2004. 
ANEXO I - llustração da ficha cadastral e questionário utilizado para determinar o lado inspiratório dos nadadores.

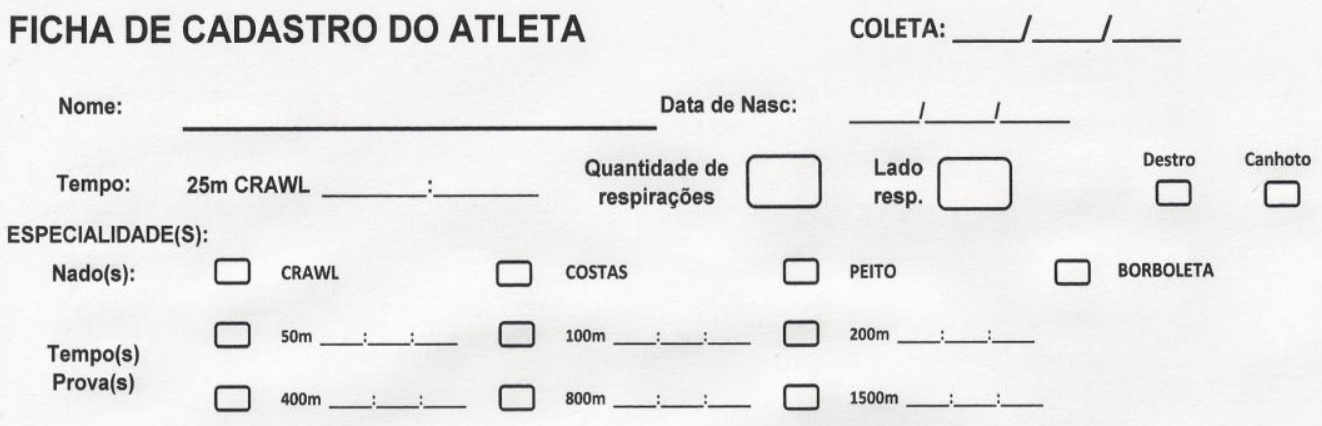

QUESTIONARIO PARA DETERMINAR LADO INSPIRATORIO (Adaptado de Seifert et al., 2005)

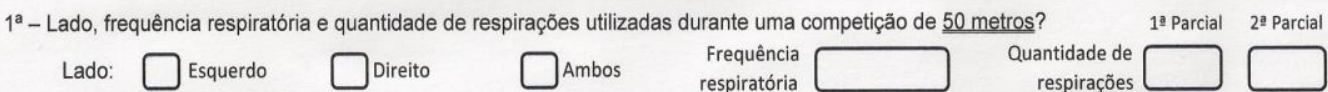

$2^{\mathrm{a}}$ - Lado e frequência respiratória utilizada durante uma competição de 100 e 200 metros ?

Lado: $\square$ Esquerdo $\square$ Direito $\square$ Ambos

$3^{\mathrm{a}}$ - Lado e frequência respiratória utilizada durante uma competição de $\underline{400,800 \text { e } 1500 \text { metros }}$ ?

Lado: $\square$ Esquerdo $\square$ Direito $\square$ Ambos $\begin{array}{r}\text { Frequência } \\ \text { respiratória }\end{array}$

$4^{\mathrm{a}}$ - Lado e frequência respiratória utilizada durante treinamento pesado??

Lado: $\square$ Esquerdo $\square$ Direito $\square$ Ambos Frequência respiratória

$5^{\mathrm{a}}$ - Lado e frequência respiratória utilizada durante treinamento leve?

Lado: $\square$ Esquerdo $\square$ Direito $\square$ Ambos

Frequência respiratória 
ANEXO II - Termo de consentimento livre e esclarecido (Continuação)

\section{DADOS SOBRE A PESQUISA CIENTÍFICA}

Este projeto intitula-se "CONSISTÊNCIA E VARIABILIDADE DA BRAÇADA DO NADO CRAWL FRENTE A DIFERENTES PADRÕES RESPIRATÓRIOS."

1. PESQUISADOR RESPONSÁVEL: Profa. Dra. Andrea Michele Freudenheim

2. CARGO/FUNÇÃO: Professor Assistente Doutor

3. AVALIAÇÃO DO RISCO DA PESQUISA:

$\begin{array}{llll}\text { RISCO MÍNIMO } & \mathbf{X} & \text { RISCO MÉDIO } & \check{Z} \\ \text { RISCO BAIXO } & \check{Z} & \text { RISCO MAIOR } & \text { Ž }\end{array}$

(probabilidade de que o indivíduo sofra algum dano como conseqüência imediata ou tardia do estudo)

4. DURAÇÃO DA PESQUISA : de 01 de janeiro de 2010 até junho de 2010.

\section{EXPLICAÇÕES DO PESQUISADOR AO INDIVÍDUO OU SEU REPRESENTANTE LEGAL SOBRE A PESQUISA, CONSIGNANDO:}

1. O objetivo do presente estudo é investigar os efeitos de diferentes padrões respiratórios no desempenho e na braçada do nado crawl. As modificações serão realizadas na braçada do nado crawl em velocidade máxima em função do lado inspiratório.

2. Para investigar o problema, todos os indivíduos serão filmados e solicitados a nadar quatro tentativas de 25 metros do nado crawl em velocidade máxima respirando segundo o padrão respiratório solicitado pelo pesquisador. Todos terão um intervalo entre as condições para descanso e preparação para próxima filmagem. Como todos possuem liberação médica prévia, não se espera riscos envolvendo a integridade dos participantes. 
ANEXO II - Termo de consentimento livre e esclarecido (Continuação)

3. Os participantes poderão se beneficiar obtendo mais informações sobre seus ajustes de nado, bem como, os ajustes realizados por indivíduos de desempenhos distintos.

\section{ESCLARECIMENTOS DADOS PELO PESQUISADOR SOBRE GARANTIAS DO SUJEITO DA PESQUISA:}

- Acesso, a qualquer tempo, às informações sobre procedimentos, riscos e benefícios relacionados à pesquisa, inclusive para dirimir eventuais dúvidas: $\mathrm{O}$ aluno pode, em qualquer momento, obter a informação que deseja a respeito de procedimentos, eventuais riscos e benefícios relacionados à pesquisa;

- Liberdade de retirar seu consentimento a qualquer momento e de deixar de participar do estudo, sem que isto traga prejuízo à continuidade da assistência: $O$ aluno tem a liberdade de retirar seu consentimento e deixar de participar do estudo, sem nenhum prejuízo;

- Salvaguarda da confidencialidade, sigilo e privacidade: Nenhuma informação a respeito da identidade do aluno se tornará pública;

Disponibilidade de assistência por eventuais danos à saúde, decorrentes da pesquisa, será feita inicialmente pelo médico plantonista da instituição onde serão realizados os testes.

V INFORMAÇÕES DE NOMES, ENDEREÇOS E TELEFONES DOS RESPONSÁVEIS PELO ACOMPANHAMENTO DA PESQUISA, PARA CONTATO EM CASO DE INTERCORRÊNCIAS CLÍNICAS E REAÇÕES ADVERSAS:

Pesquisador gerente: Marcos Roberto Apolinário - Telefone: (0XX11) 47425068

Pesquisador responsável: Andrea Michele Freudenheim - Telefone: (0XX19) 3876 0487 
ANEXO II - Termo de consentimento livre e esclarecido (Continuação)

\section{OBSERVAÇÕES COMPLEMENTARES: Não há}

\section{CONSENTIMENTO PÓS-ESCLARECIDO}

Declaro que, após convenientemente esclarecido pelo pesquisador e ter entendido o que me foi explicado, consinto meu filho a participar do presente Projeto de Pesquisa.

São Paulo, de de 2010.

Assinatura do responsável legal ou do atleta

Assinatura do pesquisador (carimbo ou nome legível)

INSTRUÇÕES PARA PREENCHIMENTO

(Resolução Conselho Nacional de Saúde 196, de 10 de outubro 1996)

1. Este termo conterá o registro das informações que o pesquisador fornecerá ao sujeito da pesquisa, em linguagem clara e accessível, evitando-se vocábulos técnicos não compatíveis com o grau de conhecimento do interlocutor.

2. A avaliação do grau de risco deve ser minuciosa, levando em conta qualquer possibilidade de intervenção e de dano à integridade física do sujeito da pesquisa.

3. O formulário poderá ser preenchido em letra de forma legível, datilografia ou meios eletrônicos.

4. Este termo deverá ser elaborado em duas vias, ficando uma via em poder do paciente ou seu representante legal e outra deverá ser juntada ao prontuário do paciente.

5. A via do Termo de Consentimento Livre e Esclarecido submetida à análise do Comitê de Ética em Pesquisa - CEP deverá ser idêntica àquela que será fornecida ao sujeito da pesquisa. 
ANEXO III - Ilustração do instrumento utilizado para captar as imagens das fases aérea e aquática da braçada do nado crawl.

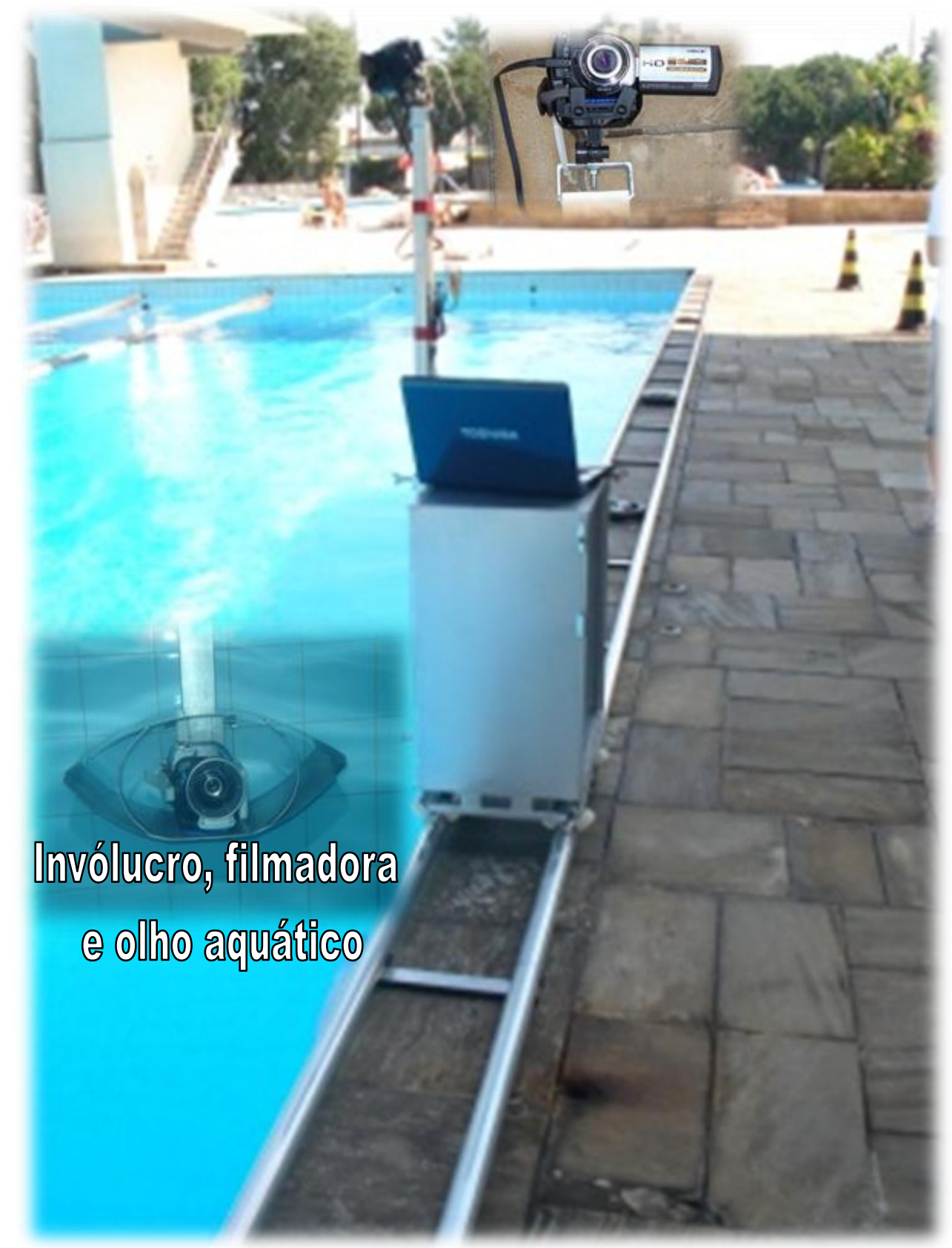




\title{
ANEXO IV - Ofício de aprovação do Comitê de Ética em Pesquisa (CEP).
}

\author{
UNIVERSIDADE DE SÃO PAULO \\ ESCOLA DE EDUCAÇÃO FÍSICA E ESPORTE
}

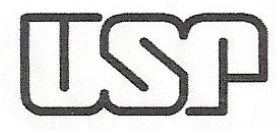

Of. CEP15209/EEFE/10122009

São Paulo, 10 de dezembro de 2009.

Senhora Pesquisadora,

O Comitê de Ética em Pesquisa (CEP) da Escola de Educação Física e Esporte da Universidade de São Paulo, em reunião ordinária realizada em 10 de dezembro de 2009, aprovou o Protocolo 2009/60- "Consistência e variabilidade da braçada do nado crawl frente a diferentes padrões respiratórios", sob sua responsabilidade.

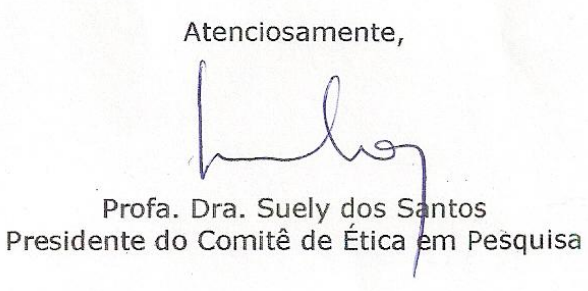

Ilma. Sra.

Profa. Dra. Andrea Michele Freudenheim

EEFEUSP - EFP 


\section{ANEXO V - Quadro das características dos atletas}

\begin{tabular}{|c|c|c|c|c|c|c|}
\hline $\mathrm{N}$ & Idade e Categoria & $\begin{array}{l}\text { Tempo dos } 25 \mathrm{~m} \\
\text { fornecido } \\
\text { pelos técnicos }\end{array}$ & $\begin{array}{c}\text { Número de } \\
\text { respiração } \\
\text { 25m nado crawl }\end{array}$ & $\begin{array}{l}\text { Dominância } \\
\text { lateral }\end{array}$ & $\begin{array}{l}\text { Lado de } \\
\text { respiração } \\
\text { preferido }\end{array}$ & $\begin{array}{c}\text { Especialidade de } \\
\text { nado }\end{array}$ \\
\hline 1 & (16) / Juvenil 2 & 13,45 & 0 & Destro & Direito & Crawl e Peito \\
\hline 2 & (15) / Juvenil 1 & 12,53 & 0 & Destro & Esquerdo & Crawl e Peito \\
\hline 3 & (16) / Juvenil 2 & 12,30 & 0 & Destro & Direito & Crawl \\
\hline 4 & (15) / Juvenil 1 & 12,20 & 0 & Sinistro & Direito & Crawl e Borboleta \\
\hline 5 & (16) / Juvenil 2 & 12,00 & 0 & Destro & Direito & Crawl e Peito \\
\hline 6 & (15) / Juvenil 1 & 11,90 & 0 & Destro & Esquerdo & Crawl e Borboleta \\
\hline 7 & (15) / Juvenil 1 & 11,80 & 0 & Destro & Direito & Crawl e Borboleta \\
\hline 8 & (16) / Juvenil 2 & 11,82 & 0 & Destro & Direito & Crawl \\
\hline 9 & (15) / Juvenil 1 & 11,35 & 1 & Sinistro & Esquerdo & Crawl \\
\hline 10 & (15) / Juvenil 1 & 11,30 & 0 & Destro & Direito & Crawl e Peito \\
\hline 11 & (16) / Juvenil 2 & 11,00 & 0 & Destro & Direito & Crawl e Borboleta \\
\hline 12 & (13) / Infantil 1 & 14,60 & 3 & Destro & Direito & Crawl \\
\hline 13 & (14) / Infantil 2 & 14,02 & 2 & Destro & Direito & Crawl e Peito \\
\hline 14 & (13) / Infantil 1 & 13,00 & 0 & Destro & Direito & Crawl e Costas \\
\hline 15 & (14) / Infantil 2 & 13,00 & 2 & Destro & Direito & Crawl \\
\hline 16 & (14) / Infantil 2 & 13,30 & 0 & Destro & Direito & Crawl \\
\hline 17 & (13) / Infantil 1 & 13,31 & 1 & Sinistro & Esquerdo & Crawl \\
\hline 18 & (13) / Infantil 1 & 12,90 & 2 & Destro & Direito & Crawl \\
\hline 19 & (13) / Infantil 1 & 12,50 & 1 & Destro & Direito & Crawl e Borboleta \\
\hline 20 & (14) / Infantil 2 & 12,00 & 0 & Destro & Direito & Crawl e Peito \\
\hline 21 & (14) / Infantil 2 & 11,21 & 2 & Destro & Direito & Crawl e Borboleta \\
\hline
\end{tabular}




\section{ANEXO VI - Dados utilizados para análise}

\section{Dados de Desempenho}

LADO PREFERIDO (LP) LADO NÃO PREFERIDO (LNP) BILATERAL (B) SEM RESPIRAÇÃO (S)

\begin{tabular}{|c|c|c|c|c|c|c|c|c|c|c|c|c|c|c|c|c|}
\hline $\mathrm{N}$ & Tempo & $\mathrm{Vm}$ & FB & CB & Tempo & $\mathrm{Vm}$ & FB & CB & Tempo & $\mathrm{Vm}$ & FB & CB & empo & $\mathrm{Vm}$ & FB & CB \\
\hline 1 & & & ,00 & & & & ,00 & & 28 & & ,00 & 1 & 00 & 67 & 0,00 & 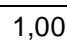 \\
\hline 2 &, 90 & 169 & 00 & 11 & & 1,62 &, 00 & & & 7 & & 1,00 & 0 & ,72 &, 00 & 1,00 \\
\hline 3 & 10 & 1,63 & 11,00 & 0,91 & 6,08 & 1,64 & 10,00 & 1,00 & 5,96 & 1,68 & 10,00 & 1,00 & 6,00 & 1,69 & 1,00 & 1,00 \\
\hline 4 & 5,80 & 1,72 & 9,00 & 1,11 & 5,88 & 1,70 & 9,00 & 1,11 & 5,84 & 1,71 & 9,00 & 1,11 & 6,00 & 1,70 & 9,00 & 1,00 \\
\hline 5 & 6,00 & 1,68 & 10,00 & 1,00 & 96 & 1,68 & 10,00 & 1,00 & ,92 & 1,69 & 10,00 & 1,00 & 6,00 & 1,71 & 10,00 & 1,00 \\
\hline 6 & 5,80 & 1,74 & 10,00 & 1,00 & 5,64 & 1,77 & 10,00 & 1,00 & 5,72 & 1,75 & 00 & 0,91 & 0 & 1,80 & 0 & 1,00 \\
\hline 7 & 80 & 1,74 & 10,00 & 1,00 & 5,84 & 1,71 & 10,00 & 1,00 & 5,72 & 1,75 & 10,00 & 1,00 & 6,00 & 1,77 & 11,00 & 1,00 \\
\hline 8 & 5,60 & 1,77 & 00 & 1,11 & 4 & 1,71 & 9,00 & 1,11 & 4 & 1 & & 1,00 & 0 & 1,84 & 9,00 & 1,00 \\
\hline 9 & 6,00 & 1,67 & 10,00 & 1,00 & 64 & 1,77 & 10,00 & 1,00 & 88 & 1,70 & 10,00 & 1,00 & 6,00 & 1,75 & 10,00 & 1,00 \\
\hline 10 & 50 & 1,81 & 9,00 & 1,11 & 5,52 & 1,81 & 9,00 & 1,11 & 56 & 1,80 & 9,00 & 1,11 & 0 & 1,82 & 00 & 1,00 \\
\hline 11 & 5,80 & 1,72 & 11,00 & 0,91 & 5,84 & 1,71 & 11,00 & 0,91 & 76 & 1,74 & 11,00 & 0,91 & 00 & 1,76 & 11,00 & 1,00 \\
\hline 12 & 6,20 & 1,61 & 10,00 & 1,00 & 6,32 & 1,58 & 10,00 & 1,00 & 6,16 & 1,62 & 10,00 & 1,00 & 6,00 & 1,62 & 10,00 & 1,00 \\
\hline 13 & 6,20 & 1,60 & 10,00 & 1,00 & 6,48 & 1,54 & 10,00 & 1,00 & 6,28 & 1,59 & 10,00 & 1,00 & 00 & 1,60 & 10,00 & 1,00 \\
\hline 14 & 6,40 & 1,55 & 10,00 & 1,00 & 6,48 & 1,54 & 10,00 & 1,00 & 6,44 & 1,55 & 10,00 & 1,00 & 6,00 & 1,56 & 11,00 & 1,00 \\
\hline 15 & 6,80 & 1,46 & 11,00 & 0,91 & 6,96 & 1,44 & 10,00 & 1,00 & 6,80 & 1,47 & 11,00 & 0,91 & 7,00 & 1,49 & 11,00 & 1,00 \\
\hline 16 & 6,30 & 1,58 & 10,00 & 1,00 & 6,28 & 1,59 & 9,00 & 1,11 & 6,20 & 1,61 & 10,00 & 1,00 & 6,00 & 1,58 & 9,00 & 1,00 \\
\hline 17 & 6,50 & 1,54 & 12,00 & 0,83 & 6,64 & 1,51 & 11,00 & 0,91 & 6,56 & 1,52 & 12,00 & 0,83 & 6,00 & 1,58 & 12,00 & 1,00 \\
\hline 18 & 6,10 & 1,63 & 9,00 & 1,11 & 6,28 & 1,59 & 9,00 & 1,11 & 5,92 & 1,69 & 9,00 & 1,11 & 6,00 & 1,68 & 10,00 & 1,00 \\
\hline 19 & 6,20 & 1,61 & 10,00 & 1,00 & 6,40 & 1,56 & 11,00 & 0,91 & 6,20 & 1,61 & 10,00 & 1,00 &, 00 & 1,62 & 11,00 & 1,00 \\
\hline 20 & 5,70 & 1,75 & 9,00 & 1,11 & 6,04 & 1,66 & 9,00 & 1,11 & 5,84 & 1,71 & 10,00 & 1,00 & 6,00 & 1,72 & 10,00 & 1,00 \\
\hline 21 & 6,30 & 1,59 & 10,00 & 1,00 & 6,24 & 1,60 & 10,00 & 1,00 & 6,40 & 1,56 & 10,00 & 1,00 & 6,00 & 1,58 & 10,00 & 1,00 \\
\hline
\end{tabular}


ANEXO VI - Dados utilizados para análise (Continuação)

Dados de distribuição e variabilidade do tempo relativo da fase aérea

\begin{tabular}{|c|c|c|c|c|c|c|c|c|}
\hline & \multicolumn{4}{|c|}{ Braço direito } & \multicolumn{4}{|c|}{ Braço esquerdo } \\
\hline $\mathrm{N}$ & Tr Ae LP & Tr Ae LNP & $\operatorname{Tr} A e B$ & $\operatorname{Tr} A$ e S & Tr Ae LP & Tr Ae LNP & $\operatorname{Tr} A e$ B & TrAe S \\
\hline 1 & 35,55 & 35,05 & 42,34 & 37,69 & 32,84 & 33,85 & 26,42 & 36,44 \\
\hline 2 & 37,49 & 34,64 & 37,48 & 34,28 & 35,76 & 33,55 & 33,98 & 32,59 \\
\hline 3 & 37,68 & 34,81 & 35,74 & 34,82 & 36,71 & 30,13 & 32,63 & 34,38 \\
\hline 4 & 34,83 & 35,81 & 34,47 & 36,46 & 34,43 & 36,04 & 34,96 & 38,09 \\
\hline 5 & 36,28 & 38,19 & 34,63 & 36,13 & 40,55 & 32,19 & 34,49 & 36,44 \\
\hline 6 & 37,84 & 33,85 & 32,55 & 31,93 & 34,58 & 33,61 & 33,25 & 36,90 \\
\hline 7 & 32,64 & 32,15 & 37,59 & 32,92 & 39,02 & 40,45 & 37,64 & 31,98 \\
\hline 8 & 32,39 & 31,72 & 29,96 & 28,35 & 30,70 & 36,66 & 34,31 & 33,25 \\
\hline 9 & 29,63 & 30,78 & 31,35 & 32,10 & 33,09 & 36,36 & 33,50 & 33,38 \\
\hline 10 & 31,14 & 31,07 & 30,87 & 29,15 & 33,54 & 40,59 & 37,24 & 35,20 \\
\hline 11 & 34,42 & 37,80 & 37,56 & 29,04 & 36,46 & 39,07 & 35,81 & 29,02 \\
\hline 12 & 33,34 & 36,50 & 39,78 & 31,74 & 37,95 & 38,65 & 39,71 & 34,32 \\
\hline 13 & 38,02 & 31,07 & 23,95 & 37,00 & 33,08 & 31,54 & 32,64 & 31,90 \\
\hline 14 & 32,65 & 30,85 & 36,18 & 37,69 & 28,97 & 35,81 & 32,15 & 28,98 \\
\hline 15 & 32,86 & 33,30 & 32,7 & 32,80 & 35,71 & 27,90 & 31,47 & 33,48 \\
\hline 16 & 32,68 & 30,14 & 30,46 & 30,88 & 27,72 & 36,62 & 35,33 & 33,20 \\
\hline 17 & 34,16 & 31,77 & 30,32 & 31,76 & 31,52 & 25,72 & 32,00 & 29,65 \\
\hline 18 & 25,81 & 30,71 & 28,57 & 28,37 & 36,09 & 32,89 & 36,58 & 37,23 \\
\hline 19 & 30,02 & 30,75 & 31,38 & 26,72 & 30,54 & 33,56 & 32,55 & 33,29 \\
\hline 20 & 31,50 & 24,32 & 30,26 & 31,27 & 23,56 & 28,94 & 28,42 & 29,34 \\
\hline \multirow[t]{2}{*}{21} & 32,28 & 33,58 & 27,73 & 29,04 & 30,03 & 31,03 & 30,76 & 29,02 \\
\hline & \multicolumn{4}{|c|}{ Braço direito } & \multicolumn{4}{|c|}{ Braço esquerdo } \\
\hline $\mathrm{N}$ & $\mathrm{V} \operatorname{Tr} \mathrm{Ae}$ LP & V Tr Ae LNP & $\mathrm{V} \operatorname{Tr} \mathrm{Ae} B$ & $\mathrm{~V} \operatorname{Tr} \mathrm{Ae} S$ & $\mathrm{~V} \operatorname{Tr} \mathrm{Ae}$ LP & V Tr Ae LNP & $\mathrm{V} \operatorname{Tr} \mathrm{Ae} B$ & $\mathrm{~V} \operatorname{Tr} \mathrm{Ae} S$ \\
\hline 1 & 1,96 & 3,01 & 7,68 & 2,23 & 1,15 & 0,90 & . & 2,28 \\
\hline 2 & 1,80 & 0,65 & 4,96 & 1,64 & 2,25 & 0,74 & 2,45 & 1,28 \\
\hline 3 & 2,47 & 2,57 & 0,74 & 3,84 & 2,48 & 2,15 & 2,57 & 2,31 \\
\hline 4 & 0,72 & 2,03 & 2,79 & 2,05 & 2,14 & 1,74 & 0,39 & 2,44 \\
\hline 5 & 2,56 & 0,64 & 3,87 & 1,49 & 4,53 & 1,06 & 2,24 & 2,28 \\
\hline 6 & 2,65 & 0,90 & 2,04 & 3,84 & 4,21 & 2,95 & 1,81 & 1,03 \\
\hline 7 & 1,20 & 2,05 & 0,33 & 3,53 & 1,47 & 1,59 & 2,18 & 0,89 \\
\hline 8 & 0,82 & 0,41 & 2,98 & 3,66 & 1,86 & 1,71 & 2,44 & 2,97 \\
\hline 9 & 2,55 & 3,56 & 2,26 & 1,72 & 2,75 & 2,00 & 3,01 & 1,48 \\
\hline 10 & 1,98 & 3,31 & 1,87 & 3,63 & 2,21 & 1,55 & 0,93 & 0,45 \\
\hline 11 & 3,03 & 2,44 & 1,88 & 0,88 & 4,12 & 1,68 & 1,65 & 3,19 \\
\hline 12 & 1,43 & 0,87 & 2,19 & 1,02 & 2,24 & 1,26 & 0,50 & 2,12 \\
\hline 13 & 0,67 & 1,36 & & 4,86 & 1,06 & 2,15 & 2,04 & 1,24 \\
\hline 14 & 1,79 & 3,50 & 5,04 & 1,48 & 2,11 & 2,03 & 0,40 & 0,77 \\
\hline 15 & 2,24 & 2,82 & 3,16 & 3,67 & 0,80 & 1,64 & 0,38 & 4,74 \\
\hline 16 & 1,29 & 2,28 & 0,79 & 2,10 & 1,16 & 0,78 & 0,65 & 2,02 \\
\hline 17 & 5,48 & 4,13 & 3,99 & 2,89 & 2,23 & 2,20 & 1,22 & 2,57 \\
\hline 18 & 0,28 & 3,35 & 1,10 & 2,37 & 1,91 & 3,57 & 4,89 & 4,32 \\
\hline 19 & 2,24 & 2,87 & 2,27 & 2,22 & 3,01 & 2,28 & 2,04 & 2,75 \\
\hline 20 & 2,57 & 2,39 & 2,66 & 2,44 & 1,75 & 3,41 & 3,03 & 0,78 \\
\hline 21 & 3,59 & 3,41 & 0,97 & 0,88 & 1,20 & 2,16 & 3,28 & 3,19 \\
\hline
\end{tabular}


ANEXO VI - Dados utilizados para análise (Continuação)

Dados de distribuição e variabilidade do tempo relativo da fase aquática

Braço direito

\begin{tabular}{|ccccc|}
\hline $\mathrm{N}$ & Tr Aq LP & Tr Aq LNP & $\operatorname{Tr}$ Aq B & $\operatorname{Tr}$ Aq S \\
\hline 1 & 64,45 & 64,95 & 57,66 & 62,31 \\
2 & 62,51 & 65,36 & 62,52 & 65,72 \\
3 & 62,32 & 65,19 & 64,26 & 65,18 \\
4 & 65,17 & 64,19 & 65,53 & 63,54 \\
5 & 63,72 & 61,81 & 65,37 & 63,87 \\
6 & 62,16 & 66,15 & 67,45 & 68,07 \\
7 & 67,36 & 67,85 & 62,41 & 67,08 \\
8 & 67,61 & 68,28 & 70,04 & 71,65 \\
9 & 70,37 & 69,22 & 68,65 & 67,90 \\
10 & 68,86 & 68,93 & 69,13 & 70,85 \\
11 & 65,58 & 62,20 & 62,44 & 70,96 \\
12 & 66,66 & 63,50 & 60,22 & 68,26 \\
13 & 61,98 & 68,93 & 76,05 & 63,00 \\
14 & 67,35 & 69,15 & 63,82 & 62,31 \\
15 & 67,14 & 66,70 & 67,30 & 67,20 \\
16 & 67,32 & 69,86 & 69,54 & 69,12 \\
17 & 65,84 & 68,23 & 69,68 & 68,24 \\
18 & 74,19 & 69,29 & 71,43 & 71,63 \\
19 & 69,98 & 69,25 & 68,62 & 73,28 \\
20 & 68,50 & 75,68 & 69,74 & 68,73 \\
21 & 67,72 & 66,42 & 72,27 & 70,96 \\
\hline
\end{tabular}

Braço direito

\begin{tabular}{|ccccc|}
\hline N & V Tr Aq LP & V Tr Aq LNP & V Tr Aq B & V Tr Aq S \\
\hline 1 & 1,96 & 3,01 & 7,68 & 2,23 \\
2 & 1,80 & 0,65 & 4,96 & 1,64 \\
3 & 2,47 & 2,57 & 0,74 & 3,84 \\
4 & 0,72 & 2,03 & 2,79 & 2,05 \\
5 & 2,56 & 0,64 & 3,87 & 1,49 \\
6 & 2,65 & 0,90 & 2,04 & 3,84 \\
7 & 1,20 & 2,05 & 0,33 & 3,53 \\
8 & 0,82 & 0,41 & 2,98 & 3,66 \\
9 & 2,55 & 3,56 & 2,26 & 1,72 \\
10 & 1,98 & 3,31 & 1,87 & 3,63 \\
11 & 3,03 & 2,44 & 1,88 & 0,88 \\
12 & 1,43 & 0,87 & 2,19 & 1,02 \\
13 & 0,67 & 1,36 & & 4,86 \\
14 & 1,79 & 3,50 & 5,04 & 1,48 \\
15 & 2,24 & 2,82 & 3,16 & 3,67 \\
16 & 1,29 & 2,28 & 0,79 & 2,10 \\
17 & 5,48 & 4,13 & 3,99 & 2,89 \\
18 & 0,28 & 3,35 & 1,10 & 2,37 \\
19 & 2,24 & 2,87 & 2,27 & 2,22 \\
20 & 2,57 & 2,39 & 2,66 & 2,44 \\
21 & 3,59 & 3,41 & 0,97 & 0,88 \\
\hline
\end{tabular}

Braço esquerdo

\begin{tabular}{|cccc|}
\hline Tr Aq LP & Tr Aq LNP & Tr Aq B & Tr Aq S \\
\hline 67,16 & 66,15 & 73,58 & 63,56 \\
64,24 & 66,45 & 66,02 & 67,41 \\
63,29 & 69,87 & 67,37 & 65,62 \\
65,57 & 63,96 & 65,04 & 61,91 \\
59,45 & 67,81 & 65,51 & 63,56 \\
65,42 & 66,39 & 66,75 & 63,10 \\
60,98 & 59,55 & 62,36 & 68,02 \\
69,3 & 63,34 & 65,69 & 66,75 \\
66,91 & 63,64 & 66,50 & 66,62 \\
66,46 & 59,41 & 62,76 & 64,80 \\
63,54 & 60,93 & 64,19 & 70,98 \\
62,05 & 61,35 & 60,29 & 65,68 \\
66,92 & 68,46 & 67,36 & 68,10 \\
71,03 & 64,19 & 67,85 & 71,02 \\
64,29 & 72,10 & 68,53 & 66,52 \\
72,28 & 63,38 & 64,67 & 66,80 \\
68,48 & 74,28 & 68,00 & 70,35 \\
63,91 & 67,11 & 63,42 & 62,77 \\
69,46 & 66,44 & 67,45 & 66,71 \\
76,44 & 71,06 & 71,58 & 70,66 \\
69,97 & 68,97 & 69,24 & 70,98 \\
\hline
\end{tabular}

\begin{tabular}{|cccc|}
\multicolumn{4}{c}{ Braço esquerdo } \\
\hline V Tr Aq LP & V Tr Aq LNP & V Tr Aq B & V Tr Aq S \\
\hline 1,15 & 0,90 & & 2,28 \\
2,25 & 0,74 & 2,45 & 1,28 \\
2,48 & 2,15 & 2,57 & 2,31 \\
2,14 & 1,74 & 0,39 & 2,44 \\
4,53 & 1,06 & 2,24 & 2,28 \\
4,21 & 2,95 & 1,81 & 1,03 \\
1,47 & 1,59 & 2,18 & 0,89 \\
1,86 & 1,71 & 2,44 & 2,97 \\
2,75 & 2,00 & 3,01 & 1,48 \\
2,21 & 1,55 & 0,93 & 0,45 \\
4,12 & 1,68 & 1,65 & 3,19 \\
2,24 & 1,26 & 0,50 & 2,12 \\
1,06 & 2,15 & 2,04 & 1,24 \\
2,11 & 2,03 & 0,40 & 0,77 \\
0,80 & 1,64 & 0,38 & 4,74 \\
1,16 & 0,78 & 0,65 & 2,02 \\
2,23 & 2,20 & 1,22 & 2,57 \\
1,91 & 3,57 & 4,89 & 4,32 \\
3,01 & 2,28 & 2,04 & 2,75 \\
1,75 & 3,41 & 3,03 & 0,78 \\
1,20 & 2,16 & 3,28 & 3,19 \\
\hline
\end{tabular}


ANEXO VI - Dados utilizados para análise (Continuação)

Dados de distribuição e variabilidade do tempo total do braço direito e esquerdo

\begin{tabular}{|ccccc|}
\multicolumn{5}{c}{ Braço direito } \\
\hline N & Tt LP & Tt LNP & Tt B & Tt S \\
\hline 1 & 450,00 & 446,67 & 433,33 & 433,33 \\
2 & 453,33 & 510,00 & 490,00 & 456,67 \\
3 & 433,33 & 450,00 & 456,67 & 430,00 \\
4 & 516,67 & 493,33 & 483,33 & 456,67 \\
5 & 486,67 & 480,00 & 460,00 & 433,33 \\
6 & 440,00 & 433,33 & 430,00 & 406,67 \\
7 & 470,00 & 456,67 & 443,33 & 413,33 \\
8 & 463,33 & 483,33 & 466,67 & 436,67 \\
9 & 426,67 & 433,33 & 446,67 & 446,67 \\
10 & 460,00 & 450,00 & 453,33 & 423,33 \\
11 & 416,67 & 423,33 & 400,00 & 493,33 \\
12 & 460,00 & 493,33 & 470,00 & 483,33 \\
13 & 473,33 & 483,33 & 473,33 & 460,00 \\
14 & 490,00 & 506,67 & 480,00 & 460,00 \\
15 & 476,67 & 510,00 & 480,00 & 466,67 \\
16 & 520,00 & 520,00 & 503,33 & 506,67 \\
17 & 446,67 & 453,33 & 416,67 & 400,00 \\
18 & 516,67 & 543,33 & 466,67 & 483,33 \\
19 & 466,67 & 466,67 & 456,67 & 436,67 \\
20 & 466,67 & 533,33 & 463,33 & 446,67 \\
21 & 506,67 & 486,67 & 516,67 & 493,33 \\
\hline
\end{tabular}

\begin{tabular}{|cccc|}
\multicolumn{4}{c}{ Braço esquerdo } \\
\hline Tt LP & Tt LNP & Tt B & Tt S \\
\hline 446,67 & 443,33 & 426,67 & 430,00 \\
456,67 & 516,67 & 490,00 & 450,00 \\
426,67 & 453,33 & 460,00 & 416,67 \\
503,33 & 490,00 & 476,67 & 463,33 \\
476,67 & 476,67 & 473,33 & 430,00 \\
433,33 & 426,67 & 423,33 & 406,67 \\
470,00 & 453,33 & 433,33 & 406,67 \\
466,67 & 473,33 & 473,33 & 450,00 \\
433,33 & 440,00 & 446,67 & 450,00 \\
456,67 & 460,00 & 456,67 & 416,67 \\
420,00 & 426,67 & 400,00 & 480,00 \\
456,67 & 500,00 & 470,00 & 476,67 \\
473,33 & 496,67 & 480,00 & 460,00 \\
483,33 & 493,33 & 466,67 & 460,00 \\
466,67 & 513,33 & 476,67 & 476,67 \\
516,67 & 510,00 & 500,00 & 513,33 \\
433,33 & 453,33 & 416,67 & 393,33 \\
516,67 & 526,67 & 473,33 & 466,67 \\
470,00 & 466,67 & 450,00 & 440,00 \\
466,67 & 540,00 & 456,67 & 443,33 \\
500,00 & 473,33 & 506,67 & 480,00 \\
\hline
\end{tabular}

Braço direito

\begin{tabular}{|ccccc|}
\hline N & V Tt LP & V Tt LNP & V Tt B & V Tt S \\
\hline 1 & 10,00 & 05,77 & 05,77 & 28,87 \\
2 & 05,77 & 10,00 & 10,00 & 11,55 \\
3 & 05,77 & 00,00 & 23,09 & 10,00 \\
4 & 20,82 & 11,55 & 15,28 & 20,82 \\
5 & 11,55 & 10,00 & 26,46 & 15,28 \\
6 & 10,00 & 15,28 & 10,00 & 30,55 \\
7 & 17,32 & 11,55 & 11,55 & 30,55 \\
8 & 11,55 & 15,28 & 15,28 & 23,09 \\
9 & 15,28 & 15,28 & 05,77 & 05,77 \\
10 & 10,00 & 10,00 & 05,77 & 15,28 \\
11 & 05,77 & 05,77 & 20,00 & 30,55 \\
12 & 10,00 & 11,55 & 26,46 & 20,82 \\
13 & 20,82 & 20,82 &. & 10,00 \\
14 & 10,00 & 30,55 & 10,00 & 10,00 \\
15 & 05,77 & 10,00 & 17,32 & 15,28 \\
16 & 10,00 & 10,00 & 05,77 & 15,28 \\
17 & 20,82 & 25,17 & 15,28 & 20,00 \\
18 & 20,82 & 11,55 & 05,77 & 35,12 \\
19 & 20,82 & 15,28 & 11,55 & 23,09 \\
20 & 20,82 & 20,82 & 23,09 & 25,17 \\
21 & 11,55 & 11,55 & 35,12 & 30,55 \\
\hline
\end{tabular}

\begin{tabular}{|cccc|}
\multicolumn{4}{c}{ Braço esquerdo } \\
\hline V Tt LP & V Tt LNP & V Tt B & V Tt S \\
\hline 11,55 & 11,55 &. & 17,32 \\
11,55 & 15,28 & 10,00 & 00,00 \\
05,77 & 05,77 & 10,00 & 05,77 \\
05,77 & 10,00 & 15,28 & 11,55 \\
25,17 & 25,17 & 25,17 & 17,32 \\
05,77 & 05,77 & 27,61 & 11,55 \\
10,00 & 05,77 & 15,28 & 11,55 \\
20,82 & 20,82 &. & 20,00 \\
15,28 & 10,00 & 20,82 & 20,00 \\
20,82 & 10,00 & 11,55 & 15,28 \\
17,32 & 05,77 & 20,00 &. \\
11,55 & 20,00 & 26,46 & 20,82 \\
25,17 & 05,77 & 17,32 & 17,32 \\
05,77 & 11,55 & 05,77 & 10,00 \\
05,77 & 11,55 & 05,77 & 15,28 \\
25,17 &. & 10,00 & 30,55 \\
05,77 & 05,77 & 05,77 & 11,55 \\
15,28 & 20,82 & 05,77 & 20,82 \\
10,00 & 05,77 & 26,46 & 10,00 \\
15,28 & 17,32 & 11,55 & 11,55 \\
20,00 & 15,28 & 51,32 &. \\
\hline
\end{tabular}


ANEXO VI - Dados utilizados para análise (Continuação)

Dados de distribuição e variabilidade do tempo total da fase aérea

\begin{tabular}{|ccccc|}
\multicolumn{5}{c}{ Braço direito } \\
\hline N & Tt Ae LP & Tt Ae LNP & Tt Ae B & Tt Ae S \\
\hline 1 & 160,00 & 156,67 & 183,33 & 163,33 \\
2 & 170,00 & 176,67 & 183,33 & 156,67 \\
3 & 163,33 & 156,67 & 163,33 & 150,00 \\
4 & 180,00 & 176,67 & 166,67 & 166,67 \\
5 & 176,67 & 183,33 & 160,00 & 156,67 \\
6 & 166,67 & 146,67 & 140,00 & 130,00 \\
7 & 153,33 & 146,67 & 166,67 & 136,67 \\
8 & 150,00 & 153,33 & 140,00 & 123,33 \\
9 & 126,67 & 133,33 & 140,00 & 143,33 \\
10 & 143,33 & 140,00 & 140,00 & 123,33 \\
11 & 143,33 & 160,00 & 150,00 & 143,33 \\
12 & 153,33 & 180,00 & 186,67 & 153,33 \\
13 & 180,00 & 150,00 & 116,67 & 170,00 \\
14 & 160,00 & 156,67 & 173,33 & 173,33 \\
15 & 156,67 & 170,00 & 156,67 & 153,33 \\
16 & 170,00 & 156,67 & 153,33 & 156,67 \\
17 & 153,33 & 143,33 & 126,67 & 126,67 \\
18 & 133,33 & 166,67 & 133,33 & 136,67 \\
19 & 140,00 & 143,33 & 143,33 & 116,67 \\
20 & 146,67 & 130,00 & 140,00 & 140,00 \\
21 & 163,33 & 163,33 & 143,33 & 143,33 \\
\hline
\end{tabular}

\begin{tabular}{|cccc|}
\multicolumn{4}{c}{ Braço esquerdo } \\
\hline Tt Ae LP & Tt Ae LNP & Tt Ae B & Tt Ae S \\
\hline 146,67 & 150,00 & 116,67 & 156,67 \\
163,33 & 173,33 & 166,67 & 146,67 \\
156,67 & 136,67 & 150,00 & 143,33 \\
173,33 & 176,67 & 166,67 & 176,67 \\
193,33 & 153,33 & 163,33 & 156,67 \\
150,00 & 143,33 & 141,00 & 150,00 \\
183,33 & 183,33 & 163,33 & 130,00 \\
143,33 & 173,33 & 163,33 & 150,00 \\
143,33 & 160,00 & 150,00 & 150,00 \\
153,33 & 186,67 & 170,00 & 146,67 \\
153,33 & 166,67 & 143,33 & 140,00 \\
173,33 & 193,33 & 186,67 & 163,33 \\
156,67 & 156,67 & 156,67 & 146,67 \\
140,00 & 176,67 & 150,00 & 133,33 \\
166,67 & 143,33 & 150,00 & 160,00 \\
143,33 & 186,67 & 176,67 & 170,00 \\
136,67 & 116,67 & 133,33 & 116,67 \\
186,67 & 173,33 & 173,33 & 173,33 \\
143,33 & 156,67 & 146,67 & 146,67 \\
110,00 & 156,67 & 130,00 & 130,00 \\
150,00 & 146,67 & 156,67 & 140,00 \\
\hline
\end{tabular}

Braço direito

\begin{tabular}{|ccccc|}
\hline N & V Tt Ae LP & V Tt Ae LNP & V Tt Ae B & V Tt Ae S \\
\hline 1 & 10,00 & 15,28 & 32,15 & 15,28 \\
2 & 10,00 & 05,77 & 20,82 & 11,55 \\
3 & 11,55 & 11,55 & 11,55 & 20,00 \\
4 & 10,00 & 11,55 & 15,28 & 15,28 \\
5 & 15,28 & 05,77 & 26,46 & 11,55 \\
6 & 15,28 & 05,77 & 10,00 & 20,00 \\
7 & 05,77 & 05,77 & 05,77 & 23,09 \\
8 & 00,00 & 05,77 & 17,32 & 11,55 \\
9 & 15,28 & 15,28 & 10,00 & 05,77 \\
10 & 11,55 & 17,32 & 10,00 & 15,28 \\
11 & 11,55 & 10,00 & 00,00 & 11,55 \\
12 & 05,77 & 00,00 & 05,77 & 05,77 \\
13 & 10,00 & 00,00 &. & 20,00 \\
14 & 10,00 & 23,09 & 20,82 & 05,77 \\
15 & 11,55 & 17,32 & 11,55 & 20,82 \\
16 & 10,00 & 11,55 & 05,77 & 15,28 \\
17 &. & 11,55 & 20,82 & 05,77 \\
18 & 05,77 & 15,28 & 05,77 & 05,77 \\
19 & 10,00 & 11,55 & 11,55 & 11,55 \\
20 & 05,77 & 17,32 & 10,00 & 17,32 \\
21 & 15,28 & 15,28 & 11,55 & 11,55 \\
\hline
\end{tabular}

\begin{tabular}{|cccc|}
\multicolumn{4}{c}{ Braço esquerdo } \\
\hline V Tt Ae LP & V Tt Ae LNP & V Tt Ae B & V Tt Ae S \\
\hline 05,77 & 00,00 &. & 11,55 \\
11,55 & 05,77 & 15,28 & 05,77 \\
11,55 & 11,55 & 10,00 & 11,55 \\
11,55 & 11,55 & 5,77 & 15,28 \\
25,17 & 05,77 & 15,28 & 11,55 \\
20,00 & 11,55 & 15,59 & 00,00 \\
05,77 & 05,77 & 15,28 & 00,00 \\
11,55 & 05,77 & 30,55 & 20,00 \\
11,55 & 10,00 & 20,00 & 00,00 \\
15,28 & 05,77 & 00,00 & 05,77 \\
20,82 & 05,77 & 11,55 & 26,46 \\
11,55 & 11,55 & 11,55 & 05,77 \\
11,55 & 11,55 & 11,55 & 05,77 \\
10,00 & 11,55 & 00,00 & 05,77 \\
5,77 & 11,55 & 00,00 & 26,46 \\
11,55 & 11,55 & 05,77 & 00,00 \\
11,55 & 11,55 & 05,77 & 11,55 \\
15,28 & 20,82 & 25,17 & 15,28 \\
11,55 & 11,55 & 15,28 & 15,28 \\
10,00 & 23,09 & 17,32 & 00,00 \\
00,00 & 05,77 & 30,55 & 26,46 \\
\hline
\end{tabular}


ANEXO VI - Dados utilizados para análise (Continuação)

Dados de distribuição e variabilidade do tempo total da fase aquática

Braço direito

\begin{tabular}{|ccccc|}
\hline N & Tt Aq P & Tt Aq LNP & Tt Aq B & Tt Aq S \\
\hline 1 & 290,00 & 290,00 & 250,00 & 270,00 \\
2 & 283,33 & 333,33 & 306,67 & 300,00 \\
3 & 270,00 & 293,33 & 293,33 & 280,00 \\
4 & 336,67 & 316,67 & 316,67 & 290,00 \\
5 & 310,00 & 296,67 & 300,00 & 276,67 \\
6 & 273,33 & 286,67 & 290,00 & 276,67 \\
7 & 316,67 & 310,00 & 276,67 & 276,67 \\
8 & 313,33 & 330,00 & 326,67 & 313,33 \\
9 & 300,00 & 300,00 & 306,67 & 303,33 \\
10 & 316,67 & 310,00 & 313,33 & 300,00 \\
11 & 273,33 & 263,33 & 250,00 & 350,00 \\
12 & 306,67 & 313,33 & 283,33 & 330,00 \\
13 & 293,33 & 333,33 & 356,67 & 290,00 \\
14 & 330,00 & 350,00 & 306,67 & 286,67 \\
15 & 320,00 & 340,00 & 323,33 & 313,33 \\
16 & 350,00 & 363,33 & 350,00 & 350,00 \\
17 & 293,33 & 310,00 & 290,00 & 273,33 \\
18 & 383,33 & 376,67 & 333,33 & 346,67 \\
19 & 326,67 & 323,33 & 313,33 & 320,00 \\
20 & 320,00 & 403,33 & 323,33 & 306,67 \\
21 & 343,33 & 323,33 & 373,33 & 350,00 \\
\hline
\end{tabular}

Braço direito

\begin{tabular}{|ccccc|}
\hline $\mathrm{N}$ & $\mathrm{V} T \mathrm{~T}$ Aq LP & $\mathrm{V}$ Tt Aq LNP & $\mathrm{V}$ Tt Aq B & V Tt Aq S \\
\hline 1 & 09,62 & 9,11 & 15,35 & 13,65 \\
2 & 05,77 & 10,87 & 13,61 & 19,25 \\
3 & 08,94 & 11,55 & 14,36 & 10,35 \\
4 & 11,55 & 07,70 & 12,79 & 08,94 \\
5 & 07,18 & 18,56 & 10,87 & 12,11 \\
6 & 15,26 & 03,85 &. & 07,70 \\
7 & 11,03 & 09,62 & 10,35 & 10,52 \\
8 & 07,70 & 10,35 & 12,27 &. \\
9 & 09,11 & 10,87 &. & 10,87 \\
10 & 07,18 & 10,00 & 07,18 & 07,18 \\
11 & 08,94 & 12,27 & 11,55 & 07,70 \\
12 & 14,36 & 11,55 & 12,79 & 19,11 \\
13 & 09,11 & 11,03 & 31,30 & 15,61 \\
14 & 06,67 & 22,06 & 14,08 & 05,77 \\
15 & 11,03 & 10,00 & 09,11 & 10,87 \\
16 & 12,27 & 12,67 & 11,55 & 07,18 \\
17 & 15,28 & 20,15 & 12,27 & 10,87 \\
18 & 12,27 & 12,79 & 19,33 & 17,37 \\
19 & 10,87 & 08,94 & 12,96 & 08,94 \\
20 & 13,96 & 22,44 & 19,66 & 03,85 \\
21 & 17,32 & 14,03 & 15,57 & 07,70 \\
\hline
\end{tabular}

\begin{tabular}{|cccc|}
\multicolumn{4}{c}{ Braço esquerdo } \\
\hline Tt Aq LP & Tt Aq LNP & Tt Aq B & Tt Aq S \\
\hline 300,00 & 293,33 & 310,00 & 273,33 \\
293,33 & 343,33 & 323,33 & 303,33 \\
270,00 & 316,67 & 310,00 & 273,33 \\
330,00 & 313,33 & 310,00 & 286,67 \\
283,33 & 323,33 & 310,00 & 273,33 \\
283,33 & 283,33 & 282,33 & 256,67 \\
286,67 & 270,00 & 270,00 & 276,67 \\
323,33 & 300,00 & 310,00 & 300,00 \\
290,00 & 280,00 & 296,67 & 300,00 \\
303,33 & 273,33 & 286,67 & 270,00 \\
266,67 & 260,00 & 256,67 & 340,00 \\
283,33 & 306,67 & 283,33 & 313,33 \\
316,67 & 340,00 & 323,33 & 313,33 \\
343,33 & 316,67 & 316,67 & 326,67 \\
300,00 & 370,00 & 326,67 & 316,67 \\
373,33 & 323,33 & 323,33 & 343,33 \\
296,67 & 336,67 & 283,33 & 276,67 \\
330,00 & 353,33 & 300,00 & 293,33 \\
326,67 & 310,00 & 303,33 & 293,33 \\
356,67 & 383,33 & 326,67 & 313,33 \\
350,00 & 326,67 & 350,00 & 340,00 \\
\hline
\end{tabular}

\begin{tabular}{|cccc|}
\multicolumn{4}{c}{ Braço esquerdo } \\
\hline V Tt Aq LP & V Tt Aq LNP & V Tt Aq B & V Tt Aq S \\
\hline 11,55 & 11,55 &. & 16,29 \\
10,87 & 07,70 & 08,59 & 10,35 \\
03,33 &. & 08,94 & 05,77 \\
12,79 & 12,27 & 10,87 & 07,70 \\
13,85 & 12,79 & 08,94 & 09,62 \\
08,59 & 05,26 & 34,28 & 11,55 \\
05,26 & 20,84 & 03,85 & \\
12,79 & 12,27 & 15,56 & 20,00 \\
07,18 & 05,77 & 11,03 & 13,65 \\
10,87 & 11,55 & 08,59 & 10,35 \\
07,18 & 03,85 & 03,85 & 15,49 \\
07,70 & 07,70 & 12,20 & 15,40 \\
08,94 & 07,18 & 31,00 & 17,50 \\
05,26 & 10,52 & 16,12 & 09,62 \\
10,87 & 06,67 & 13,61 & 13,47 \\
08,59 & 11,55 & 01,92 & 12,71 \\
08,59 & 11,03 & 14,64 & 05,26 \\
07,70 & 14,08 & 09,11 & 15,40 \\
19,68 & 16,67 & 12,24 & 09,62 \\
23,85 & 17,12 & 13,61 & 11,55 \\
15,53 & 11,03 & 17,33 & 15,49 \\
\hline
\end{tabular}


ANEXO VI - Dados utilizados para análise (Continuação)

Índice de coordenação (IdC)

\begin{tabular}{|rrrrr|}
\hline $\mathrm{N}$ & LP & LNP & \multicolumn{1}{c}{$\mathrm{B}$} & \multicolumn{1}{c}{$\mathrm{S}$} \\
\hline 1 & 4,76 & 0,37 & 0,03 & 1,90 \\
2 & 8,19 & 8,13 & 8,79 & 6,60 \\
3 & 2,17 & $-3,64$ & 2,32 & 3,15 \\
4 & 1,39 & 6,78 & 4,26 & 6,86 \\
5 & 8,22 & 7,63 & 9,38 & 4,25 \\
6 & 3,19 & $-1,16$ & 0,00 & $-4,92$ \\
7 & 3,03 & 4,78 & 2,12 & 2,61 \\
8 & 1,99 & 3,49 & 1,44 & 3,67 \\
9 & 0,73 & 1,90 & 0,00 & $-2,96$ \\
10 & 0,00 & 1,09 & 1,09 & 0,00 \\
11 & $-0,83$ & 1,17 & 1,21 & 4,26 \\
12 & 13,52 & 9,38 & 7,99 & 5,56 \\
13 & 5,80 & 2,06 & 0,00 & 2,21 \\
14 & 0,35 & 2,64 & 0,00 & 0,00 \\
15 & 0,70 & 0,65 & 0,35 & 2,82 \\
16 & 0,67 & 1,65 & $-1,31$ & 1,33 \\
17 & 2,02 & 1,14 & 1,88 & $-0,41$ \\
18 & $-0,38$ & 3,39 & 1,31 & 0,77 \\
19 & 1,80 & 2,85 & 4,26 & 1,12 \\
20 & 2,88 & 3,09 & 1,42 & 0,74 \\
21 & 4,48 & 1,38 & 3,62 & 4,26 \\
\hline
\end{tabular}




\section{ANEXO VII - Índice de coordenação (IdC) adotado pelos atletas nas quatro condições experimentais.}

\begin{tabular}{|c|c|c|c|c|}
\hline $\mathrm{N}$ & LP & LNP & B & $S$ \\
\hline 1 & Sobreposição & Oposição & Oposição & Sobreposição \\
\hline 2 & Sobreposição & Sobreposição & Sobreposição & Sobreposição \\
\hline 3 & Sobreposição & Deslizamento & Sobreposição & Sobreposição \\
\hline 4 & Sobreposição & Sobreposição & Sobreposição & Sobreposição \\
\hline 5 & Sobreposição & Sobreposição & Sobreposição & Sobreposição \\
\hline 6 & Sobreposição & Deslizamento & Oposição & Deslizamento \\
\hline 7 & Sobreposição & Sobreposição & Sobreposição & Sobreposição \\
\hline 8 & Sobreposição & Sobreposição & Sobreposição & Sobreposição \\
\hline 9 & Oposição & Sobreposição & Oposição & Deslizamento \\
\hline 10 & Oposição & Sobreposição & Sobreposição & Oposição \\
\hline 11 & Oposição & Sobreposição & Sobreposição & Sobreposição \\
\hline 12 & Sobreposição & Sobreposição & Sobreposição & Sobreposição \\
\hline 13 & Sobreposição & Sobreposição & Oposição & Sobreposição \\
\hline 14 & Oposição & Sobreposição & Oposição & Oposição \\
\hline 15 & Oposição & Oposição & Oposição & Sobreposição \\
\hline 16 & Oposição & Sobreposição & Deslizamento & Sobreposição \\
\hline 17 & Sobreposição & Sobreposição & Sobreposição & Oposição \\
\hline 18 & Oposição & Sobreposição & Sobreposição & Oposição \\
\hline 19 & Sobreposição & Sobreposição & Sobreposição & Sobreposição \\
\hline 20 & Sobreposição & Sobreposição & Sobreposição & Oposição \\
\hline 21 & Sobreposição & Sobreposição & Sobreposição & Sobreposição \\
\hline
\end{tabular}

